Final Report on the Assessment of the

U.S. Geological Survey's Bureauwide Research Grade Evaluation (RGE) Process

Open-File Report 2021-1035 



\section{Final Report on the Assessment of the U.S. Geological Survey's Bureauwide Research Grade Evaluation (RGE) Process}

By U.S. Geological Survey Research Grade Evaluation Review Team

Open-File Report 2021-1035 


\section{U.S. Geological Survey, Reston, Virginia: 2021}

For more information on the USGS — the Federal source for science about the Earth, its natural and living resources, natural hazards, and the environment-visit https://www.usgs.gov or call 1-888-ASK-USGS.

For an overview of USGS information products, including maps, imagery, and publications, visit https://store.usgs.gov.

Any use of trade, firm, or product names is for descriptive purposes only and does not imply endorsement by the U.S. Government.

Although this information product, for the most part, is in the public domain, it also may contain copyrighted materials as noted in the text. Permission to reproduce copyrighted items must be secured from the copyright owner.

Suggested citation:

U.S. Geological Survey Research Grade Evaluation Review Team, 2021, Final report on the assessment of the U.S. Geological Survey's bureauwide Research Grade Evaluation (RGE) process: U.S. Geological Survey Open-File Report 2021-1035, 106 p., https://doi.org/10.3133/ofr20211035.

ISSN 2331-1258 (online) 


\section{Contents}

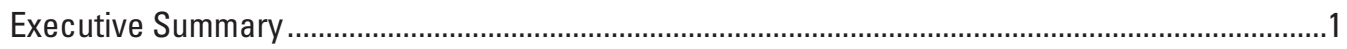

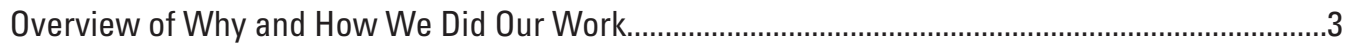

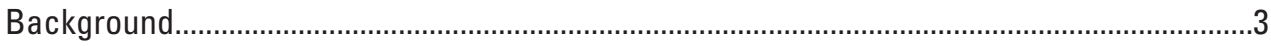

Charge

Task A

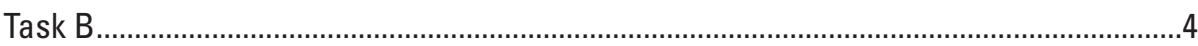

Task C .

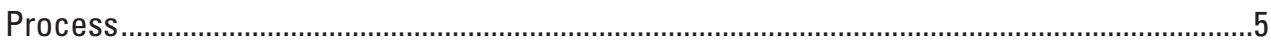

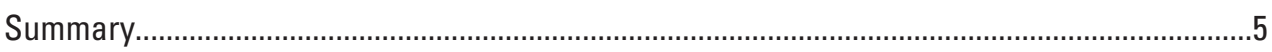

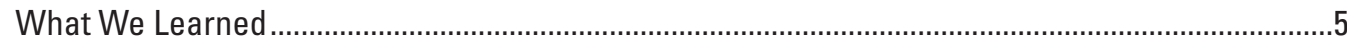

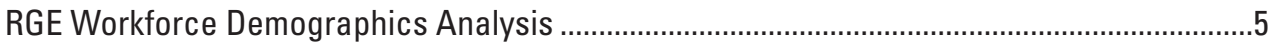

Surveys of Stakeholders........................................................................................................

Benchmarking Against Other Federal Science Agencies ...........................................................8

Beta Test of Recommended Changes for the Research Scientist Record and

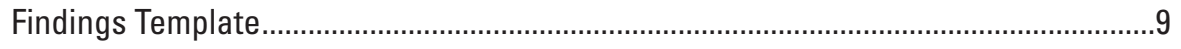

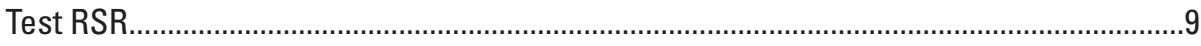

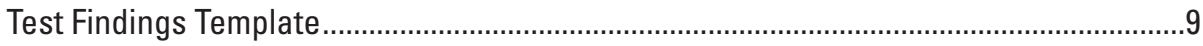

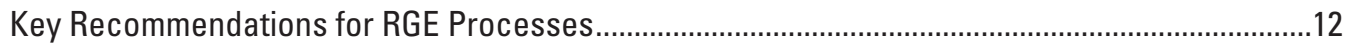

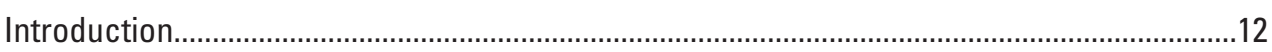

Recommended Review Process for Scientists in RGE or EDGE Positions..............................12

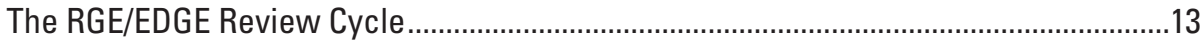

Pre-Panel Processes ......................................................................................................13

Peer Review Panel Processes ......................................................................................16

Post-Panel Processes.................................................................................................

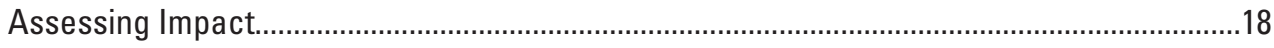

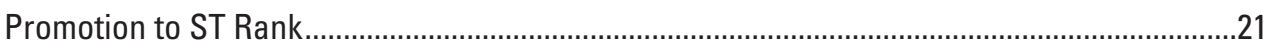

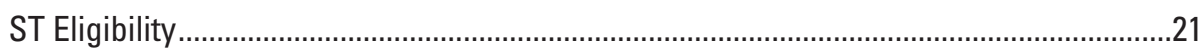

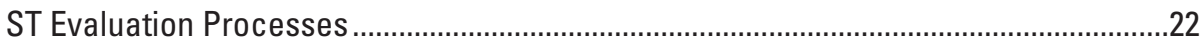

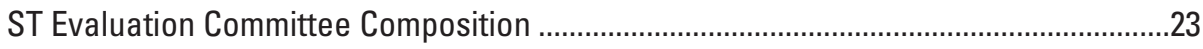

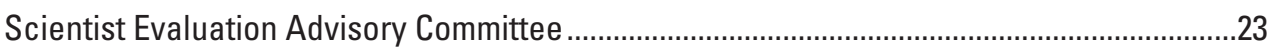

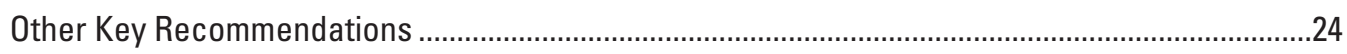

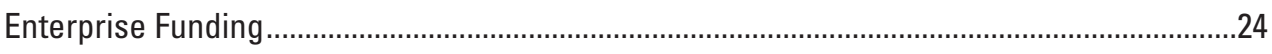

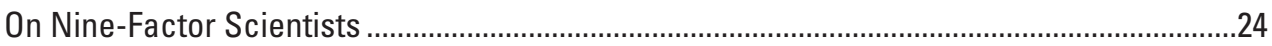

Continuing Conversations with Federal Science Agencies_EDGE Evaluation ......................25

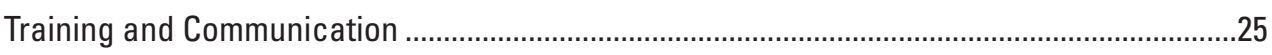

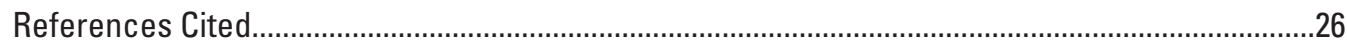

Appendix 1A. Charge Given to the Research Grade Evaluation Review Team of the

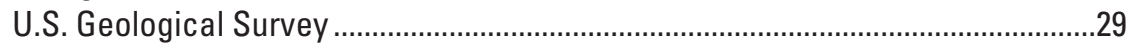

Appendix 1B. Members of the Research Grade Evaluation Review Team of the

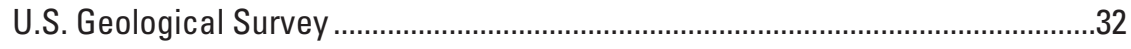

Appendix 2. Detailed Evaluation of Workforce Data ............................................................35

Appendix 3. Graphic Summary of Results of Surveys of Three Groups of Stakeholders About the Research Grade Evaluation Process in the U.S. Geological Survey....49 
Appendix 4. Benchmarking Information From a Comparison of Methods Used To

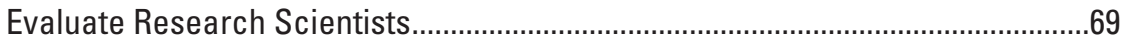

Appendix 5A. Research Scientist Record Template.....................................................................77

Appendix 5B. Findings Template for Use After Review of a Research Scientist Record..............81

Appendix 5C. Development Scientist Record Template ............................................................82

Appendix 5D. Findings Template for Use After Review of a Development Scientist Record .....88

Appendix 5E. Cover Sheet for Research Scientist Record (RSR) or Development

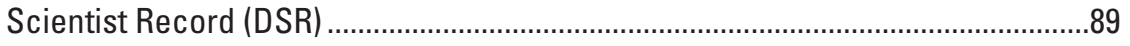

Appendix 5F. Guidelines for Scoring in Excess of Level E......................................................90

Appendix 5G. Findings Form for Scientist Considered for Promotion to Senior Scientist (ST) ...92

Appendix 5H. Standard Reviewer Questions for References...................................................94

Appendix 6. Report on Beta Test of the Recommended New Formats for the Research Scientist Record and Findings Templates and Processes Used by Peer

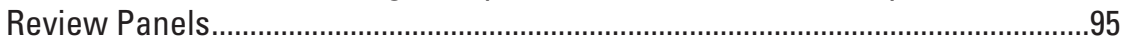

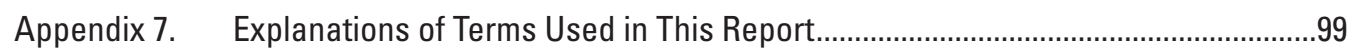

Appendix 8. Additional Criteria for Senior Scientist Positions...................................................102

Appendix 9. Key Recommendations for Updating the Research Grade Evaluation Process for the U.S. Geological Survey..............................................................104

\section{Figures}

1. Chart comparing eight processes evaluated in this study for determining the grades of research and development scientists... 10

2. Flowchart of the Research Grade Evaluation review processes, as recommended for the U.S. Geological Survey in this report.

3. Flowchart of the senior scientist evaluation and promotion processes, as recommended for the U.S. Geological Survey in this report..

2.1. Bar graph showing percentages by gender of 4,520 U.S. Geological Survey research, development, and senior scientists holding different terminal educational degrees

2.2. Bar graph showing percentages by gender of positions in eight scientific disciplines held by 4,520 U.S. Geological Survey research, development, and senior scientists.

2.3. Bar graph showing numbers and percentages of nonwhite U.S. Geological Survey scientists in 3,115 research, development, and senior scientist positions by gender in several race and ethnicity categories

2.4. Bar graph showing the number of U.S. Geological Survey research, development, and senior scientists who were active in each year from 1990 through 2017.

2.5. Line graphs showing the number of U.S. Geological Survey research, development, and senior scientists who were in each of eight disciplines in each year from 1990 through 2017.

2.6. Line graph showing the number of male and female U.S. Geological Survey employees in research, development, and senior scientist positions who were active in each year from 1990 through 2017

2.7. Line graphs showing the annual average age and average grade level of U.S. Geological Survey employees in research, development, and senior scientist positions who were active in each year from 1990 through 2017. 
2.8. Line graph showing the average grade level at entry into U.S. Geological Survey research, development, and senior scientist positions for female, male, and all scientists who were active in each year from 1990 through 2017.

2.9. Bar graph showing the number of years to promotion from one General Schedule level to the next for female and male research, development, and senior scientists in the U.S. Geological Survey during 1990-2017.

2.10. Graphs comparing the probability of evaluation above grade (odds of promotion being recommended) resulting from peer review panel evaluations during 2012-2017 for General Schedule grades GS-12 to GS-15 and among men and women in research and development scientist positions across all 13

U.S. Geological Survey peer groups and for five selected individual peer groups.........43

2.11. Bar graph showing the percentages of support from reimbursable funding for 149 U.S. Geological Survey cost centers during 2012-2017.

2.12. Bar graph showing the numbers of research, development, and senior scientists working in U.S. Geological Survey cost centers with less than or more than 50-percent reimbursable funding during 1990-2017.

2.13. Bar graph showing the average number of years to promotion from one General Schedule level to the next for research, development, and senior scientists in U.S. Geological Survey cost centers with less than or more than 50-percent reimbursable funding during 2000-2017

2.14. Line graph showing the cumulative percentage of research, development, and senior scientists active in the U.S. Geological Survey in fiscal year 2017 becoming eligible for retirement over the next three decades, by General Schedule and senior scientist grade level.

2.15. Line graph showing the cumulative percentage of research, development, and senior scientists active in the U.S. Geological Survey in fiscal year 2017 becoming eligible for retirement over the next three decades, by discipline

2.16. Graph showing the percentages of male and female U.S. Geological Survey scientists in research, development, and senior scientist positions who were active in 2017 in each General Schedule grade level and in senior scientist positions

2.17. Bar graph showing General Schedule and senior scientist grade-level distributions for female, male, and all U.S. Geological Survey scientists in research, development, and senior scientist positions who were active at the end of fiscal year 2017

\section{Tables}

1. Recommended names for committees and forms to be used by the U.S. Geological Survey in the revised Research Grade Evaluation process, Equipment Development Grade Evaluation process, and senior scientist review process

2. Review cycle for U.S. Geological Survey scientists subject to the Research Grade Evaluation and Equipment Development Grade Evaluation processes............................14

3. Timeline for actions before the peer review panel is to meet........................................15

4. Peer review panel actions, reasons for actions, and identification of responsible parties ....................................................................................................................

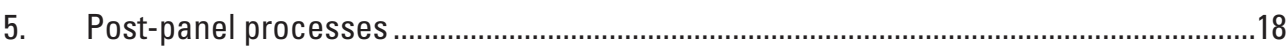

6. Guidance on how to evaluate the impact of a scientist's work in the area of scientific understanding.... 
7. Guidance on how to evaluate the impact of a scientist's work in the area of the U.S. Geological Survey and U.S. Department of the Interior missions.....

8. Guidance on how to evaluate the impact of a scientist's work in the area of advancing the health, safety, economic vitality, or ecological integrity of the United States and other parts of the world.....

2.1. Eight U.S. Geological Survey informal disciplines aggregated from occupational series of research scientists in the Federal Personnel and Payroll System dataset described in this appendix 2

4.1. Data on general and overall processes for evaluating research scientists.....................70

4.2. Data on level 1 panels used for evaluating research scientists......................................72

4.3. Data on level 2 panels used for evaluating research scientists......................................74

4.4. Data on guidance, training, and challenges for people involved in evaluating research scientists.

8.1. Examples of roles and responsibilities that characterize a successful ST scientist....103

9.1. Summary of key recommendations discussed in the text for updating the Research Grade Evaluation process for the U.S. Geological Survey..... 


\title{
Final Report on the Assessment of the U.S. Geological Survey's Bureauwide Research Grade Evaluation (RGE) Process
}

\author{
By U.S. Geological Survey Research Grade Evaluation Review Team
}

\section{Executive Summary}

The U.S. Geological Survey (USGS) Executive Leadership Team (ELT) approved the formation of the Research Grade Evaluation (RGE) Review Team in May 2017. The RGE Review Team was charged with three tasks:

- Review the processes of other Federal science agencies and determine what flexibility the USGS has to make changes to the evaluation criteria provided by the U.S. Office of Personnel Management (OPM)

- Survey USGS scientists evaluated under Research Grade Evaluation (RGE) and Equipment Development Grade Evaluation (EDGE) processes, their supervisors, center directors, and panelists about the current processes

- Recommend improvements to the USGS Research Grade Evaluation process for scientists and develop a long-term approach to inform managers on the vitality of the USGS scientific workforce

The RGE Review Team had two guiding principles that team members agreed to apply to all recommendations:

- The RGE review process will be fair, efficient, timely, consistent, transparent, and easy to understand

- Those involved in the review process will trust peer review panels to make good decisions and will verify, through a standing advisory committee, that processes are being faithfully followed

The RGE Review Team (also called the Team) conducted the first-ever quantitative assessment of the USGS workforce evaluated under the RGE process. Some clear trends emerged from this assessment, although some questions of interest could not be readily answered with the available data.

Key findings from the analysis of the RGE workforce data follow:

- The number of USGS scientists is declining
- The number of female scientists is increasing, although male scientists still outnumber female scientists by more than $2: 1$

- The gender imbalance is more pronounced at higher grade levels

- The gender imbalance is most pronounced at the senior scientist level

- White scientists far outnumber scientists of color

- The gender, grade, and age gaps are narrowing

- Men and women have similar promotion probabilities

- Reimbursable funding at a center slightly affects length of time to promotion

- Projected retirement eligibility may significantly affect the USGS scientific workforce

The RGE Review Team hosted a benchmarking meeting in March 2018 of the USGS and 11 other Federal science agencies to compare how each conducts research scientist evaluation. The agencies evaluated research scientists with either the General Schedule (GS) pay system or one of several alternative pay systems. Through the benchmarking, the Team found:

- RGE guidelines issued by OPM allow more flexibility than the USGS is currently using

- Second-level panels are rarely used by other agencies

- The USGS peer review process under RGE guidelines has advantages over pay-band or other systems because the USGS system:

- Leads to better engagement, trust, and recruitment and retention of the highest quality scientists

- Is more transparent and less subject to bias than payband systems

- Provides better data to assess workforce vitality and inform planning 
To understand USGS employee perceptions of the RGE/ EDGE evaluation process, the Team conducted extensive surveys of four internal stakeholder groups: the ELT; research and development scientists; supervisors of scientists who are subject to the RGE/EDGE process; and members of RGE/EDGE peer review panels. Through these surveys, the Team found:

- USGS stakeholders value the evaluation process, which is seen as fair and as generally resulting in appropriate decisions

- All stakeholder groups are dissatisfied with how the process is implemented. Timeliness, the two-panel system, and the feedback provided to scientists were of special concern

- Perceptions about how scientists are evaluated in the RGE process influence how scientists manage their assigned work

On the basis of the analysis of workforce data, evaluation outcomes data, benchmarking with other Federal agencies, and analysis of survey results and comments, the Team made the following initial recommendations for the RGE/ EDGE processes:

- Eliminate the second-level panel

- Place the duties of forming, scheduling, and chairing of panels with the Office of Science Quality and Integrity (OSQI)

- Develop new formats for the Research Scientist Record (RSR; formerly the Research/Development Scientist Record, RDSR) and the Development Scientist Record (DSR; formerly the RDSR) that more closely match the OPM guidelines for factor scoring

- Develop new RSR and DSR findings templates to provide more meaningful feedback to scientists

- Extend the review periods for GS-14 and GS-15 scientists to 6 and 7 years, respectively

- Establish and follow clear timelines for the annual review process

- Formalize processes and roles for primary and secondary peer reviewers, who must be assigned to each peer review panel

- Finalize scoring and scientist findings during peer review panel meetings

- Eliminate the language developed by the USGS for the RGE checklist; instead, use the OPM guidance as the scoring rubric

- Create a standing committee to continue the work of the RGE Review Team and call it the Scientist Evaluation Assessment Committee (SEAC)
On the basis of survey results, benchmarking, and close review of OPM evaluation criteria, the RGE Review Team recommends that the RGE review process emphasize the importance of outcomes resulting from a scientist's efforts, rather than focusing on easily quantified outputs such as peer-reviewed papers, presentations, and posters. The Team recommends that a scientist's work be assessed according to contributions and impacts in three areas: (1) scientific understanding, (2) the missions of the U.S. Geological Survey and the U.S. Department of the Interior, and (3) society more broadly.

The RGE Review Team also recommends changes to how GS-15 scientists are nominated for senior scientist (ST) positions, including:

- Clarify that ST positions are non-executive leadership roles, with different selection criteria, expectations, and responsibilities than research positions evaluated under the RGE process

- Create an ST Evaluation Committee (STEC)

- Eliminate the requirements for multiple recommendations from a first-level panel and a second-level panel prior to referral to the proposed STEC. The Team recommends removing second-level panels for RGE/ EDGE and ST reviews

- Develop additional ST criteria consistent with the roles of senior scientists

- Conduct an annual meeting of the STEC instead of meeting every other year as was done by the former Senior Scientist Review Panel (SSRP)

Additional recommendations made by the RGE Review Team include the following:

- Provide enterprise funding for travel to participate in peer review panels and SEAC and STEC meetings

- Charter a committee to investigate how operational scientist (nine-factor) positions are classified and evaluated; these positions differ from the research and development positions classified under OPM's fourfactor system

- Formalize a recurring Federal Science benchmarking meeting and develop new guidelines for evaluating development scientists to submit to the U.S. Department of the Interior and OPM

- Communicate the new RGE processes through leaders' blogs, townhalls, listening sessions, and training programs 


\section{Overview of Why and How We Did Our Work}

\section{Background}

\author{
U.S. Geological Survey mission: The USGS \\ serves the Nation by providing reliable scientific \\ information to describe and understand the Earth; \\ minimize loss of life and property from natural \\ disasters; manage water, biological, energy, and \\ mineral resources; and enhance and protect our \\ quality of life. The USGS combines and enhances \\ its diverse programs, capabilities, and talents to \\ provide science leadership and contribute to the \\ resolution of complex issues.
}

\section{-U.S. Geological Survey Manual, chapter 120.1 https:/www.usgs.gov/about/organization/ science-support/survey-manual/1201- creation-mission-and-functions}

To execute its mission, the U.S. Geological Survey (USGS) relies on a workforce that includes approximately 4,000 scientists, each hired under one of two classification systems: a nine-factor system used for 2,840 operational scientists and technical specialists and a four-factor system used for 1,160 research and development scientists (as of September 2018). The nine-factor and four-factor designations refer to the elements that define a particular classification or grade level. This report discusses scientists managed under the four-factor system.

Scientists whose positions are classified on the basis of a work assignment that is more than 25 percent directed to research activities are subject to the Research Grade Evaluation (RGE) process to determine the appropriate position classification level as the scientist moves from entry level to full performance level (GS-15; that is, grade 15 of the General Schedule described by the Classification Act of 1949 for Federal civilian employees). In addition to scientists in positions classified as research, the USGS employs a small number of scientists whose responsibilities are focused on technology, instrumentation, and model development. These scientists' positions are classified through the Equipment and Development Grade Evaluation (EDGE) process, which is functionally the same as the RGE process. In this report, these two types of scientists classified under the four-factor system are called research scientists and development scientists. The focus in this report is on the RGE process, although some recommendations may also apply to the EDGE process.

Throughout its history, the USGS has placed a high value on scientific peer review, which is ingrained in its culture, is widely recognized in academic and research fields as vital for providing credibility, and serves as an important recruitment incentive for hiring research scientists. The RGE/EDGE process is guided by a peer review ethic and has been the standard for the classification of positions for research and development scientists in the USGS. For decades, the USGS maintained an organizational structure based on several broad academic disciplines: geology, hydrology, geography, and, since 1995, biology. Historically, the RGE/EDGE process was managed by each of these individual discipline-based management lines, resulting in four separate implementations of standards and implementation of processes and procedures.

The publication in 2007 of the recommendations from a committee looking at USGS science directions for the next decade (U.S. Geological Survey, 2007), coupled with discussions at the 2008 managers' meeting, resulted in the determination that discipline-based management of the RGE/EDGE process did not adequately support the emerging emphasis on integrated and large-project science. The final transition from discipline-based management to mission area program development and regional line management in 2010 dictated that the RGE/EDGE process be managed as an enterprise system. The move from a discipline-based approach to a standard, bureauwide system for RGE/EDGE position classification was fully implemented in 2012. At that time, it was suggested that the system be allowed to operate for 5 years before being assessed for effectiveness. This report details the result of that assessment.

\section{Charge}

Craig Robinson, the director of the USGS Office of Scientific Quality and Integrity (OSQI) proposed to the Executive Leadership Team (ELT) that a team be chartered to look at the RGE program as implemented in the USGS. Two ELT members, representing the regional management (Aimee Devaris, Alaska Regional Director) and mission area management (Virginia Burkett, Associate Director for Climate and Land Use Change) joined Robinson as sponsors of the effort. In 2018, Virginia Burkett was replaced as a sponsor by Geoff Plumlee, Associate Director for Environmental Health. The OSQI director drafted a charge for a Research Grade Evaluation Review Team (hereinafter referred to as the Team) that was approved in May 2017 (app. 1A), and each member of the ELT nominated individuals to serve on the Team. Fifteen individuals were selected to serve on the original team, and additional members were added to address specific functions (app. 1B); Suzette Kimball, former Director of the USGS, was selected to chair the Team. 
The charge (app. 1A) identifies three specific tasks as enumerated below:

\section{Task A}

1) Review practices at a sample of other Federal science agencies to understand their processes for evaluation of research scientists and to determine what flexibility exists for USGS.

a. For those agencies using RGE panels:

i. How are other agency implementations of RGE similar to or different from USGS?

ii. From these different approaches, what lessons can we learn to strengthen USGS practices?

iii. What methods and metrics are used to track success?

iv. How do these agencies monitor trends in panel results (e.g. promotion rates as a whole as well as for different demographic and disciplinebased groups) over time?

v. How are other activities (e.g. gathering external funding, temporary supervisory details, community service including as part-time liaisons to other agencies, etc.) considered, if at all, within the RGE process? If they are not considered, do these agencies have other processes or pathways for evaluation?

b. For those agencies not using RGE panels:

i. What evaluation practices are used?

ii. Did the agency receive approval from OPM or Congress to differ from OPM guidance?

c. Determine if data are available that would permit your team to compare, in aggregate, evaluation outcomes (e.g. promotion rates) for RGE scientists at USGS with those at similar agencies. Also compare, if possible, whether different pathways or evaluation practices are leading to better outcomes regarding contributions, impact and stature of scientists. If differences exist, can you attribute these to the evaluation practices or rather to other differences between USGS and these agencies?

2) Determine to what extent USGS can make changes, with OPM approval, to the evaluation criteria and processes presented in the OPM Research Grade Evaluation Guide (RGEG; 2006) to meet specific USGS needs.
In particular, consider the flexibility provided on page 20 of the RGEG: "The nature, type, importance, and significance of various professional contributions, research products, and other scientific outputs vary across agencies and disciplines. Therefore, agencies may find it helpful to develop supplements to this guide to aid in evaluating research work in their specific research environments."

On this same page, also note that: "Agencies have discretion in establishing and evaluating research positions; however, OPM recommends applying the same evaluation method to all research positions within an agency."

Also consider the proper way to guide panels in interpreting guidance from the RGEG, on page 6 , that factor levels should be assigned "based on the best match between the factor level criteria and the researcher's work" and that for each factor level the work should "fully satisfy" the criteria.

\section{Task B}

3) Gather feedback from a sample of USGS scientists evaluated under the RGE process, their supervisors, center directors and RGE panelists regarding current practices. What common themes are emerging?

4) Interview current and past USGS staff to understand the full extent and intent of the 2011 change to a consistent, bureauwide practice. What are the perceived benefits and challenges of that transition? Determine where the current practices have met expectations and where additional work is needed.

\section{Task C}

5) Based upon the practices at other agencies, the flexibilities that USGS has under OPM guidelines, and the feedback obtained from within USGS, recommend improvements to the USGS research evaluation process for scientists.

6) Recommend a long-term approach for providing advice regarding the evaluation of USGS scientists as well as a periodic evaluation of the health of the USGS scientific workforce. 


\section{Process}

The Team formally convened in September 2017 and established a 16-month timeline for its activities (later adjusted to accommodate a Federal Government shutdown and related scheduling difficulties). Work was conducted through six face-to-face meetings, quasi-monthly telephone calls between meetings, shared document production, and three progress reports to the ELT. The first 14 months were devoted to data collection and analysis under Tasks A and B; 4 months were dedicated to field testing key recommendations.

The RGE Review Team was directed to assess the current RGE process and recommend new processes. The EDGE evaluation process has always worked in parallel with the RGE processes, so the Team also designed a new EDGE template, a findings template, and a cover sheet, which are included in appendixes 5C, 5D, and 5E. The most obvious need in the EDGE review process is an update to the 1968 "Equipment Development Grade Evaluation Guide" by the U.S. Office of Personnel Management (see the section in this report on "Continuing Conversations with Federal Science AgenciesEDGE Evaluation"). The USGS does not have the authority to change the EDGE evaluation criteria in the OPM document. In designing new EDGE and findings templates, the Team is recommending that development scientists use the same peer review processes that are recommended for research scientists.

The Team identified two guiding principles that we agreed to apply to all recommendations:

- The RGE review process will be fair, efficient, timely, consistent, transparent, and easy to understand

- Those involved in the review process will trust peer review panels to make good decisions and will verify, through a standing advisory committee, that processes are being faithfully followed

\section{Summary}

The fundamental question addressed by this review is whether the RGE process is the classification mechanism that best serves the needs of the USGS. If not, what classification process would be more effective? If yes, is the current implementation effective or do changes need to be made? To answer these questions, the Team conducted discussions with 12 Federal agencies that employ research scientists (see the section on "Benchmarking Against Other Federal Science Agencies" and app. 4); reviewed processes other than RGE against the standards of science, mission, and community; and analyzed the results from three internal surveys, including more than 200 pages of submitted comments and 60 pages of interviews (see the section on "Surveys of Stakeholders" and app. 3).

After doing this research, the Team endorses the RGE process, modified from current practice, as the best alternative to serve the needs of the USGS.
The internal surveys of scientists, peer review panel members, and supervisors/managers support a finding that the RGE process is highly valued in concept. Surveys highlight the value a peer review system plays in the recruitment and retention of highly qualified scientists. Other agencies are asking for information from the USGS in order to migrate to an RGE practice.

However, significant problems exist with operational aspects, especially timeliness, feedback, and supervisor/ manager engagement. In addition, the surveys and interviews uncovered widespread misunderstandings of the RGE process as a classification tool and the flexibilities that are inherent in the system for supervisors to manage the workforce in the cost centers. Managers and scientists share the misconception that the findings of the peer review panels are mandates rather than recommendations. Although the full performance level for an RGE position is GS-15, scientists have a general misconception that the full performance level is a senior-level scientific or professional (ST) position in the U.S. Federal Government; ST positions, however, are governed by different hiring rules and guidelines.

Some of the recommendations in this report require a significant change in the culture and expectations of the organization. Thus, strong training modules and effective and ongoing communication strategies will be essential for success.

\section{What We Learned}

\section{RGE Workforce Demographics Analysis}

The RGE Review Team was charged with examining whether our current practices are meeting the expectations for the change from a discipline-based RGE system to a standard, bureauwide system in 2012. The Team was also asked to determine if data were available that could be used to provide the USGS leaders with insights into the vitality of the USGS scientific workforce.

The Team formed a data committee to assess the status and trends of the RGE workforce, which consists of research, development, and senior scientists. To our knowledge, this is the first-ever quantitative assessment of the USGS workforce evaluated under the RGE process; see appendix 2 for the data analysis. Some clear trends emerged from this assessment, although many questions of interest to the Team could not be readily answered with the available data. The value of data obtained from individual RGE peer review panels and datasets that allow tracking of research and development scientists (in aggregate) and panel composition cannot be overstated in terms of our ability to respond to the charge we were given. This section includes key findings and recommendations that should lead to a more thorough and effective quantitative assessment of the RGE process in future years. 
Key Findings (see appendix 2 for supporting data analysis):

- The cumulative number of U.S. Geological Survey (USGS) research, development, and senior scientists is declining: Since 1996, the USGS has experienced a net loss of 20 four-factor scientists per year for a total net loss of 465 . This loss contrasts sharply with near-term labor forecasts (2016-2026) for increased employment in the occupational fields of most USGS research, development, and senior scientists.

- The number of female research scientists is increasing: Since 1996, the number of female scientists in the research scientist workforce has steadily increased by about 5 per year for a total net gain of 83 .

- In spite of women's gains, male scientists still outnumber female scientists in the research scientist workforce by more than 2:1: In 2017, 29 percent of research scientists were women.

- The gender imbalance is more pronounced at higher General Schedule (GS) grade levels in the research and development scientist workforces and is most pronounced at the senior scientist level: Since 1990, only 7 of the total number of 134 senior scientists in the USGS have been female, and, in 2017, only 3 of 47 active senior scientists were female (6 percent).

- White research scientists far outnumber research, development, and senior scientists of color: In 2017, only 7 percent of USGS research, development, and senior cientists were of color.
- Gender, grade, and age gaps in the research and development scientist workforces persist, but they are narrowing: The average grade level for women is about one grade less than that for men, and women enter the research and development scientist workforces at one GS level lower than men. These grade and age gaps have all been narrowing, and the difference in grade level at entry into the workforce has nearly disappeared in recent years.

- Men and women have similar promotion probabilities: When all research and development scientists and grade levels after 2012 are considered, men and women have similar promotion probabilities. This similarity means that the grade gap between men and women is likely due to other factors, such as the gender age gap and the difference in grade level at entry into the workforce.

- Reimbursable funding at a center slightly affects length of time to promotion: It takes slightly longer (on average less than 1 year) for scientists at centers with more than 50-percent reimbursable funding to be promoted when compared with scientists at centers with more than 50-percent appropriated funding.

- Retirements may significantly affect numbers of research, development, and senior scientists: In 8 years, 56 percent of research, development, and senior scientists active in 2017 will be retirement eligible. In hydrology, that proportion will be 75 percent. Between September 2017 and May 2019, the number of senior scientists declined by 28 percent (from 47 to 34 ) mostly by retirements.
The Team's data committee initially posed a series of questions to guide its data collection and analysis work. As its work proceeded, the committee found that many questions could not be answered with the available data or would require additional data that we could not access. The following are the questions that could be answered with the available data:

- What is the current composition of the USGS RGE workforce and how has it changed since 2012 when the current review process was established? How has it changed over several decades?

- Is there parity in promotion and retention among RGE scientists across the scientific disciplines and peer groups?
- Are there differences in peer review panel outcomes for women and men in RGE review? Is there a difference in years since last promotion? Is there a difference in mean GS level in 2017 and GS level in 2012 when the current review process was established?

- Does a difference in funding source affect years in grade and promotion of RGE employees?

- What is the composition of RGE panels and how has that changed over the past 5 years?

- What areas of expertise among our RGE employees are we likely to lose in the next 5-10 years as employees become eligible for retirement? 
Through data analysis (see app. 2 for details) driven by the guiding questions, the data committee put forth the following key recommendations.

\section{Key Recommendations:}

- Collect and maintain, in digital format, a complete record of results from RGE peer review panels going back in time as far as possible.

- Develop and implement a digital recordkeeping system for all RGE peer review panels and results moving forward so that the data needed to monitor the systems are easily available.

- Integrate datasets from the USGS Office of Science Quality and Integrity (OSOI), the Federal Personnel and Payroll System (FPPS), and the USGS Office of Diversity and Equal Opportunity (DEO) so that the information needed to evaluate the processes and workforce trends is easily available.

- Use an integrated, online system for submission of results and feedback from peer review panels so that data are automatically recorded correctly for each scientist.

- Maintain data moving forward and report annually on trends and concerns.

- Explore the value of grouping position titles into informal disciplines for tracking and assessment of RGE outcomes in the face of peer group and organizational changes.

\section{Surveys of Stakeholders}

In accordance with the charge to the RGE Review Team, surveys were developed to understand how USGS personnel view the RGE system overall. The Team identified four stakeholder groups to survey: members of the USGS Executive Leadership Team (ELT); research, development, and senior scientists; members of RGE peer review panels, and supervisors of scientists subject to the RGE process. The ELT survey was conducted first via individual interviews, which took place in person when possible. Some of these responses informed questions for the other three surveys, which were developed and administered by USGS social scientist Steve Gillespie. The Team proposed questions, and Steve worked them into formats informed by his expertise. The survey deployment was a random draw from the appropriate pools, and we worked hard to achieve a high return from those randomly chosen. In addition, we allowed people to self-select (volunteer) to take each survey. The random draw and the selfselected pools were analyzed separately. See appendix 3 for graphic summaries of the surveys.
The overall response rate for the surveys was 86 percent (258/300), and an additional 144 volunteered surveys were returned. Questions relating to the goals, importance, efficacy, and effects of the RGE process were asked on all surveys. A strong consensus among all stakeholders emerged. All agreed that the goal of the RGE process is to properly grade scientists and ensure fairness across the USGS ( $>90$ percent on all surveys responded "critical" or "very important"); they also agreed that providing feedback and enhancing the reputation of the USGS are also important. However, all respondents also felt these goals were not being met. For example, "properly grading" was considered "very important" or "critical" for 94-99 percent of the respondents; however, when asked how well this goal was being met, scientists and supervisors responded "well" or "very well" in much lower numbers (49 percent and 55 percent, respectively). Panelists gave themselves a higher grade ( 75 percent) for how well they did this. This theme of considering something important but not well done was repeated throughout the survey.

Key Finding: USGS stakeholders value the RGE process but are dissatisfied with the implementation.

There was consensus among all stakeholders that the peer groups and panels of peers work well. Overall, people saw the process as fair and felt that they did not experience discrimination. They thought that panels have come up with appropriate recommendations most of the time. However, parts of the panel process were considered less effective. All stakeholders also agreed that the following things were not working: the two-panel system, the timeliness of processes, and the quality of feedback from panels. Comments indicated that the RGE coordinators from OSQI and representatives from the USGS Office of Human Resources (HR) in panel meetings were sometimes overly involved in the discussions. In addition, everyone, especially supervisors, felt that supervisors needed to have more input into the reviews and that communication should be improved.

Key Recommendation: Develop robust processes and trust peer review panels to make sound judgments.

Key Recommendation: Involve supervisors and center directors earlier and more explicitly in the process.

We asked questions specifically to address some concerns that ELT members raised about perceptions of the RGE grading criteria and how they may affect the behavior of research scientists. There was a very strong perception ( $>80$ percent) that peer-reviewed publications and outside journals were the most valued elements of the evaluation and that other types of research contributions were not equally valued. This perception motivates scientists to emphasize work leading to peer-reviewed publications. In addition, there 
was strong agreement that the RGE scoring criteria limit the willingness of scientists to support stakeholders and to perform nonresearch tasks.

Key Finding: Perceptions about how scientists are evaluated in the RGE process influence how scientists manage their assigned work.

\section{Benchmarking Against Other Federal Science Agencies}

The RGE Review Team was also charged with determining the flexibilities that the USGS has under the rules of the U.S. Office of Personnel Management (U.S. Office of Personnel Management, 2006) to evaluate research scientists. To determine the flexibilities, the USGS hosted a meeting among Federal science agencies that employ research scientists. In March 2018, a total of 12 Federal agencies participated in the meeting: 10 in person and 2 by phone. The 10 agencies having representatives at the meeting were the Centers for Disease Control and Prevention (CDC), National Institute of Standards and Technology (NIST), National Park Service (NPS), U.S. Army Research Laboratory (ARL), U.S. Department of Agriculture Agricultural Research Service (ARS), U.S. Department of Agriculture Economic Research Service (USDA ERS), U.S. Department of Agriculture Forest Service (USFS), U.S. Department of Veterans Affairs (VA), U.S. Food and Drug Administration (FDA), and U.S. Geological Survey (USGS). The 2 agencies from which representatives joined by phone were the National Oceanic and Atmospheric Administration (NOAA) and the U.S. Environmental Protection Agency (EPA).

Of the 12 agencies that were represented at the meeting, 8 are within the General Schedule (GS) pay system and conduct an RGE process with panels (ARS, CDC, EPA, FDA, USDA ERS, USFS, USGS, and VA), whereas 3 operate under pay bands (ARL, NOAA, and NIST), and 1 was not ready to share data (NPS). NOAA and NIST are within the OPM Pay for Performance, Alternative Personnel Management System, and Commerce Alternative Personnel System (https://www.commerce.gov/hr/practitioners/caps), respectively, and ARL is within the Department of Defense's Pay for Performance system (https://www.arl.army.mil/www/default. cfm?page $=529$ ). The RGE Review Team compared data on the various systems used by 11 agencies, and the benchmarking results are summarized in appendix 4 (tables 4.1 to 4.4).

Evaluation of scientists within the agencies using a payband system is quite different from evaluation in the agencies using the GS system. Most significantly, in pay-band systems, promotion and pay decisions are made at the sole discretion of the supervisor or upper level management. The RGE Review Team considers decision making by a single individual to be a shortcoming. This system leads to concerns about bias and transparency, as well as the potential to limit advancement due to budgetary pressures. Because of the downsides of the payband system, NOAA is developing a pilot RGE-type process.

The RGE Review Team compared features of the RGE process for evaluating scientists as recommended in this report for the USGS against alternative processes, including those discussed at the benchmarking meeting. The results are shown in figure 1 on $\mathrm{p} .10-11$.

A move to a pay-band system for the USGS would require approval from the U.S. Department of the Interior and OPM. Even with approvals, the move would be a lengthy process requiring a detailed statistical assessment of our current GS pay system, identification and assessment of an alternative system, and development of a detailed business case based on our science portfolio.

On the basis of comparisons with other science agencies, the RGE Review Team members unanimously agreed that improving the RGE process, rather than abandoning it, is the best way forward. The advantages of retaining the RGE process are as follows:

- Engagement: The process engages people from many parts of the USGS, such as scientists, managers, and administrators

- Trust: Scientists, their supervisors, and peer review panel members have trust in the current process

- Recruitment and retention: The process helps in the recruitment and retention of highly qualified scientists

- Relatively low implementation costs: Keeping the current process would avoid the potential high cost of changing to another system

- Data gathering: Information gained from the process can be used to assess workforce vitality and inform planning

Key Finding: Members of the RGE Review Team unanimously agreed that the RGE process leads to better engagement, trust, and recruitment and retention of the highest quality scientists while offering lower implementation costs and better data to assess workforce vitality and inform planning than a pay-band process.

The eight agencies that use the GS pay system all agreed that the system was fair, efficient, timely, consistent, transparent, and easy to understand, but implementation of OPM guidelines for the RGE system (U.S. Office of Personnel Management, 2006) differs among the agencies (app. 4, tables 4.1 to 4.4). The frequency of review of research scientists ranges from 1 to 6 years. In all agencies except the ARS, an above-grade finding is a recommendation, not a binding determination (app. 4, table 4.1).

Key Finding: The RGE system allows for more flexibility than the USGS is currently using. 
The USFS and the EPA require scientists to address impact in their packets (app. 4, table 4.2). The ARS, USGS, and VA require the panel to reach a consensus for each numerical factor score. The FDA panels use a majority vote to reach a factor score and a grade, whereas the EPA uses a majority vote for or against promotion (app. 4, table 4.2). Panel makeup also varies among agencies: some agency panels include members from outside the agency, and some agency panels include members of several peer groups from within the agency. Most agencies have strict timelines for post-review actions, so any recommended or mandated promotions happen quickly (app. 4 , tables 4.1 and 4.2 ).

The most significant difference between agencies is in the presence or absence of a second-level panel (table 4.3): only the USGS and the VA require a second-level panel. Agencies that do not require a second-level panel trust the first-level panel process and feel that second-level panels are unnecessary. Training for scientists, panelists, and supervisors also differs among the agencies, but all agencies, both in the GS system and in pay-band systems, report challenges (table 4.4) that include the identification and evaluation of impact and the need to balance the weight of internal and external publications.

Key Finding: The USGS second-level panel is ineffective (according to survey results) and unnecessary.

Key Recommendation: Eliminate the second-level panel.

\section{Beta Test of Recommended Changes for the Research Scientist Record and Findings Template}

After the survey and benchmarking exercises, the RGE Review Team recommended a new format for the Research Scientist Record (RSR; formerly the Research and Development Scientist Record [RDSR]) that more closely matched the criteria for evaluation. In the new format, the bulk of the RSR is in four narratives, one for each scored factor. In addition, the Team recommended some changes to panel processes and the development of formal findings templates. The format for the Development Scientist Record (DSR; formerly RDSR) was also updated. These templates and related forms are in appendixes $5 \mathrm{~A}$ through $5 \mathrm{H}$.

Key Recommendation: Align the Research Scientist Record (RSR) and Development Scientist Record (DSR) with OPM guidelines for factor scoring.

In the fall of 2018, the RGE Review Team conducted a beta test of the proposed RSR, the panel processes, and the findings template. We invited scientists subject to RGE processes to volunteer either to create an RSR in the proposed new format or to serve on a beta test panel. Sixteen scientists submitted beta RSRs, and all of these were submitted to RGE peer review panels for evaluation. An additional five scientists formed a beta test panel to evaluate the RSRs by using all the new processes, and 5 of the 16 beta RSRs were evaluated by this panel. All of the volunteers understood that this was a mock process and results were not official. The remaining beta RSRs were evaluated in regular peer review panels.

Two surveys were conducted to collect reactions to the test RSR and findings templates: one to the authors of the test RSR packets and one to panel members who reviewed the test packets and used the new findings template. The RGE coordinators from OSQI also collected verbal comments during panel review of the test packets. The beta test results are summarized below, and a detailed report on the beta test is in appendix 6.

\section{Test RSR}

Overall, survey responses from scientists submitting the RSRs in the beta format (app. 5A) and the members reviewing the beta packets was positive. Relative to the current format, all test RSR respondents rated the test format either about the same or much better.

To determine reactions to the RGE process, respondents were asked to quantify their experience submitting an RSR for evaluation and their experience serving on an RGE review panel. All respondents who submitted a beta RSR had completed at least one RDSR in the past and were therefore familiar with the old format. Fifty percent of these respondents had also served on at least one panel in the past. Of the panel members who submitted responses after reviewing the test RSRs, 58 percent had served on at least one prior panel, and 83 percent had experience writing and submitting an RDSR for review.

Because the most significant change to the RSR format required the research scientist to address each factor in a narrative format, both of the groups surveyed - scientists who submitted test RSR packets and test packet reviewers - were asked to comment on that change. Several of the test RSR authors expressed concerns with this new approach, but the majority were in favor of this change. Similarly, the majority of the test packet reviewers found the new format to be an improvement over the old format, but a few respondents had concerns. The Team thinks that most of those concerns can be addressed through training on the new processes.

\section{Test Findings Template}

The team developed a test findings template (app. 5B). The goal of the findings template was to provide meaningful accounting of how the factor score was determined, and, importantly, why the research record did not support a higher score. 


\begin{tabular}{|c|c|c|c|c|}
\hline \multicolumn{3}{|c|}{ Process evaluated and details about advancement } & \multicolumn{2}{|c|}{ Indicator } \\
\hline Process & $\begin{array}{l}\text { How does grade-level } \\
\text { advancement occur? }\end{array}$ & $\begin{array}{l}\text { Who determines if } \\
\text { advancement is } \\
\text { justified? }\end{array}$ & Transparency & Efficiency \\
\hline \multicolumn{5}{|c|}{ RGE processes in the U.S. Geological Survey-Current and recommended } \\
\hline $\begin{array}{l}\text { RGE process as currently } \\
\text { implemented in the USGS }\end{array}$ & $\begin{array}{l}\text { Peer review on a } \\
\text { predetermined } \\
\text { schedule }\end{array}$ & Peer review panel & $\begin{array}{l}\text { Peer review process is estab- } \\
\text { lished and documented, but } \\
\text { panel determinations (espe- } \\
\text { cially those of second-level } \\
\text { panels) are opaque.** }\end{array}$ & $\begin{array}{l}\text { First- and second-level } \\
\text { panels require substantial invest- } \\
\text { ments of personnel } \\
\text { and financial resources. }{ }^{*}\end{array}$ \\
\hline $\begin{array}{l}\text { RGE process with recommended } \\
\text { changes for the USGS }\end{array}$ & $\begin{array}{l}\text { Peer review on a } \\
\text { predetermined } \\
\text { schedule }\end{array}$ & Peer review panel & $\begin{array}{l}\text { Training and education on new } \\
\text { RGE processes and revised } \\
\text { feedback templates promote } \\
\text { greater transparency.*** }\end{array}$ & $\begin{array}{l}\text { The RGE process requires invest- } \\
\text { ments of personnel and financial } \\
\text { resources. } * *\end{array}$ \\
\hline \multicolumn{5}{|c|}{ Processes for determining grades that were evaluated and not recommended } \\
\hline $\begin{array}{l}\text { RGE process without peer review } \\
\text { panels (HR makes classification } \\
\text { determinations) }\end{array}$ & $\begin{array}{l}\text { HR review on a } \\
\text { predetermined } \\
\text { schedule }\end{array}$ & HR specialist & $\begin{array}{l}\text { HR classification processes } \\
\text { are not well understood by } \\
\text { many USGS employees.** }\end{array}$ & $\begin{array}{l}\text { HR specialists are required to } \\
\text { independently classify scientist } \\
\text { position descriptions with limited } \\
\text { knowledge of the scientific disciplines } \\
\text { and limited personnel to complete } \\
\text { the tasks.* }\end{array}$ \\
\hline $\begin{array}{l}\text { 4- or 9-factor career-ladder } \\
\text { positions with } \\
\text { supervisor review }\end{array}$ & $\begin{array}{l}\text { Review schedule } \\
\text { determined by } \\
\text { supervisor }\end{array}$ & Supervisor & $\begin{array}{l}\text { Promotion decisions made by } \\
\text { supervisors are often } \\
\text { opaque to others in the } \\
\text { USGS.* }\end{array}$ & $\begin{array}{l}\text { Individual supervisors make promotion } \\
\text { decisions. } * * *\end{array}$ \\
\hline $\begin{array}{l}\text { 4- or 9-factor non-career-ladder } \\
\text { positions }\end{array}$ & $\begin{array}{l}\text { Competition for } \\
\text { vacant positions }\end{array}$ & Hiring official & $\begin{array}{l}\text { Selection uses a well- } \\
\text { established and widely } \\
\text { understood process. } * * *\end{array}$ & No promotion potential.*** \\
\hline
\end{tabular}

\begin{tabular}{|c|c|c|c|c|}
\hline $\begin{array}{l}\text { Hybrid system: Scientists hired into } \\
\text { 9-factor positions: SCIENTISTS } \\
\text { have discretion over whether } \\
\text { to seek conversion to research } \\
\text { positions following RGE process. } \\
\text { (Assumes recommended changes } \\
\text { are implemented.) }\end{array}$ & $\begin{array}{l}\text { Competition for } \\
\text { vacant 9-factor } \\
\text { positions with } \\
\text { conversion to } \\
\text { RGE positions }\end{array}$ & $\begin{array}{l}\text { Hiring official is re- } \\
\text { sponsible for initial } \\
\text { selection; SCIENTISTS } \\
\text { have discretion over } \\
\text { whether to seek conver- } \\
\text { sion }\end{array}$ & $\begin{array}{l}\text { Training and education on new } \\
\text { RGE processes and revised } \\
\text { feedback templates promote } \\
\text { greater transparency.*** }\end{array}$ & $\begin{array}{l}\text { The RGE process requires investments } \\
\text { of personnel and financial resources. } \\
\text { Supervisors and centers } \\
\text { may struggle with position } \\
\text { management.* }\end{array}$ \\
\hline $\begin{array}{l}\text { Hybrid system: Scientists hired into } \\
\text { 9-factor positions; SUPERVISORS } \\
\text { have discretion over whether to } \\
\text { allow scientists to seek con- } \\
\text { version to research positions } \\
\text { following RGE process. (Assumes } \\
\text { recommended changes are } \\
\text { implemented.) }\end{array}$ & $\begin{array}{l}\text { Competition for } \\
\text { vacant } 9 \text {-factor } \\
\text { positions with } \\
\text { conversion to } \\
\text { RGE positions }\end{array}$ & $\begin{array}{l}\text { Hiring official is responsible } \\
\text { for initial selection; } \\
\text { SUPERVISORS have } \\
\text { discretion over whether } \\
\text { to allow scientists to } \\
\text { seek conversion. }\end{array}$ & $\begin{array}{l}\text { Selection and conversion use } \\
\text { well-established and widely } \\
\text { understood processes. } \\
\text { Process by which scientists } \\
\text { in 9-factor positions are } \\
\text { approved to request conver- } \\
\text { sion needs to be defined.** }\end{array}$ & $\begin{array}{l}\text { The system requires development of } \\
\text { conversion criteria and } \\
\text { implementation of an RGE } \\
\text { system for scientists to be converted } \\
\text { to research positions. }{ }^{* *}\end{array}$ \\
\hline Pay-band system & $\begin{array}{l}\text { Within a pay band, } \\
\text { the supervisor } \\
\text { recommends } \\
\text { promotion }\end{array}$ & Supervisor & $\begin{array}{l}\text { Promotion decisions made by } \\
\text { supervisors are often } \\
\text { opaque to others in the } \\
\text { USGS.* }\end{array}$ & $\begin{array}{l}\text { Extensive statistical analysis } \\
\text { followed by Department } \\
\text { and OPM approval would be needed } \\
\text { for a change to a pay-band system, } \\
\text { likely requiring several years of } \\
\text { effort. } \\
\text { Individual supervisors make promotion } \\
\text { decisions.* }\end{array}$ \\
\hline
\end{tabular}

Figure 1. Chart comparing eight processes evaluated in this study for determining the grades of research and development scientists. The Research Grade Evaluation (RGE) process recommended in this report for research and development scientists in the U.S. Geological Survey (USGS) is described in the second row. Green indicates better ( 3 asterisks in cell, $\left.{ }^{* *}\right)$, yellow is moderate $\left({ }^{* *}\right)$, and red is worse $\left({ }^{*}\right)$ for seven indicators: transparency, efficiency, accuracy, potential for bias, consistency, flexibility, and a combination of recruitment, retention, and morale. The 9-factor and 4-factor designations for processes in column 1 refer to the elements that define a particular classification or grade level for operational scientists or research and development scientists, respectively (U.S. Office of Personnel Management, 2006). 
Indicator-Continued

\begin{tabular}{|c|c|c|c|c|}
\hline Accuracy & Potential for bias & Consistency & Flexibility & $\begin{array}{c}\text { Recruitment, retention, and } \\
\text { morale }\end{array}$ \\
\hline \multicolumn{5}{|c|}{ RGE processes in the U.S. Geological Survey-Current and recommended-Continued } \\
\hline $\begin{array}{l}\text { Peer review of each } \\
\text { RDSR leads to more } \\
\text { accurate classification } \\
\text { determinations. } * * *\end{array}$ & $\begin{array}{l}\text { Established structures, } \\
\text { peer review process, } \\
\text { and OSQI oversight } \\
\text { reduce potential for } \\
\text { bias.*** }\end{array}$ & $\begin{array}{l}\text { Peer review panel process and OSQI } \\
\text { oversight create consistency, though } \\
\text { many perceive the process to be } \\
\text { inconsistently applied across peer } \\
\text { groups.** }\end{array}$ & $\begin{array}{l}\text { RGE facilitates grade } \\
\text { determination and } \\
\text { conversion of operational } \\
\text { scientists to research } \\
\text { positions. } * * *\end{array}$ & $\begin{array}{l}\text { Limited transparency, process } \\
\text { delays, and feedback of } \\
\text { limited utility create } \\
\text { challenges. }{ }^{* *}\end{array}$ \\
\hline $\begin{array}{l}\text { Peer review of each RSR/ } \\
\text { DSR leads to more accurate } \\
\text { classification determina- } \\
\text { tions. }{ }^{* *}\end{array}$ & $\begin{array}{l}\text { Established structures, } \\
\text { peer review process, } \\
\text { and OSQI oversight } \\
\text { reduce potential for } \\
\text { bias.*** }\end{array}$ & $\begin{array}{l}\text { New guidance, improved } \\
\text { training, and standing } \\
\text { SEAC increase consistency of the } \\
\text { RGE process. } * * *\end{array}$ & $\begin{array}{l}\text { RGE facilitates grade } \\
\text { determination and } \\
\text { conversion of operational } \\
\text { scientists to research } \\
\text { positions.*** }\end{array}$ & $\begin{array}{l}\text { The RGE process is valued by } \\
\text { USGS employees; } \\
\text { improvements in process } \\
\text { and training increase } \\
\text { satisfaction.*** }\end{array}$ \\
\hline \multicolumn{5}{|c|}{ Processes for determining grades that were evaluated and not recommended-Continued } \\
\hline $\begin{array}{l}\text { HR specialists are required to } \\
\text { independently classify } \\
\text { scientist position } \\
\text { descriptions with limited } \\
\text { knowledge of the scientific } \\
\text { disciplines.* }\end{array}$ & $\begin{array}{l}\text { HR specialists are highly } \\
\text { knowledgeable about } \\
\text { prohibited personnel } \\
\text { practices. } * * *\end{array}$ & $\begin{array}{l}\text { Lack of familiarity with scientific } \\
\text { disciplines may lead to inconsistency } \\
\text { among HR specialists and across } \\
\text { disciplines.* }\end{array}$ & $\begin{array}{l}\text { RGE facilitates grade } \\
\text { determination and } \\
\text { conversion of operational } \\
\text { scientists to research } \\
\text { positions. } * * *\end{array}$ & $\begin{array}{l}\text { Limited transparency, } \\
\text { potential for delays in } \\
\text { classification actions, and } \\
\text { potential for problems with } \\
\text { accuracy and consistency } \\
\text { may create challenges.** }\end{array}$ \\
\hline $\begin{array}{l}\text { Supervisors have knowledge } \\
\text { of the employee and the } \\
\text { scientific discipline. }{ }^{* *}\end{array}$ & $\begin{array}{l}\text { Promotion decisions } \\
\text { made by individual } \\
\text { supervisors may be } \\
\text { subject to bias.* }\end{array}$ & $\begin{array}{l}\text { Promotion decisions made by individual } \\
\text { supervisors may lead to inconsistent } \\
\text { decisions among supervisors and } \\
\text { across centers, disciplines, regions, } \\
\text { and mission areas.* }\end{array}$ & $\begin{array}{l}\text { With proper position manage- } \\
\text { ment, career-ladder } \\
\text { positions create flexibility } \\
\text { for supervisors and scien- } \\
\text { tists.*** }\end{array}$ & $\begin{array}{l}\text { Lack of transparency, poten- } \\
\text { tial for bias, and potential } \\
\text { for inconsistent promotion } \\
\text { decisions may create } \\
\text { significant challenges. }{ }^{*}\end{array}$ \\
\hline $\begin{array}{l}\text { Lack of career ladder and } \\
\text { periodic review may } \\
\text { increase the number of } \\
\text { research scientists working } \\
\text { outside of grade level.* }\end{array}$ & $\begin{array}{l}\text { No promotion } \\
\text { potential. } * * *\end{array}$ & No promotion potential.*** & No promotion potential.* & $\begin{array}{l}\text { Employees seeking promotion } \\
\text { are required to apply for } \\
\text { vacant positions. Incum- } \\
\text { bents' dissatisfaction with } \\
\text { current positions and } \\
\text { increased employee } \\
\text { turnover are likely.* }\end{array}$ \\
\hline $\begin{array}{l}\text { Peer review of each } \\
\text { RDSR leads to more } \\
\text { accurate classification } \\
\text { determinations. } * * *\end{array}$ & $\begin{array}{l}\text { Established structures, } \\
\text { peer review process, } \\
\text { and OSQI oversight } \\
\text { reduce potential for } \\
\text { bias.*** }\end{array}$ & $\begin{array}{l}\text { New guidance, improved } \\
\text { training, and standing } \\
\text { SEAC increase } \\
\text { consistency of the } \\
\text { RGE process.*** }\end{array}$ & $\begin{array}{l}\text { RGE facilitates grade deter- } \\
\text { mination and conversion } \\
\text { of operational scientists } \\
\text { to research positions. } \\
\text { Supervisors and centers } \\
\text { may struggle with position } \\
\text { management.** }\end{array}$ & $\begin{array}{l}\text { The RGE process is valued by } \\
\text { USGS employees; } \\
\text { improvements in process } \\
\text { and training will increase } \\
\text { satisfaction.*** }\end{array}$ \\
\hline $\begin{array}{l}\text { Peer review of each RDSR } \\
\text { leads to more accurate } \\
\text { classification determina- } \\
\text { tions. Supervisor approval } \\
\text { of conversion request } \\
\text { may lead to inaccurate } \\
\text { classification.* }\end{array}$ & $\begin{array}{l}\text { Supervisory discretion } \\
\text { over conversion } \\
\text { requests may be suscep- } \\
\text { tible to individual, cen- } \\
\text { ter, region, and mission } \\
\text { area biases.* }\end{array}$ & $\begin{array}{l}\text { Conversion decisions made by } \\
\text { individual supervisors may lead to } \\
\text { inconsistent decisions among super- } \\
\text { visors and across centers, disciplines, } \\
\text { regions, and mission areas.* }\end{array}$ & $\begin{array}{l}\text { The system provides } \\
\text { organizational flexibility. } \\
\text { Some operational scientists } \\
\text { may be prevented from } \\
\text { seeking conversion.** }\end{array}$ & $\begin{array}{l}\text { It may be difficult to recruit } \\
\text { qualified scientists into } \\
\text { 9-factor positions. Reten- } \\
\text { tion and morale may suffer } \\
\text { depending on criteria used } \\
\text { to allow scientists in } \\
\text { 9-factor positions to seek } \\
\text { conversion.* }\end{array}$ \\
\hline $\begin{array}{l}\text { Within a pay band, employees } \\
\text { are likely to be properly } \\
\text { classified. Promotion } \\
\text { across pay bands requires } \\
\text { employees to apply for } \\
\text { vacant positions, which } \\
\text { may lead to improperly } \\
\text { graded employees.** }\end{array}$ & $\begin{array}{l}\text { Supervisory discre- } \\
\text { tion over promotion } \\
\text { decisions may be sus- } \\
\text { ceptible to individual, } \\
\text { center, region, and } \\
\text { mission area biases. }\end{array}$ & $\begin{array}{l}\text { Promotion decisions made by individual } \\
\text { supervisors may lead to inconsistent } \\
\text { decisions among supervisors and } \\
\text { across centers, disciplines, regions, } \\
\text { and mission areas.* }\end{array}$ & $\begin{array}{l}\text { Within a pay band, employees' } \\
\text { pay can be adjusted to } \\
\text { recognize performance. } \\
\text { Promotion across pay bands } \\
\text { requires employees to apply } \\
\text { for vacant positions, which } \\
\text { may lead to improperly } \\
\text { graded employees. }{ }^{* *}\end{array}$ & $\begin{array}{l}\text { Within-band promotions } \\
\text { may be limited by agency } \\
\text { financial issues. Lack of } \\
\text { transparency, increased } \\
\text { potential for bias, and } \\
\text { potential for inconsistent } \\
\text { decision making may create } \\
\text { significant challenges. }{ }^{*}\end{array}$ \\
\hline
\end{tabular}

\section{EXPLANATION OF TERMS}

Department, U.S. Department of the Interior HR, Human Resources Office (USGS) OPM, U.S. Office of Personnel Management OSOI, Office of Science Quality and Integrity (USGS)
RDSR, Research and Development Scientist Record (former term) RSR/DSR, Research Scientist Record or Development Scientist Record (proposed separate forms)

SEAC, Scientist Evaluation Advisory Committee proposed for USGS

Figure 1. - Continued 
Key Recommendation: Provide justification aligning evidence in research record with factor score.

Panel members were asked to rate the current and the test findings formats on a scale of 1 (poor) to 5 (excellent). For the current format, 38.8 percent of respondents gave ratings in the $4-5$ range, whereas for the test format, 61.5 percent gave ratings in that range. Just over half of the respondents (53.8 percent) found the test format easier to write than the old format, whereas 30.8 percent thought it was about the same. After the beta test of the new findings template, we developed official versions to report the panel findings for both research (app. 5B) and development (app. 5D) scientists.

Key Finding: The recommended changes to both the Research Scientist Record (RSR) and the findings template improve these documents and facilitate better processes. It is important to develop training and exemplars for the new formats and processes.

\section{Key Recommendations for RGE Processes}

\section{Introduction}

On the basis of the data, surveys, benchmarking, and beta testing, the RGE Review Team recommends substantial changes to the RGE and ST processes. This section outlines those recommendations. The Office of Science Quality and Integrity (OSQI), in association with the Human Resources Office (HR), oversees and manages the Research Grade Evaluation (RGE) and Equipment and Development Grade Evaluation (EDGE) processes; therefore, the adoption and implementation of any recommendations will be their responsibility.

Because the RGE Review Team is recommending substantial changes to processes, we are also recommending new names. The key terms in table 1 are important in this section. Additional terms and acronyms are defined in appendix 7.

\section{Recommended Review Process for Scientists in RGE or EDGE Positions}

The new processes recommended by the RGE Review Team are described in this section. Upon selection or conversion to an RGE or EDGE position, scientists review guidelines for their respective positions and take training as itemized below:

- Review the USGS RGE and EDGE guidelines in the "Research and Equipment Development Grade Evaluation Process Handbook" (U.S. Geological Survey, 2014), which is currently being updated
Table 1. Recommended names for committees and forms to be used by the U.S. Geological Survey in the revised Research Grade Evaluation (RGE) process, Equipment Development Grade Evaluation (EDGE) process, and senior scientist (ST) review process.

\begin{tabular}{|c|c|}
\hline Recommendation & Former term or definition \\
\hline Peer review panel (PRP) & First-level panel \\
\hline $\begin{array}{l}\text { No replacement (eliminate } \\
\text { the second-level panel) }\end{array}$ & Second-level panel \\
\hline $\begin{array}{l}\text { Research Scientist Record } \\
\text { (RSR) or Development } \\
\text { Scientist Record (DSR) }\end{array}$ & $\begin{array}{r}\text { Research and Development } \\
\text { Scientist Record (RDSR) }\end{array}$ \\
\hline Findings template & Feedback \\
\hline $\begin{array}{l}\text { Scientist Evaluation Advisory } \\
\text { Committee (SEAC) }\end{array}$ & $\begin{array}{l}\text { New (replaces RGE Review Team } \\
\text { with ongoing evaluation) }\end{array}$ \\
\hline $\begin{array}{l}\text { ST Evaluation Committee } \\
\text { (STEC) }\end{array}$ & $\begin{array}{l}\text { New (combines functions of } \\
\text { second-level panels and Senior } \\
\text { Scientist Review Panels } \\
\text { (SSRPs) }\end{array}$ \\
\hline ST-eligible pool & $\begin{array}{l}\text { Scientists who scored } 56 \text { or more } \\
\text { points on their last review and } \\
\text { have not applied for promotion } \\
\text { to ST }\end{array}$ \\
\hline STEC-approved pool & $\begin{array}{l}\text { Scientists whose applications have } \\
\text { been approved by the STEC for } \\
\text { consideration for promotion to } \\
\text { ST rank }\end{array}$ \\
\hline
\end{tabular}

- Review either the "Research Grade Evaluation Guide" (U.S. Office of Personnel Management, 2006) or the "Equipment Development Grade Evaluation Guide" (U.S. Office of Personnel Management, 1968)

- Take the OSQI RGE overview training (currently being updated)

The GS-15 scientists are advised to also review the guidelines for scoring in excess of level E (app. 5F), ST findings form (app. 5G), and additional ST criteria (app. 8). More information is provided below in the sections on "Promotion to ST Rank," "ST Eligibility," and "ST Evaluation Process."

Supervisors provide new research and development scientists with links to the information summarized in the above list. In addition, supervisors of research and development scientists, center directors, managers, and peer review panel members should review these documents and take OSQI and USGS training classes to better manage research and development scientists. OSQI should have the responsibility to develop and deliver training courses on the new RGE processes. As much as possible, the courses should be interactive and conducted in person. In addition, OSQI should develop examples of exemplary RSR/DSRs at each grade level and new "Peer Review Panel Findings" forms for use in the training modules. 
Key Recommendation: Develop and implement new guidelines and training classes for multiple stakeholders.

The following pages provide detailed recommendations for the RGE processes. Figure 2 is an overview of the RGE process recommendations. Assessing the process for development scientists was not part of the charge for the Team, although a template for the Development Scientist Record is provided in appendix $5 \mathrm{C}$ and a findings template for use after review of a DSR is in appendix 5D. As mentioned above, the EDGE evaluation process has always worked in parallel with the RGE process, so most descriptions in the next section apply to both RGE and EDGE processes.

\section{The RGE/EDGE Review Cycle}

The RGE Review Team recommends that the current review schedule for each year be kept. Research and development scientists should continue to submit packets to OSQI for review in one of two regularly scheduled annual review periods that are normally held during May through August and November through February. Packets are normally due and submitted to OSQI on March 21st and September 21st.

The Team recommends different numbers of years for review cycles for research and development scientists at different grade levels (table 2). Scientists at GS grades of 11, 12 , and 13 should continue to be reviewed every 4 years, as scientists at these grade levels are typically promoted at faster rates than scientists in higher grade levels. The GS-14 scientists should be reviewed every 6 years, and GS-15 scientists should be reviewed every 7 years. At all grade levels, candidates should be allowed a single early or late review with center director concurrence. Additional early or late review requests should be approved by the appropriate ELT member (the scientist's mission area director or regional director).

Key Recommendation: Extend review cycle for research and development scientists in GS-14 and GS-15 positions to 6 years and 7 years, respectively.

Tables 3-5 provide information about the timing of steps before, during, and after a peer review panel meeting and about the person or entity responsible for each action. Details are discussed below.

\section{Pre-Panel Processes}

To ensure that scientists have ample time to prepare their RSR/DSR packets and that OSQI and peer review panel members have sufficient time to prepare for the review, the RGE Review Team recommends that OSQI should provide center directors with a list of the names of the scientists who are up for review 6 months before the packet submission cycle deadlines (table 3).

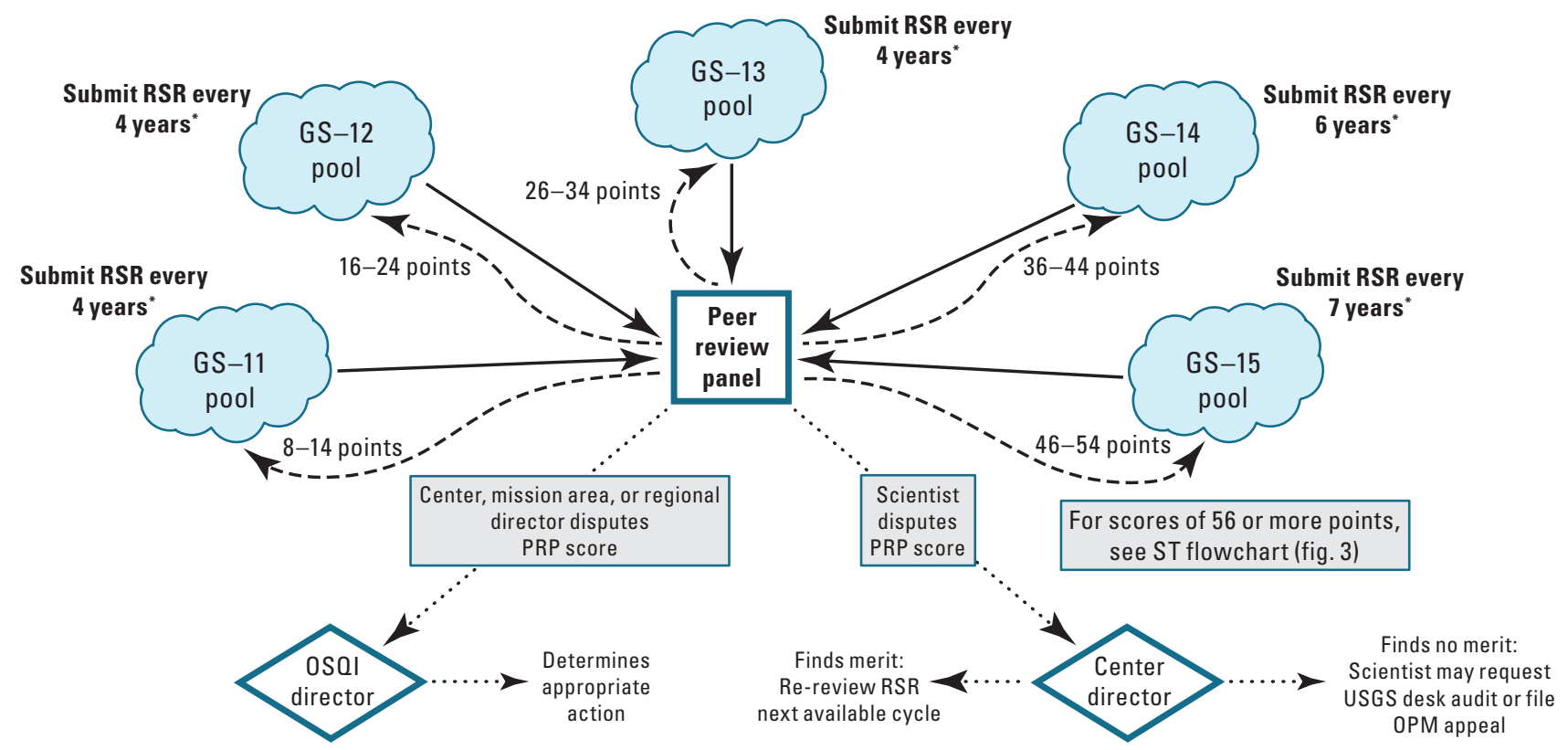

A scientist may request an early or late review once per cycle with the center director's concurrence. A scientist may request a USGS desk audit or file an appeal with the U.S. Office of Personnel Management (OPM) at any time.

Figure 2. Flowchart of the Research Grade Evaluation (RGE) review processes, as recommended for the U.S. Geological Survey (USGS) in this report. GS, General Schedule; OSOI, Office of Scientific Quality and Integrity of the USGS; PRP, peer review panel; RSR, Research Scientist Record. 
Table 2. Review cycle for U.S. Geological Survey scientists subject to the Research Grade Evaluation (RGE) and Equipment Development Grade Evaluation (EDGE) processes.

[The review cycle is the number of years that should elapse before an RGE/ EDGE packet is submitted for review]

\begin{tabular}{cc}
\hline General Schedule (GS) grade & $\begin{array}{c}\text { Review cycle } \\
\text { (length in years) }\end{array}$ \\
\hline $11,12,13$ & 4 \\
14 & 6 \\
15 & 7 \\
\hline
\end{tabular}

The center director shall be required to notify the scientists on the OSQI review list about the need to prepare for review; at the same time, the director should notify their supervisors. Center directors should update the list by including the names of those scientists who are requesting (1) a conversion from operational positions to research positions, (2) an early review, or (3) a delayed review. The modified review list should also contain the names of scientists who (1) have been newly hired, (2) have been reclassified to an operational position, or (3) have departed from service.

Within 1 month of receipt, 5 months before the packet submittal deadline (table 3), the center director should return the modified review list, along with the names of potential panel members and panel observers, to OSQI. Requests for early or delayed reviews (which could originate from a scientist) and conversions to research or development positions should be communicated to OSQI and HR through the center director.

Key Recommendation: Develop and strictly follow an annual timeline that allows ample time for all phases of the review.

The RGE coordinator in OSQI should use the center directors' modified review lists of scientists and suggested panel members to form peer review panels. The panels should be organized by peer group or related science fields, which should be defined in an update of the "Research and Equipment Development Grade Evaluation Process Handbook" (U.S. Geological Survey, 2014), hereinafter called the USGS Handbook. Members of OSQI should select individual peer group panel members on the basis of their scientific expertise and ensure that each panel's members represent a diverse range of grades, experience, gender, ethnicity, USGS organizations, and expertise. The RGE coordinator in OSQI should invite non-USGS scientists to serve on a peer group panel if there is a need for expertise in additional and wider fields of study.

Scientists up for review should be strongly encouraged to attend OSQI's RSR/DSR training prior to submitting their packets. This training, which should be available online 4 months before packet submission deadlines (table 3), should cover packet development, provide examples of well-written RSRs, and introduce scientists to prescribed formats, RSR/ DSR templates, and timelines for submission. The training modules must be based on the USGS Handbook (U.S. Geological Survey, 2014, currently being updated), the "Research Grade Evaluation Guide" (U.S. Office of Personnel Management, 2006), and the "Equipment Development Grade Evaluation Guide" (U.S. Office of Personnel Management, 1968). It is highly recommended that scientists become familiar with all the resources available to them as they write their RSR/DSRs.

Key Recommendation: Encourage all scientists subject to the Research Grade Evaluation (RGE) and Equipment and Development Grade Evaluation (EDGE) processes to participate in panels. Consider requiring all such scientists to at least observe a panel before their first review.

All research and development scientists should write or update their RSR/DSRs according to the new recommended narrative format, which is aligned with OPM's four factors, to emphasize their contributions and outcomes. Scientists should also become familiar with guidelines for assessing impact (tables 6-8) to better understand the differences between counting outputs (counting publications) and describing the outcomes (impact, use, and application) of their contributions; see the section below on "Assessing Impact."

All scientists who write or update their RSR/DSRs should be strongly encouraged to ask other scientists and their supervisors to review their forms and offer early suggestions for improvement. These reviews will help scientists refine their RSR/DSRs before a required internal review by the center director or designee. Center directors should set an internal deadline (table 3 ) that provides themselves sufficient time to review the RSR/DSR(s) and provide comments, while also giving scientists time to reconcile the center director's comments and update RSR/DSRs for submittal before OSQI submission deadlines, typically March 21 and September 21.

The committee highly recommends that the submitted packet include a cover sheet (app. 5E) signed by the scientist, supervisor, and center director or designee. In signing the document, the scientist certifies that the RSR/DSR was prepared in accordance with USGS guidelines and that it is a complete and accurate representation of his or her work record. In addition, the scientist should certify that he or she adheres to the Bureau's ethics and scientific integrity guidelines. If a submitted RSR/DSR does not conform to USGS guidelines, OSQI should be allowed to pull the packet and return it to the scientist for a rewrite. This action would result in the review being delayed until the next review period.

Primary and secondary reviewers should be chosen and assigned by the RGE coordinator from OSQI. Panel members should be confirmed and notified of panel dates 3 months before packet submission deadlines (table 3), allowing them sufficient time to access required panel member training modules, understand their time commitments, and prepare for 
Table 3. Timeline for actions before the peer review panel is to meet.

[OPM, U.S. Office of Personnel Management; OSQI, Office of Science Quality and Integrity of the U.S. Geological Survey; RGE, Research Grade Evaluation; RSR/DSR, Research Scientist Record (RSR) or Development Scientist Record (DSR)]

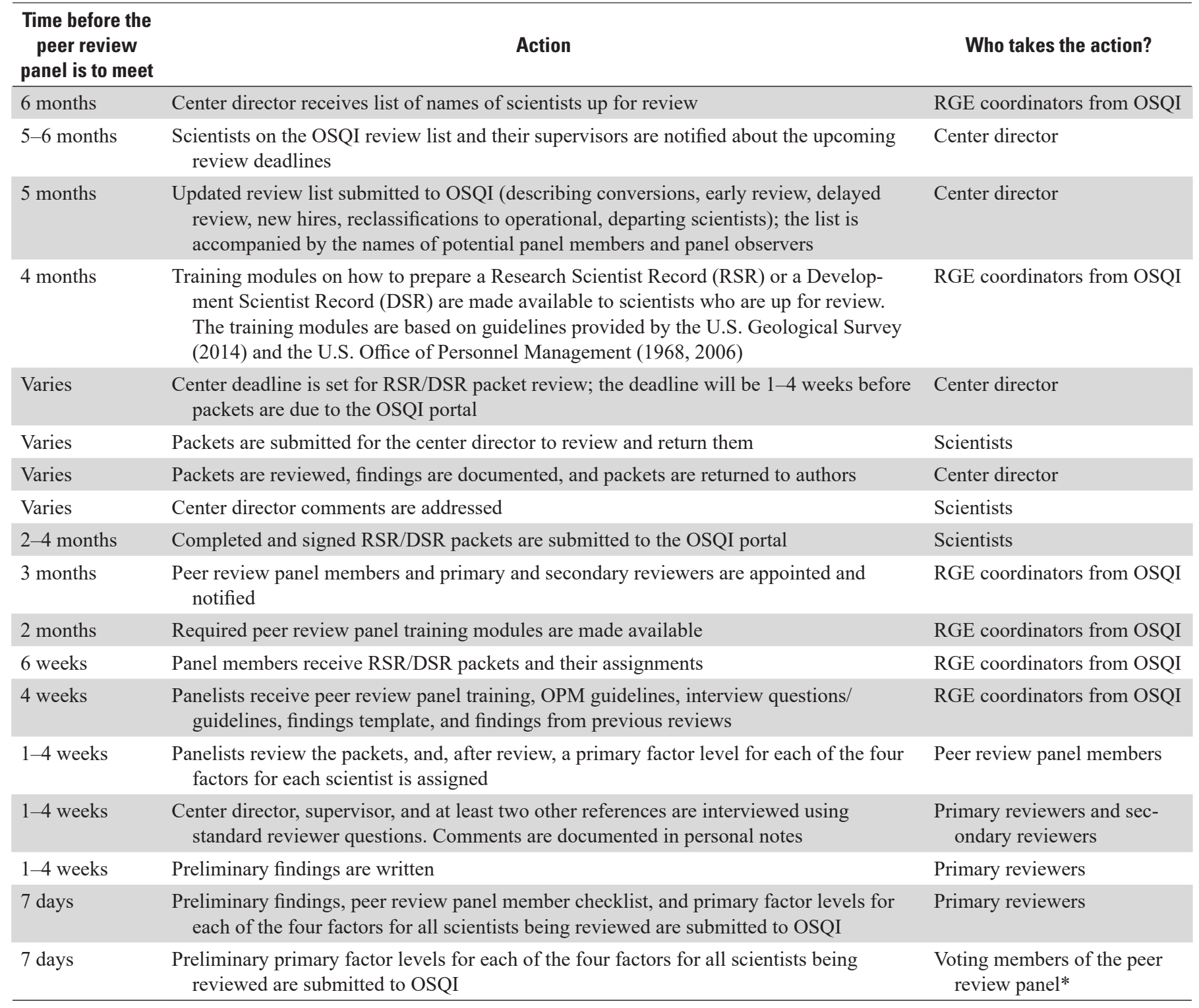

${ }^{*}$ The RGE coordinator, Human Resources Office representative, and observers are nonvoting members of the peer review panel; all other panel members are voting members.

the panels. Panel training should be available 2 months prior to packet submission deadlines, and panel members should receive the RSR/DSR packets and their assignments at least 6 weeks prior to the panel start date (table 3 ).

After panel members receive the packets assigned to the peer group, all panel members should carefully review each RSR/DSR assigned to their panel. The primary reviewer continues to be responsible for evaluating the top three contributions listed in his or her assigned RSR/DSRs and writing preliminary findings in the provided format. Note that the top three contributions need not be scientific papers; see the section below on "Assessing Impact." The principal responsibilities of the secondary reviewer are to carefully read the RSR/DSR and supporting documents and to join the primary reviewer in the interviews with references to increase consistency and decrease bias. At a minimum, the primary and secondary reviewers shall together interview the scientist's supervisor, center director, and two additional references. The reviewers should use the standard reviewer questions (app. $5 \mathrm{H})$ and take written notes on the reference's response to those questions. The roles of primary and secondary reviewers are important to the process; they help to ensure consistency across disciplines and panels, which is critically important to the overall equity of the RGE system. 
Primary reviewers will prepare a completed "Panel Member Checklist," written preliminary findings, and a factor score for each of the four factors for the scientists who were assigned to them; these documents must be submitted to OSQI 7 days before the peer review panel meets. Voting members of the panel will prepare preliminary scores for every scientist assigned to their peer group and submit them to OSQI 7 days before the panel convenes.

Key Recommendation: Formalize processes for the primary and secondary reviewers and ensure they are followed.

\section{Peer Review Panel Processes}

During the peer review panel (PRP) meeting, the RGE coordinator from OSQI facilitates the discussion, ensures that panel members are aware of their roles and responsibilities and follow panel processes, and supports the members in completing their work. In addition, the RGE coordinator will be responsible for gathering appropriate information for the proposed Scientist Evaluation Advisory Committee (SEAC) and ensuring that all PRPs operate similarly and make final point assignments (scores) and grade determinations consistently across peer groups. The HR representative ensures that the process is legal and fair and provides clarification of OPM guidelines, as needed. The RGE coordinator, HR representative, and observers are nonvoting panel members; all other PRP members are voting members.

During the meeting, PRP members review and discuss each RSR/DSR assigned to their peer group. The discussion of an individual's packet is led by the primary reviewer (table 4), who has knowledge of the scientist's career and accomplishments through studying the RSR/DSR, interviewing references, and carefully evaluating the scientist's top three contributions. The discussion should center on the scientist's contributions and outcomes, not the number of publications or the citation indices of those publications. The conversation should directly define and address how research or accomplishments by the scientist being reviewed influence (impact) the scientific community, the USGS and DOI missions, society, the Nation, or a local community. Important outcomes include science that is used by land managers and policymakers in other Federal or State agencies even if contributions are not published in the peer-reviewed literature. These outcomes can be documented in white papers, fact sheets, open-file reports, and other USGS publications. Some data products and innovative code and models may be more valuable to the missions of the USGS and other Federal agencies than peer-reviewed publications. Service on USGS, DOI, U.S., and international committees, especially if they affect policy, land management, or economics, leads to critical non-research outcomes that must be given consideration.

Following the discussion on a candidate, panel members will achieve consensus on the factor level for each of the four factors to reach the final point assignment and grade determination (table 4). The "Research Grade Evaluation Guide" (U.S. Office of Personnel Management, 2006) for research scientists and the "Equipment Development Grade Evaluation Guide" (U.S. Office of Personnel Management, 1968) for development scientists are the rubrics against which the final point assignment and grade determination will be scored. The grade determination and final findings for each scientist under review, typically an edited copy of the primary reviewer's written preliminary review in the findings template (app. 5B, $5 \mathrm{D}$ ), will be finalized before the panel is adjourned (table 4). Findings must provide the reasons, with specific examples, on why the panel reached a specific factor level and not the next higher one.

All discussions that occur within a panel and between panel members are confidential. Signing the panel findings transfers the responsibility for safeguarding, maintaining, and archiving the confidential findings and records to OSQI and allows the RGE coordinator to communicate panel results to the center director and supervisor within 7 days of the adjournment of the peer review panel.

Key Recommendation: Finalize findings during the panel meeting and refrain from changing them after the panel adjourns.

Before the panelists are dismissed, the RGE coordinator will provide panelists a survey to obtain comments on their panel experience. Data collected will be forwarded to the Scientist Evaluation Advisory Committee to indicate how the RGE/EDGE processes are working.

The RGE coordinator has the option to dismiss a panel member or to disband a panel in the event that a fatal flaw affecting the integrity of the panel process emerges during the peer review panel discussions. The RGE coordinator is charged with notifying the OSQI director if a panel member is dismissed or if the entire panel is disbanded due to violations of panel integrity. After receiving the notification, the OSQI director will contact the center directors(s) of the panelist(s) involved.

Key Recommendation: Forward data and evaluations from peer review panels to the Scientist Evaluation Advisory Committee (SEAC) so that the committee can conduct its oversight functions.

\section{Post-Panel Processes}

The RGE coordinator provides the finalized panel findings to the center director within 7 days of the adjournment of the peer review panel (table 5). At the same time, the RGE coordinator notifies the scientists who were reviewed and their supervisors to alert them that the panel findings have been sent to the center director. 
Table 4. Peer review panel actions, reasons for actions, and identification of responsible parties.

[The RGE coordinator, HR representative, and observers are nonvoting panel members; all other peer review panel members are voting members. Terms: HR, Human Resources Office of the U.S. Geological Survey (USGS); OPM, U.S. Office of Personnel Management; OSQI, Office of Science Quality and Integrity of the USGS; RGE, Research Grade Evaluation; SEAC, Scientist Evaluation Advisory Committee proposed for the USGS]

\begin{tabular}{|c|c|c|}
\hline Action during or after the peer review panel meeting & Why? & Who takes the action? \\
\hline $\begin{array}{l}\text { Facilitates discussion, ensures panel members are } \\
\text { prepared, and supports panel members in com- } \\
\text { pleting their work; also ensures that methods are } \\
\text { consistent across peer groups }\end{array}$ & To ensure fairness, timeliness, and transparency & RGE coordinator from OSQI \\
\hline Provides clarification of OPM guidelines & To ensure that the process is fair and legal & HR representative \\
\hline Observes panel process & $\begin{array}{l}\text { To offer additional opportunities to RGE scientists } \\
\text { and managers to participate and understand how } \\
\text { the process works }\end{array}$ & Observer \\
\hline $\begin{array}{l}\text { Primary reviewer leads the individual packet } \\
\text { discussion }\end{array}$ & $\begin{array}{l}\text { To take advantage of the in-depth knowledge of the } \\
\text { scientists that the primary reviewer has gained } \\
\text { from reviewing the scientist's top three contribu- } \\
\text { tions and interviewing references }\end{array}$ & Primary reviewer \\
\hline $\begin{array}{l}\text { Discuss and achieve consensus on the factor level } \\
\text { for each of the four factors to reach the final point } \\
\text { assignment and grade determination }\end{array}$ & $\begin{array}{l}\text { To make the process fair, equitable, and transparent } \\
\text { by reaching consensus }\end{array}$ & All voting panel members \\
\hline Sign off on panel findings & $\begin{array}{l}\text { To transfer responsibility for the confidential findings } \\
\text { and record to the RGE coordinator in OSQI for } \\
\text { archiving and for communicating panel findings to } \\
\text { center directors }\end{array}$ & All voting panel members \\
\hline Turn in "Panel Experience Survey" & $\begin{array}{l}\text { To provide information to the SEAC to improve } \\
\text { panel processes }\end{array}$ & All panel members \\
\hline $\begin{array}{l}\text { Dismisses panel member or disbands panel because } \\
\text { of a fatal flaw affecting the integrity of the panel } \\
\text { process }\end{array}$ & $\begin{array}{l}\text { To ensure fairness, equity, and adherence to ethics } \\
\text { and scientific integrity }\end{array}$ & $\begin{array}{l}\text { RGE coordinator from OSQI } \\
\text { or HR representative }\end{array}$ \\
\hline
\end{tabular}

There may be an occasion when the center director, mission area director, or regional director disagrees with the panel findings; if so, that director can appeal the findings to the OSQI director (table 5). The OSQI director has the following options to address the concerns of the center director, mission area director, or regional director:

1. Confirm the final point assignment and grade determination submitted by the peer review panel and verify the panel results. In this case, the original point assignment and the grade determination stand
2. Find merit in the appeal and return the packet to the peer review panel, with comments, for re-scoring

3. Find that the RSR/DSR is not well enough written to evaluate and return the packet to the scientist to rewrite for submittal and review in the next regularly scheduled review period

Generally, within 14 days of receiving the panel findings, the center director discusses the panel findings with both the scientist and his or her supervisor (table 5). If the scientist 
Table 5. Post-panel processes.

[HR, Human Resources Office of the U.S. Geological Survey (USGS); OSQI, Office of Science Quality and Integrity of the USGS; RGE, Research Grade Evaluation]

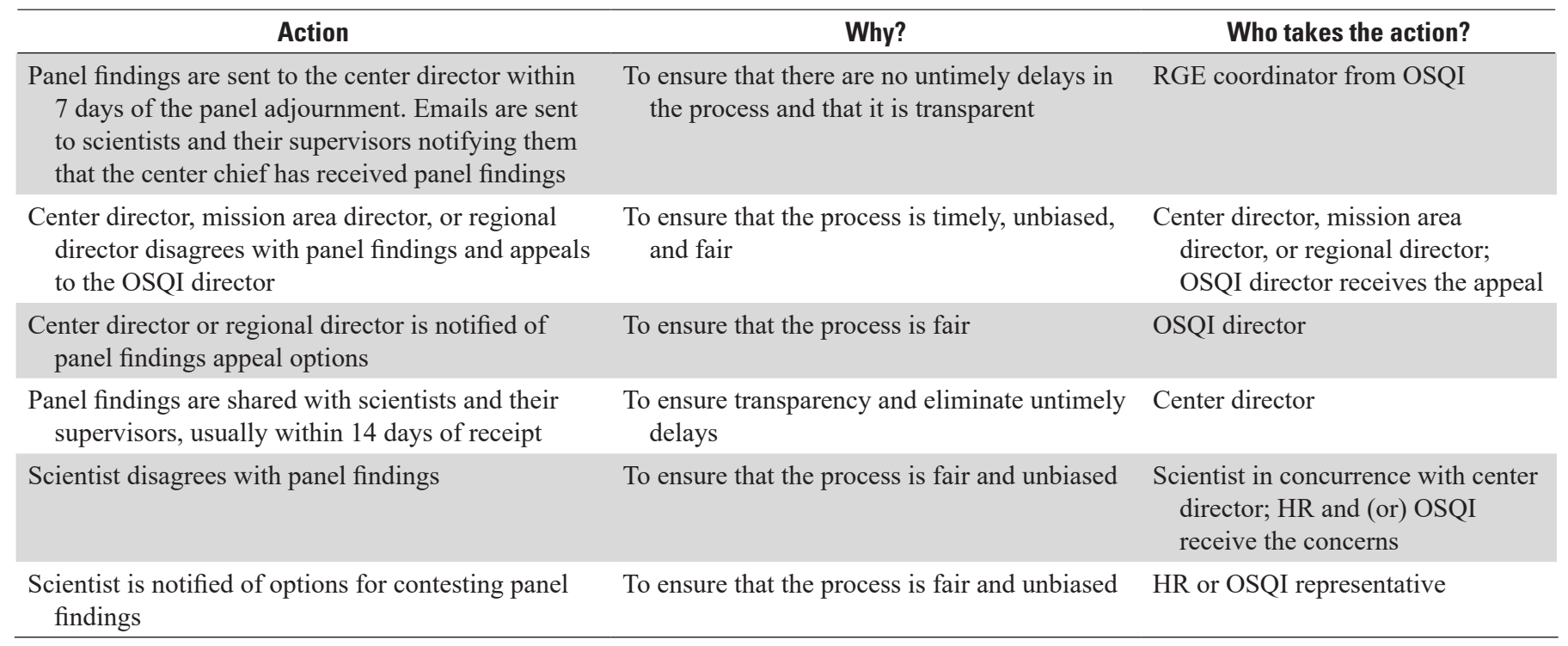

disagrees with the panel findings, he or she can share concerns with HR and (or) OSQI (table 5). If the science center director concurs with the concerns of the scientist, the scientist will be given options for contesting the findings that may include the following:

1. The RSR/DSR can be revised and then reviewed in the next regularly scheduled review period

2. The scientist can request a USGS appeal

3. The scientist can request an OPM appeal

For RSR packets scoring at 56 or more points, the packet will be referred to the center director and OSQI director for conversations about ST rank. Center directors will talk with the scientist about the expectations, requirements, and steps required to become an ST candidate, so the scientist can decide whether to apply to become an ST scientist. See the section below on "Promotion to ST Rank."

Key Recommendation: Provide timely feedback. Create clear guidelines for next steps if the scientist or supervisor disagrees with panel findings.

Under certain circumstances, and very rarely, panel findings can be invalidated. Individual reviews will be annulled if the HR representative or the RGE coordinator deems that the review process for one or more packets was inadequate or the findings were biased or flawed and if these problems could not be resolved during the panel meeting. Under these circumstances, the review (or reviews) will be discarded at the end of the panel by the HR representative and the RGE coordinator from OSQI. The HR representative must notify the center director(s) within 7 days of the conclusion of the panel that the review(s) were annulled and provide them with three options for rectifying the flawed review:

1. The RSR/DSR of the scientist affected can be sent to the next available panel (the scientist has the option to update the packet)

2. HR can conduct a desk audit

3. An ad hoc review panel can be convened by OSQI to review the as-submitted RSR/DSR (the scientist does not have the option to update the packet)

\section{Assessing Impact}

A major recommendation from the RGE Review Team is to change the culture of RGE/EDGE review from a process that has a heavy reliance on quantifying a scientist's outputs (such as peer-reviewed papers, presentations, and posters) to a process that characterizes the outcomes resulting from a scientist's efforts. Outcomes are defined as the impact, use, and application of the science produced by the employee. However, characterizing the outcomes of a scientist's work is the most difficult aspect of the USGS evaluation process, challenging the scientists creating their RSR/DSRs, the panel members evaluating them, and the SEAC that will be charged with providing oversight of the process and ensuring equity and fairness across the mission areas and peer groups. Although there is no single best way to assess outcomes, for purposes of the USGS RGE/EDGE processes, the RGE Review Team recommends that a scientist's work be assessed in three areas: in its contributions to scientific understanding; 
in its contributions to the missions of the USGS and DOI; and in its contributions to society more broadly. In addition, although the RGE Review Team did not specifically recommend a new process for development scientists, we recommend that their contributions also be assessed in these three areas. In this framework, three questions become paramount when describing and evaluating a scientist's work:

- Contributions to science: How and to what extent does the work advance scientific understanding?

- Contributions to mission: How and to what extent does the work advance the USGS and DOI missions?

- Contributions to society: How and to what extent does the work protect and advance the health, safety, economic vitality, or ecological integrity of the United States and other parts of the world?

In answering these questions, we recommend that both the scope (an area in which the science potentially applies) and scale (the degree to which the attribute is affected) be considered. Tables 6-8 provide examples of scope and scale for each of the three outcome areas. Please note, however, that these are not comprehensive lists, nor is it necessary for a scientist to demonstrate significant advancement in all areas for their science to have led to meaningful outcomes. This is especially true when assessing outcomes in the area of contributions to society (table 8 ), where significant contributions in any single area may be sufficient to demonstrate a high impact. The tables also provide examples of questions that can be used to identify evidence defining the scope and scale of a scientist's work. This evidence is essential when applying OPM's "Research Grade Evaluation Guide" and "Equipment Development Grade Evaluation Guide" to determine a scientist's grade level. Again, these are examples that can and should be supplemented with additional questions as appropriate for a specific field and scientist.

Key Recommendation: Focus on impact when scoring factor 4. Provide guidelines on how impact can be documented and assessed.

The focus on outcomes rather than outputs is not intended to diminish the importance of peer-reviewed and published science. Indeed, peer-reviewed, published science is the foundation on which USGS contributions to science, USGS and DOI missions, and society are based. By focusing on outcomes, however, the RGE Review Team is attempting to address concerns associated with the current process. For example, how can scientists in different peer groups, with different publication rates, products, outlets, and cultures be evaluated equitably? How should a peer review panel value work published in a journal with a high impact factor compared to work published in a USGS series? How should a panel value work published in a regional journal compared to work published in an international journal such as Science or Nature? Certainly, publications with a broader reach and a

Table 6. Guidance on how to evaluate the impact of a scientist's work in the area of scientific understanding (contributions to science).

\begin{tabular}{|c|c|c|c|}
\hline \multicolumn{4}{|c|}{ How and to what extent does the work advance scientific understanding? } \\
\hline \multirow{2}{*}{ Scope } & \multicolumn{2}{|c|}{ Scale } & \multirow{2}{*}{ Evidence } \\
\hline & Limited advancement & Significant advancement & \\
\hline Disciplinary & $\begin{array}{l}\text { Advances understanding } \\
\text { in a narrow sub-disci- } \\
\text { pline }\end{array}$ & $\begin{array}{l}\text { Advances understanding in a } \\
\text { broad discipline or across } \\
\text { multiple disciplines }\end{array}$ & $\begin{array}{l}\text { What are the disciplines of the scientists citing the work? } \\
\text { Does the work have applicability in more than one area? }\end{array}$ \\
\hline Methodological & $\begin{array}{l}\text { Incremental advance to } \\
\text { existing methods }\end{array}$ & $\begin{array}{l}\text { Develops new or improves } \\
\text { existing methods with } \\
\text { broad applicability }\end{array}$ & $\begin{array}{l}\text { Are the methods cited and used by other researchers? Is the } \\
\text { scientist invited or asked to provide training? }\end{array}$ \\
\hline $\begin{array}{l}\text { Importance } \\
\text { of lines of } \\
\text { research }\end{array}$ & $\begin{array}{l}\text { Limited interest and chal- } \\
\text { lenge to the scientific } \\
\text { community }\end{array}$ & $\begin{array}{l}\text { Significant interest and } \\
\text { challenge to the scientific } \\
\text { community }\end{array}$ & $\begin{array}{l}\text { To what extent is the work cited, used, and expanded upon? } \\
\text { Is the work published and disseminated in high-profile } \\
\text { outlets? Is the research area receiving substantial atten- } \\
\text { tion from the scientific community? Does the scientist } \\
\text { take leadership positions, advancing the state of the } \\
\text { science? Is the scientist's work critical for state-of-the- } \\
\text { science syntheses? }\end{array}$ \\
\hline
\end{tabular}


Table 7. Guidance on how to evaluate the impact of a scientist's work in the area of the U.S. Geological Survey (USGS) and U.S. Department of the Interior (DOI) missions (contributions to mission).

\begin{tabular}{|c|c|c|c|}
\hline \multicolumn{4}{|c|}{ How and to what extent does the work advance the USGS and DOI missions? } \\
\hline \multirow{2}{*}{ Scope } & \multicolumn{2}{|c|}{ Scale } & \multirow{2}{*}{ Evidence } \\
\hline & Limited advancement & Significant advancement & \\
\hline Geographic applicability & $\begin{array}{l}\text { Limited applicability } \\
\text { beyond local area }\end{array}$ & $\begin{array}{l}\text { National or global appli- } \\
\text { cability }\end{array}$ & $\begin{array}{l}\text { Where is the work being applied? Who is making policy and } \\
\text { management decisions based on the work? }\end{array}$ \\
\hline
\end{tabular}

Table 8. Guidance on how to evaluate the impact of a scientist's work in the area of advancing the health, safety, economic vitality, or ecological integrity of the United States and other parts of the world (contributions to society).

How and to what extent does the work protect and advance the health, safety, economic vitality, or ecological integrity of the United States and other parts of the world?

\begin{tabular}{|c|c|c|c|}
\hline \multirow{2}{*}{ Scope } & \multicolumn{2}{|r|}{ Scale } & \multirow{2}{*}{ Evidence } \\
\hline & Limited advancement & Significant advancement & \\
\hline Health benefits & $\begin{array}{l}\text { Limited or local health } \\
\text { benefits }\end{array}$ & $\begin{array}{l}\text { Substantial impact on under- } \\
\text { standing, protecting, and } \\
\text { improving human, wildlife, } \\
\text { and plant health }\end{array}$ & $\begin{array}{l}\text { What actions are being taken that are based on the work of } \\
\text { the scientist? To what extent can the benefits be quanti- } \\
\text { fied? Is the scientist invited to participate on or lead high- } \\
\text { level panels and workshops? How does the work influence } \\
\text { policy and management decisions? }\end{array}$ \\
\hline Economic benefits & $\begin{array}{l}\text { Limited or local } \\
\text { economic benefits }\end{array}$ & $\begin{array}{l}\text { Substantial impact on } \\
\text { understanding, protecting, } \\
\text { and expanding economic } \\
\text { activity }\end{array}$ & $\begin{array}{l}\text { What actions are being taken that are based on the work of } \\
\text { the scientist? To what extent can the benefits be quanti- } \\
\text { fied? Is the scientist invited to participate on or lead high- } \\
\text { level panels and workshops? How does the work influence } \\
\text { policy and management decisions? To what extent has the } \\
\text { work informed resource development or restoration activi- } \\
\text { ties? To what extent has the work led to more efficient use } \\
\text { of taxpayer funds? }\end{array}$ \\
\hline Ecological benefits & $\begin{array}{l}\text { Limited or local } \\
\text { ecological benefits }\end{array}$ & $\begin{array}{l}\text { Substantial impact on } \\
\text { understanding, protecting, } \\
\text { restoring, and sustaining } \\
\text { ecological integrity }\end{array}$ & $\begin{array}{l}\text { What actions are being taken that are based on the work of } \\
\text { the scientist? To what extent can the benefits be quanti- } \\
\text { fied? Is the scientist invited to participate on or lead high- } \\
\text { level panels and workshops? Does the work influence } \\
\text { policy and management decisions? Has the work been } \\
\text { used to conserve any imperiled species, eradicate any } \\
\text { invasive species, or protect habitat? }\end{array}$ \\
\hline
\end{tabular}


higher profile may lead to higher visibility for USGS science. In and of itself, though, that does not provide evidence that the science has had a meaningful impact. It is only through an understanding of a scientist's contributions to science, the USGS and DOI missions, and society that such an assessment can be made.

\section{Promotion to ST Rank}

Under the current system, promotion from research scientist at GS-15 to ST rank requires a score of 56 or more points from two different first-level panels (see app. 7, "Explanations of Terms Used in This Report"), and two different secondlevel panels, followed by a recommendation to the USGS Director. There is a high degree of frustration with this system, both from potential ST candidates and from members of peer review panels who end up scoring the candidates four times. Consistent with the RGE Review Team's philosophy to put solid processes in place and trust panels, we recommend removing the three additional layers of evaluation. In addition, the Team is recommending changes in how ST candidates are evaluated and advanced.

Key Recommendation: Any candidate receiving a score of 56 or more points from a peer review panel will be eligible to apply for a senior scientist (ST) position.

The following pages provide detailed recommendations for the ST processes. Figure 3 is an overview of the senior scientist (ST) process recommendations.

\section{ST Eligibility}

An ST position is not the full performance level of the RGE process, nor is it a part of OPM's RGE process. It is a commonly held misconception that an ST position is just the next step on the RGE ladder after GS-15. In fact, the ST position is a senior-level scientific or professional position

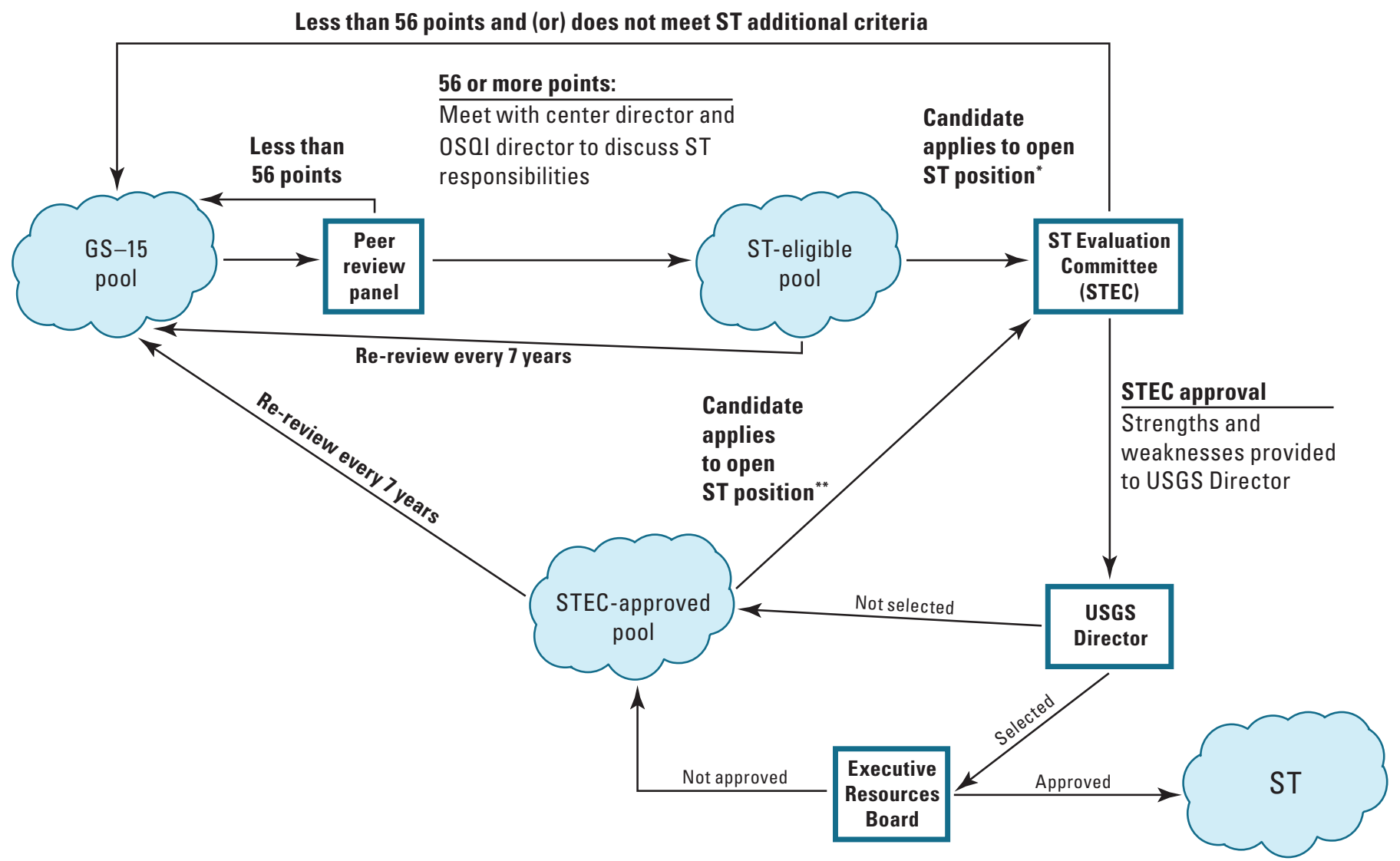

"Develop and submit full ST packet. Required review: EEO, Ethics, HR, IG.

"** Revise and submit ST additional criteria statement. Required review: EEO, Ethics, HR, IG.

Figure 3. Flowchart of the senior scientist (ST) evaluation and promotion processes, as recommended for the U.S. Geological Survey (USGS) in this report. EEO, Equal Employment Opportunity Program of the USGS; Ethics, Ethics Office of the U.S. Department of the Interior (DOI); HR, Human Resources Office of the USGS; IG, Inspector General of DOI; OSOI, Office of Scientific Quality and Integrity of the USGS; STEC, ST Evaluation Committee proposed for the USGS. The EEO reviews will be done by the Office of Diversity and Equal Opportunity (DEO) of the USGS. 
in the Senior Executive Service of the Federal Government; the category has its own hiring processes and additional duties. Selection for an ST position first requires a score of 56 or higher in the RGE system. Next, there is an entirely new process, with additional criteria, leading to a possible recommendation by the USGS Director to the DOI Executive Resources Board (ERB), which ultimately makes the appointment. It is important that all stakeholders within the USGS achieve a broad and shared understanding of ST positions.

Key Recommendation: Clearly articulate the requirements for and role of ST scientists in the science enterprise, as both leaders in their fields and ambassadors for USGS science.

The Team recommends the following process for becoming a senior (ST) scientist:

1. The peer review panel scores the candidate using the "Guidelines for Scoring in Excess of Level E" (app. 5F) criteria on the ST findings form (app. 5G) with the highest possible score for any factor being Level $\mathrm{G}$. Any packet scoring 56 or greater will be placed in the ST-eligible pool.

2. The candidate meets with the center director, supervisor, and OSQI director to determine if the scientist is interested in becoming an ST.

A. This group will discuss the implications of being ST, including the following factors:

- The need to pass an EEO/Ethics/HR/IG review (that is, reviews by the Office of Diversity and Equal Opportunity (DEO) of the USGS for conformance with the USGS Equal Employment Opportunity (EEO) Program, the Ethics Office of DOI, the Human Resources Office of the USGS, and the Inspector General of DOI)

- Implications for salary

- Monthly and annual financial reporting requirements

- A different annual review process

- The expectation that the scientist will assume Bureau-level responsibilities in the USGS (for example, strategic planning or proposal review)

B. This group will also discuss the steps and application packet required for ST consideration. The application packet includes the following items:

- An updated RSR (in the new format) to include scientific activities since the peer review panel evaluation

- A 1-page summary of these recent activities
- A 2-page summary of how the candidate has met the additional criteria required for ST status (app. 8)

- Five reference letters that speak to the scientific impact, leadership, and societal relevance of the scientist's work. These should include three letters from highly regarded external (outside the USGS) scientists in the field, one letter from a highly regarded scientist in the field from within the USGS, and one letter from a stakeholder (for example, a land manager or decision maker who is using the results from the candidate's work)

- Signature sheet from the DEO, Ethics, HR, and OSQI reviewers affirming that the candidate is not involved in any ongoing ethical, personnel, or scientific integrity investigations and has no significant past breaches in these areas.

Key Recommendation: Fully inform all scientists who score 56 or more points about the process, requirements, and expectations of ST rank.

With an understanding of the position and the process, and if interested, the GS-15 scientist will be placed in the STeligible pool. Members of this pool can apply to the proposed ST Evaluation Committee (STEC; defined below in the section "ST Evaluation Committee Composition") in response to any ST application call for 7 years after being placed in the pool. The application will be prepared in accordance with the above guidelines. If the scientist does not reach ST status within 7 years, he or she will leave the ST-eligible pool and return to OPM's RGE process.

\section{ST Evaluation Processes}

If the scientist decides to go forward and pursue an ST position, the process is as follows:

1. The OSQI director initiates a call for ST packets to be submitted.

2. A candidate announces an interest in an ST position. His or her name is submitted for a DEO/Ethics/HR/IG investigation. If the investigation finds any issues, the scientist cannot submit a packet to the STEC at that time; rather, the candidate will remain in the ST-eligible pool until the issue is resolved or the candidate reaches 7 years in the ST-eligible pool.

3. If no DEO/Ethics/HR/IG issues are identified, or after resolution of any issues, the scientist may apply for ST status in response to any ST application call within a 7-year period following scoring 56 or more points in an RGE review. The scientist will prepare a packet according to the above guidelines and submit it to the 
STEC. The STEC, which will meet annually, will score the packet according to OPM guidelines. (This can be done without the attendance of the USGS Director or an assigned representative.) If the packet receives a score lower than 56 points, a summary of the strengths and weaknesses of the packet will be provided to the scientist, who will remain a GS-15. If the packet is scored at 56 or more points, the STEC will then consider the additional ST criteria. (The presence of the USGS Director or an assigned representative is critical for this stage.) If the packet fails to meet the additional criteria, a summary of the strengths and weaknesses of the packet will be provided to the scientist, who will remain a GS-15.

4. All scientists whose packets scored 56 points or more and who meet the ST criteria form the STEC-approved pool, and their names are forwarded to the USGS Director, along with the summary of strengths and weaknesses for each candidate. Scores associated with the RSR are not included. The USGS Director can ask for more background information from the STEC if desired. The scientist receives a copy of the strengths and weaknesses summary. At the same time, the Scientist Evaluation Advisory Committee (SEAC), via the OSQI director, provides the USGS Director with a profile of the ST cadre that includes gender, discipline, demographic profile, discipline balance, and other outstanding specific expertise (for example, communication, strategic planning skills) present in the current ST group.

5. The USGS Director selects scientists to recommend for promotion to ST rank, and their packets are then forwarded to the Executive Resources Board of the U.S. Department of the Interior.

6. For scientists who are not selected by the Director or who are not approved by the ERB, feedback is provided to the scientist as to why the application was rejected. The scientist remains in the STEC-approved pool from which he or she can reapply in response to any ST application call. Reapplications from the STEC-approved pool will be rechecked by DEO/Ethics/HR/IG reviewers, and, if no issues are found, the 1-page summary of scientific accomplishments and 2-page summary of other ST-relevant activities since the last application will be evaluated by the STEC. The scientist may update his or her RSR, but it will not be rescored by the STEC. If the scientist does not reach ST status within 7 years, he or she will return to the RGE process and be evaluated as part of the usual 7-year cycle.

\section{ST Evaluation Committee Composition}

The ST Evaluation Committee is recommended as a replacement for both the second-level peer review panel and the Senior Scientist Review Panel. The STEC will consist of a core standing group and ad hoc members.

1. Voting members (seven standing members plus one ad hoc expert):

A. Standing committee (voting) members:

i. Science representation: three STs, representing different scientific disciplines

ii. Management representation: USGS Director and either a regional director or an associate director

iii. OSQI representation: OSQI director

iv. External-to-USGS representation: one highlevel scientist who has worked with and understands USGS science

B. Ad hoc (voting) science representation: one ST who is as close to the field as possible for each packet. The ST representing the discipline of the packet will vote only on that specific packet.

2. Nonvoting members:

A. Ad hoc in-depth reviewer: one subject matter expert per candidate who attends only for the presentation of that candidate

B. Ad hoc representation from the Human Resources Office of the USGS

C. Ad hoc early career scientist (nonvoting because he or she will likely be at a lower grade than GS-15 and will not necessarily be familiar with ST-level work)

\section{Scientist Evaluation Advisory Committee}

The RGE Review Team recommends a standing committee to carry on the work that it has done. The value of a standing committee is that it can monitor the process recommendations as they are implemented and make adjustments as necessary.

The Scientist Evaluation Advisory Committee (SEAC) should be chaired by the OSQI director or designee, and members should have multiyear, staggered terms to maintain consistency. The committee would have the following responsibilities:

1. On an ongoing basis, monitor new data on processes and on the RGE workforce to identify trends and areas of concern

2. Archive data generated through the RGE/EDGE processes, as such data can be valuable to the agency for workforce planning and evaluation of workforce vitality 
3. Ensure that RGE/EDGE evaluation processes are fair, equitable, and timely. Ensure consistency across panels, peer groups, and review cycles

4. Recommend adjustments to the processes as needed

5. Share information about the processes, their application, and the workforce data with the ELT and the USGS workforce to ensure transparency

6. Periodically review training materials and panel outcomes and recommend updates as needed

The SEAC could also be the body that looks at the scientific workforce overall and recommends further actions. The data show that women and minorities are underrepresented in the RGE workforce, especially at higher grades. The RGE Review Team recommends that the SEAC continue to monitor diversity and take action as needed including, but not limited to, recommendations for recruiting, retaining, and mentoring women and minorities in the RGE workforce.

Key Recommendation: Create a standing committee to continue the work of the RGE Review Team by providing ongoing evaluation of the processes for continuous improvement and by maintaining data on the vitality and diversity of the scientific workforce.

\section{Other Key Recommendations}

The RGE Review Team's charge and focus were to evaluate the RGE system, and that process resulted in a series of key recommendations highlighted (boxed) throughout the text of this report and summarized in appendix 9. In addition, the Team has other recommendations related to the process but outside of our original charge that are described below.

\section{Enterprise Funding}

Enterprise (Bureau-level) funding is recommended to pay (1) for travel to peer review panels, the annual SEAC meeting, and the annual STEC meeting and (2) for collation of data on RGE/EDGE workforce accomplishments. This funding would ensure a fair, timely, and cost-effective review process that would allow for panel and committee participation by all RGE/EDGE scientists. The availability of this funding from the Bureau would signal to the USGS workforce that the ELT is committed to ensuring that all aspects of the RGE process are open and accessible to all scientists, regardless of the financial situation of their cost centers.

The RGE/EDGE review process advances the USGS science mission by demanding excellence and identifying research and development strengths and needs and is thus critical for making informed hiring decisions and retaining the best scientists. The scientists' records and panel evaluations provide a rich database on the productivity of USGS scientists, the scientific depth and breadth of USGS research, the extent of stakeholder engagement, and the impact and leadership roles of USGS scientists. Maintaining such a database with cross-linking of data and a common portal would inform the ELT's evaluation of workforce trends, including strengths and needs, and highlight opportunities for growth into new research directions. The recommended RGE/EDGE process also would provide information on (1) high-profile science to feature in a variety of communications and (2) scientists deserving nomination for awards. In addition, this database would pinpoint existing inequities and bias in the scientific workforce that need correction. Thus, such a database would allow the ELT to ensure the most effective, creative, resilient, diverse, and productive workforce possible. Given that funds are already expended to support the RGE/EDGE review process, with some cost centers more burdened than others, enterprise funding is not an additional burden, but an equitable and cost-effective way to support this valuable mission process.

Key Recommendation: Provide enterprise funding for travel to participate in peer review panels and meetings of the Scientist Evaluation Advisory Committee (SEAC) and ST Evaluation Committee (STEC).

\section{On Nine-Factor Scientists}

The mission of the USGS is to serve the Nation by providing reliable scientific information to describe and understand the Earth; minimize loss of life and property from natural disasters; manage water, biological, energy, and mineral resources; and enhance and protect our quality of life. Mission-critical science is conducted by both operational (nine-factor) scientists and research, development, and senior (four-factor) scientists, yet the USGS does not have a peer review process in place to evaluate the operational scientists. The lack of a review and peer evaluation process for operational scientists creates an impression of unfairness and bias. The Team is concerned that many of these operational scientists, especially in the remote sensing, modeling, geographic information system (GIS), and computer science fields, may leave the USGS for private industry and other government agencies where opportunities for advancement are more favorable. The USGS needs to retain, provide feedback to, and reward these critical members of our scientific staff.

A process that provides constructive feedback and a potential path towards advancement is needed. Also, this process will help the organization identify potential research, development, and senior scientists from the USGS operational staff.

Key Recommendation: Charter a committee to investigate the possibility of implementing a peer review process for operational scientist (nine-factor) positions. 


\section{Continuing Conversations with Federal Science Agencies-EDGE Evaluation}

All of the agencies that attended a benchmarking meeting hosted by the USGS agreed that it was valuable to share information in this way and that they would like to continue to meet and collaborate on solutions together; see the section above on "Benchmarking Against Other Federal Science Agencies." The RGE Review Team recommends that the USGS take a lead in maintaining an ongoing dialogue with our fellow Federal agencies regarding scientist review.

The OPM guidelines for EDGE scientist review are more than 50 years old (U.S. Office of Personnel Management, 1968), which is a significant problem recognized by all Federal agencies. The EDGE scientist track is underused at the USGS and the guidelines, which are out of touch with the 21 st century, are one reason for that. The Team recommends that the USGS work with other agencies to develop guidelines appropriate to current and future development scientists; then the USGS could ask DOI to participate in a consortium to work with OPM on adopting them.

Key Recommendation: Formalize a recurring Federal Science Benchmarking meeting and collaboratively develop new guidelines for evaluating development scientists that DOI could submit to OPM.

\section{Training and Communication}

The new processes recommended by the RGE Review Team will require new training to be developed and implemented. In addition, the USGS Handbook (U.S. Geological Survey, 2014) will need to be updated to reflect any new processes implemented. In implementation, it is important that every place these processes are explained-USGS internal websites, USGS external websites, HR websites, and USGS Handbook - say the same thing.

New scientists entering the USGS should receive a comprehensive orientation to scientist evaluation at USGS. This could potentially be in person or in a self-paced online class offered through DOI Talent. It is also recommended that research and development scientists either participate in a panel or observe a panel before going up for their first review.

The Team recommends the following trainings:

- For OSOI staff responsible for RGE: Facilitation training so the staff members can effectively guide panels and committee meetings.

- For HR staff: Training in how to ensure that panels follow OPM processes

- For scientists: Training, including exemplars, on the new RSR and DSR format. It is important that scientists understand the role of the factor narratives and the page limits so that they can present their records in the strongest way.

- For panelists: Training on the roles of primary reviewer and secondary reviewer and on how to write effective findings. The training should also focus on the OPM guidelines and how to apply them to scoring.

- For supervisors and center directors: Both scientist and panelist training so that they understand the process. A piece could be added to USGS supervisory challenge classes that explains the RGE position and processes for evaluation. Classes are listed at https://www.usgs.gov/about/organization/sciencesupport/human-capital/usgs-supervisory-development.

- For center directors: Comprehensive training on the entire system covering guidance on how to supervise research, development, and senior scientists; the responsibilities and flexibilities of center directors in the evaluation process; the difference between Research Grade Evaluation and performance evaluation; workforce planning for research, development, and senior scientist positions; differences between nine-factor operational positions and four-factor research, development, and senior scientist positions; processes for conversion; differences between GS-15 and ST positions; procedures for promotion to ST; and what to do when a scientist is found to be performing below grade.

- For members of the ST Evaluation Committee: Training on the new ST processes and expectations.

A communication plan for the rollout of changes to the RGE processes is critical. There was substantial interest and participation from stakeholders, and it is important that they hear the results. The Team recommends the following:

- An initial report to the OSQI director and ELT sponsors

- A briefing about the recommended new processes by the OSQI director to the ELT and the USGS Director

- A leaders' blog or equivalent linked from the NeedToKnow (NTK) - the weekly e-mail digest of news that USGS employees need to know

- A townhall delivered by an interactive web-based seminar (webinar)

- Development and implementation of new training materials

- Listening sessions held at USGS science centers across the country and led by RGE Review Team members

- Publication of the report 
Key Recommendation: Communicate the new RGE processes through leaders' blogs, townhalls, listening sessions, and training.

Key Recommendation: Publish the RGE Review Team's final report in its entirety as a USGS report.

\section{References Cited}

U.S. Geological Survey, 2007, Facing tomorrow's challenges-U.S. Geological Survey science in the decade 2007-2017: U.S. Geological Survey Circular 1309, 67 p. [Also available at https://pubs.usgs.gov/circ/2007/1309/.]

U.S. Geological Survey, 2014, Research and Equipment Development Grade Evaluation process handbook: U.S. Geological Survey handbook, 44 p., accessed April 23, 2021, at https://www.usgs.gov/media/files/researchand-equipment-development-grade-evaluation-processhandbook.
U.S. Office of Personnel Management, 1968, Equipment Development Grade Evaluation guide: U.S. Office of Personnel Management guide, 60 p., accessed October 16, 2019, at https://www.opm.gov/policy-dataoversight/classification-qualifications/classifying-generalschedule-positions/functional-guides/gsequpdv.pdf.

U.S. Office of Personnel Management, 2006, Research Grade Evaluation guide: U.S. Office of Personnel Management guide, 24 p., accessed April 23, 2021, at https://www.opm. gov/policy-data-oversight/classification-qualifications/ classifying-general-schedule-positions/functional-guides/ gsresch.pdf. 


\section{Appendixes 1-9}

Appendix 1A. Charge Given to the Research Grade Evaluation Review Team of the

U.S. Geological Survey.

Appendix 1B. Members of the Research Grade Evaluation Review Team of the

U.S. Geological Survey. 32

Appendix 2. Detailed Evaluation of Workforce Data 35

Appendix 3. Graphic Summary of Results of Surveys of Three Groups of

Stakeholders About the Research Grade Evaluation Process in the

U.S. Geological Survey.

Appendix 4. Benchmarking Information From a Comparison of Methods Used To

Evaluate Research Scientists.

Appendix 5A. Research Scientist Record Template ................................................................. 77

Appendix 5B. Findings Template for Use After Review of a Research Scientist

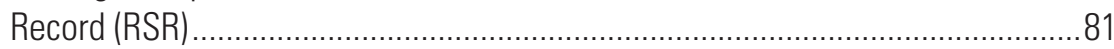

Appendix 5C. Development Scientist Record Template .........................................................82

Appendix 5D. Findings Template for Use After Review of a Development Scientist

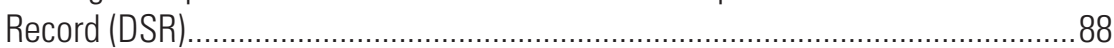

Appendix 5E. Cover Sheet for Research Scientist Record (RSR) or Development Scientist

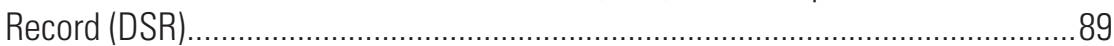

Appendix 5F. Guidelines for Scoring in Excess of Level E _..................................................90

Appendix 5G. Findings Form for Scientist Considered for Promotion to Senior

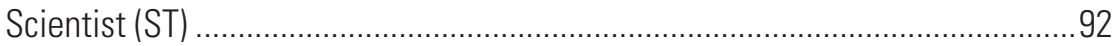

Appendix 5H. Standard Reviewer Questions for References .................................................94

Appendix 6. Report on Beta Test of the Recommended New Formats for the Research Scientist Record and Findings Templates and Processes Used by Peer Review Panels

Appendix 7. Explanations of Terms Used in This Report ……...............................................

Appendix 8. Additional Criteria for Senior Scientist (ST) Positions ......................................102

Appendix 9. Key Recommendations for Updating the Research Grade Evaluation Process for the U.S. Geological Survey. 



\title{
Appendix 1A. Charge Given to the Research Grade Evaluation Review Team of the U.S. Geological Survey
}

\author{
RGE Review Team Charge
}

May 22, 2017

\section{$\underline{\text { Introduction }}$}

The USGS workforce is the most important asset for the Bureau and the scientists engaged in research and development activities are essential to our success. For many decades, the Bureau has evaluated these scientists through the government-wide Research Grade Evaluation (RGE) and Equipment Development Grade Evaluation (EDGE) process. Prior to 2012, RGE/EDGE (from now on "RGE" will mean both "RGE" and "EDGE" for simplicity) evaluations were conducted via separate disciplinespecific processes. Since the change to a Bureau-wide evaluation process five years ago, there has not been a systematic analysis of the RGE process, the impact of the process on USGS, and the flexibilities currently available to science agencies when evaluating RGE staff.

The transition from discipline-based to a Bureau-wide process was important for consistency and improved oversight. However, the process is perhaps not being leveraged to the full extent possible. For example, aggregated information from the evaluation could be used to provide USGS leadership insights into the health of the USGS scientific workforce. To date, systematic analyses in this area are not routinely performed as part of the RGE process. Furthermore, information collected from scientists in the submission of their "RDSR" evaluation packets could be used to update professional profiles and perhaps maintain an internal database of expertise from across the Bureau.

Is the RGE process, as now practiced, meeting the needs of USGS? What flexibilities does USGS have to make improvements? How should other activities (e.g. gathering external funding, temporary supervisory details, community service including as part-time liaisons to other agencies, other operational duties, etc.) be considered, if at all, within the RGE process? What are the appropriate roles of supervisors and center directors? Is the Bureau-wide process meeting the intended goals of the 2011 change? Are there lessons to learn from RGE implementation and scientist evaluations at other science agencies? These are some of the questions to be posed to an RGE Review Team from across the Bureau.

\section{Purpose}

The RGE Review Team consists of USGS employees and is charged with: 1) reviewing research scientist evaluation practices in other agencies; 2) determining what flexibility USGS has to alter current practices; 3) gathering feedback regarding current practices; 4) assessing whether the current practices are meeting the expectations from the change; 5) recommending improvements to existing RGE processes; and 6) recommending a long-term approach for using evaluation processes to obtain feedback on the health and vitality of the USGS science workforce.

\section{ELT Co-Champions}

The ELT Co-Champions for this effort are:

Craig Robinson, Director, Office of Science Quality and Integrity

Virginia Burkett, Associate Director for Climate and Land Use Change (later Virginia Burkett became a member of the Team and was replaced as Co-Champion by Geoff Plumlee, Associate Director for Environmental Health)

Aimee Devaris, Regional Director, Alaska Region 


\section{Membership}

The RGE review team will consist of approximately 12 members from across USGS to include RGE scientists, RGE panelists, Center Directors, a staff member from OSQI, and one or more representatives from Human Capital. The review team will have a chairperson and will form subgroups, as needed, focused on individual activities under each Task.

\section{Timeframe}

The RGE Review Team will be established in June 2017 and will submit reports on each of the Task areas as they are completed. Reports will go to the ELT co-champions who will communicate the results to the Executive Leadership Team (ELT) for discussions on next steps.

\section{Detailed Charge}

The activities of the Review Team are grouped by Tasks to permit interim reports of findings. The purpose of the interim reports is to permit the co-champions to adjust, if warranted, later Tasks.

\section{Task A}

1) Review practices at a sample of other Federal science agencies to understand their processes for evaluation of research scientists and to determine what flexibility exists for USGS.

a. For those agencies using RGE panels:

i. How are other agency implementations of RGE similar to or different from USGS?

ii. From these different approaches, what lessons can we learn to strengthen USGS practices?

iii. What methods and metrics are used to track success?

iv. How do these agencies monitor trends in panel results (e.g. promotion rates as a whole as well as for different demographic and discipline-based groups) over time?

v. How are other activities (e.g. gathering external funding, temporary supervisory details, community service including as part-time liaisons to other agencies, etc.) considered, if at all, within the RGE process? If they are not considered, do these agencies have other processes or pathways for evaluation?

b. For those agencies not using RGE panels:

i. What evaluation practices are used?

ii. Did the agency receive approval from OPM or Congress to differ from OPM guidance?

c. Determine if data are available that would permit your team to compare, in aggregate, evaluation outcomes (e.g. promotion rates) for RGE scientists at USGS with those at similar agencies. Also compare, if possible, whether different pathways or evaluation practices are leading to better outcomes regarding contributions, impact and stature of scientists. If differences exist, can you attribute these to the evaluation practices or rather to other differences between USGS and these agencies? 
2) Determine to what extent USGS can make changes, with OPM approval, to the evaluation criteria and processes presented in the OPM Research Grade Evaluation Guide (RGEG; 2006) to meet specific USGS needs.

In particular, consider the flexibility provided on page 20 of the RGEG: "The nature, type, importance, and significance of various professional contributions, research products, and other scientific outputs vary across agencies and disciplines. Therefore, agencies may find it helpful to develop supplements to this guide to aid in evaluating research work in their specific research environments."

On this same page, also note that: "Agencies have discretion in establishing and evaluating research positions; however, OPM recommends applying the same evaluation method to all research positions within an agency."

Also consider the proper way to guide panels in interpreting guidance from the RGEG, on page 6, that factor levels should be assigned "based on the best match between the factor level criteria and the researcher's work" and that for each factor level the work should "fully satisfy" the criteria.

\section{Task B}

3) Gather feedback from a sample of USGS scientists evaluated under the RGE process, their supervisors, center directors and RGE panelists regarding current practices. What common themes are emerging?

4) Interview current and past USGS staff to understand the full extent and intent of the 2011 change to a consistent, Bureauwide practice. What are the perceived benefits and challenges of that transition? Determine where the current practices have met expectations and where additional work is needed.

\section{Task C}

5) Based upon the practices at other agencies, the flexibilities that USGS has under OPM guidelines, and the feedback obtained from within USGS, recommend improvements to the USGS research evaluation process for scientists.

6) Recommend a long-term approach for providing advice regarding the evaluation of USGS scientists as well as a periodic evaluation of the health of the USGS scientific workforce. 


\section{Appendix 1B. Members of the Research Grade Evaluation Review Team of the U.S. Geological Survey}

Fifteen individuals were selected to be on the original Research Grade Evaluation (RGE) Review Team of the U.S. Geological Survey (USGS), and additional members were added to address specific functions.

Suzette Kimball, former USGS Director (retired); chair of the RGE Review Team

Jayne Belnap, Research Ecologist, senior (ST) scientist

Virginia R. Burkett, Chief Scientist, Land Resources Mission Area

Co-Chair, U.S. Global Change Research Program; Alternate US Principal, Group on Earth Observations. Formerly: USGS Associate Director for Climate and Land Use Change, Deputy Regional Chief Biologist, and Branch Chief, National Wetlands Research Center

Carol A. Finn, Research Geophysicist, Geology, Geophysics and Geochemistry Science Center

Bill Guertal, Deputy Associate Director, Water Mission Area

Manuela Huso, Research Statistician, Forest and Rangeland Ecosystem Science Center

Christopher Johnson, Deputy Director, Office of Science Quality and Integrity

Formerly: RGE Coordinator

Tamara Lamb-Ghenee, Bureau Classifier, Office of Human Resources

David E. Lytle, Supervisory Biologist and Center Director, Southwest Biological Science Center

Formerly: State Forester and Chief, Ohio Division of Forestry; Forest Ecologist, The Nature Conservancy; Research Ecologist, U.S. Department of Agriculture Forest Service 
Anke Mueller-Solger, Associate Director, California Water Science Center

Regina Neal-Mujahid, Director, Office of Diversity, Equity, and Inclusion

Randall C. Orndorff, Research Geologist, Florence Bascom Geosciences Center

Formerly: Acting Director, Office of Science Quality and Integrity; Director, Eastern Geology and Paleoclimate Science Center; Associate Program Coordinator, National Cooperative Geologic Mapping Program

Kenneth G. Rice, Supervisory Biologist and Center Director, Wetland and Aquatic Research Center

Formerly: Branch Chief and RGE Wildlife Biologist with Southeast Ecological Science Center, also former Student Career Experience Program (SCEP) member of Florida Cooperative Fish and Wildlife Research Unit and term with Georgia Cooperative Fish and Wildlife Research Unit

Leslie F. (Jingle) Ruppert, Supervisory Research Geologist, Eastern Energy Resources Science Center

Eleanour Snow, National Manager of Youth and Education in Science programs, Office of Science Quality and Integrity

John D. Thompson, Supervisory Biologist and Deputy Chief, Cooperative Research Units, Ecosystems Mission Area Formerly: RGE Coordinator, Office of Science Quality and Integrity and Biological Resources Discipline

Christian E. Zimmerman, Supervisory Biologist and Center Director, Alaska Science Center

Formerly: Office Chief, Water, Ice, and Landscape Dynamics Office at Alaska Science Center; Research Fish Biologist 



\section{Appendix 2. Detailed Evaluation of Workforce Data}

\section{Introduction}

The Research Grade Evaluation (RGE) Review Team was charged with examining whether current practices in the U.S. Geological Survey (USGS) are meeting the expectations for the change from a discipline-based RGE system to a standard, bureauwide system in 2012. The Team was also asked to determine if data were available that could be used to provide the USGS leaders with insights into the vitality of the USGS scientific workforce.

The Team formed a data committee to assess the status and trends of the RGE workforce, which consists of research, development, and senior scientists. To our knowledge, this is the first-ever quantitative assessment of the USGS workforce evaluated under the RGE process. Some clear trends emerged from this assessment, although many questions of interest to the Team could not be readily answered with the available data. The value of data obtained from individual RGE peer review panels and datasets that allow tracking of research and development scientists (in aggregate) and panel composition cannot be overstated in terms of our ability to respond to the charge we were given.

\section{Guiding Questions}

The Team's data committee initially posed a series of questions to guide its data collection and analysis work. As its work proceeded, the committee found that many questions could not be answered with the available data or would require additional data that we could not access. The following are the questions that could be answered with the available data:

- What is the current composition of the USGS RGE workforce and how has it changed since 2012 when the current review process was established? How has it changed over several decades?

- Is there parity in promotion and retention among RGE scientists across the scientific disciplines and peer groups?

- Are there differences in peer review panel outcomes for women and men in RGE review? Is there a difference in years since last promotion? Is there a difference in mean General Schedule (GS) grade level in 2017 and GS grade level in 2012?

- Does a difference in funding source affect years in grade and promotion of RGE employees?

- What is the composition of RGE peer review panels and how has that changed over the past 5 years?
- What areas of expertise among our RGE employees are we likely to lose in the next 5-10 years as employees become eligible for retirement?

\section{Datasets}

The data used in this assessment included data about research, development, and senior scientists and about funding sources. The data were obtained from the following confidential datasets:

- FPPS dataset: The Workforce Data and Analysis Program of the USGS Human Resources Office (HR) provided data about 4,520 scientists. The data were extracted from the Federal Personnel and Payroll System (FPPS) and were provided as annual snapshots at the end of each fiscal year from 1990 to 2017 (last pay period of each year for 28 years). For the purpose of this assessment, 286 position titles in 45 occupational series occupied by the RGE scientists in this dataset were combined into 8 scientific disciplines (table 2.1).

- DEO dataset: The USGS Office of Diversity and Equal Opportunity (DEO) provided data about the race and ethnicity of 3,115 RGE scientists for 2002-2017 (16 years). For comparison, DEO also provided race and ethnicity data about 6,123 non-RGE scientists in similar occupational series for the same period. Race and ethnicity are self-reported by employees on standard form SF 181.

- OSQI datasets: The USGS Office of Science Quality and Integrity (OSQI) provided data about peer review panel outcomes for 1,184 research and development scientists who were reviewed from 2012 to 2017. Of the scientists reviewed, 98 percent were research scientists and only 2 percent were development scientists. These data did not include gender information. RGE peer review panel data were not available from the former disciplines, so patterns and trends in panel outcomes could not be evaluated for the period before the bureauwide review process was adopted in 2012. OSQI also provided data on 126 panels that met during 2012-2016. The data included the genders of panel members and the scientists under review, but they were aggregated at the panel level, so did not include information on any individual scientist's rank.

- FBMS dataset: Data about appropriated and reimbursable funding in 149 USGS cost centers were obtained from the USGS Financial and Business Management System (FBMS, in use since 2012) for 2012-2017. 
Table 2.1. Eight U.S. Geological Survey informal disciplines aggregated from occupational series of research scientists in the Federal Personnel and Payroll System (FPPS) dataset described in this appendix 2.

[U.S. Geological Survey (USGS) disciplines do not directly align with occupational series defined by the U.S. Office of Personnel Management (OPM); thus, some occupational series of OPM (such as Geology, General Engineering, and Physical Science) are assigned to two different USGS disciplines]

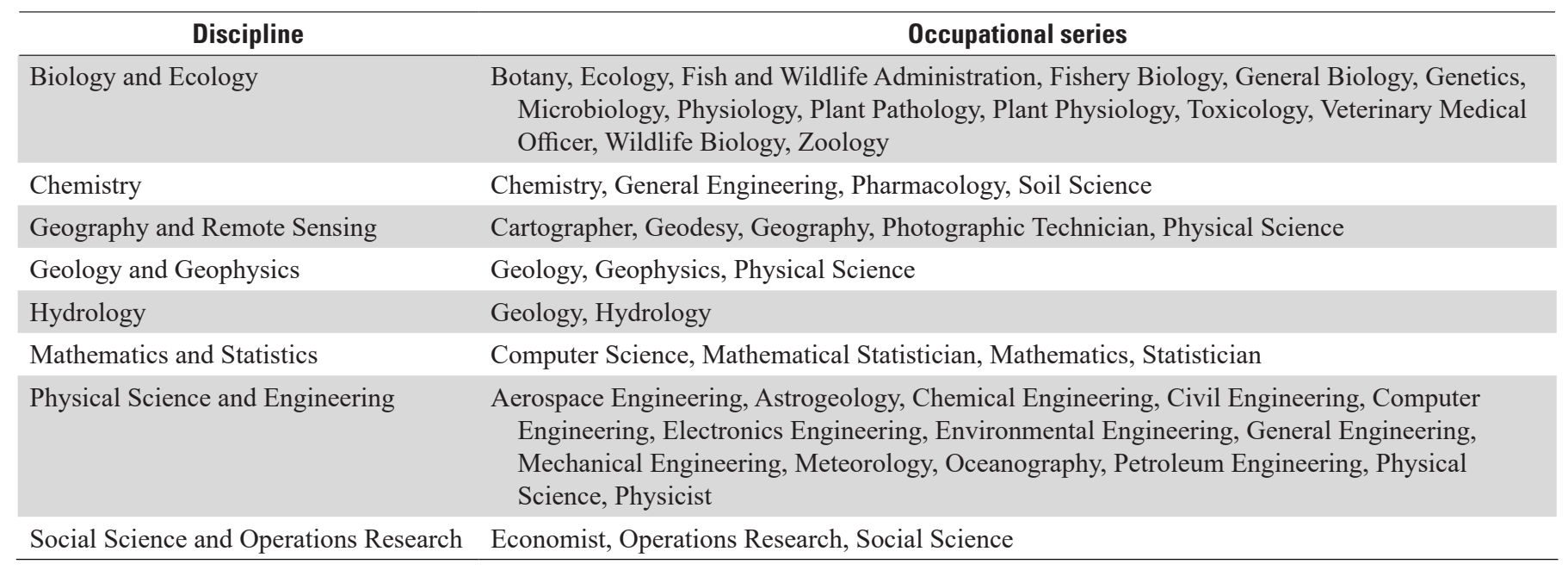

In addition, we used data provided by the National Science Foundation (NSF) about diversity in science and engineering in 2017, occupational outlooks provided by the Bureau of Labor Statistics of the U.S. Department of Labor, and statistics from the U.S. Census Bureau about diversity in the general U.S. population in $2017 .{ }^{1}$

\section{Summary of Long-Term Demographics}

Over the last few decades, the USGS RGE workforce has in many respects lacked diversity. Of the 4,520 RGE scientists in the 1990-2017 FPPS dataset, 89 percent were research and senior scientists, while only 11 percent were development scientists. Seventy-eight percent were men and 22 percent were women. Fifty-three percent of research, development, and senior scientists had a Ph.D. Since 1990, a higher proportion of men have a Ph.D. as their terminal degree than do women (54 percent of men, 49 percent of women), whereas a higher proportion of women have M.S. or B.S. degrees as their terminal degree (43 percent of women, 37 percent of men; fig. 2.1).

Seventy-nine percent of the 4,520 research, development, and senior scientists were in the three largest of eight scientific disciplines in the USGS. These three disciplines had different gender compositions: the Geology and Geophysics discipline and the Hydrology discipline had a higher percentage of men, whereas the Biology and Ecology discipline had a higher

\footnotetext{
${ }^{1}$ These data were accessed at the following URLs between August 2018 and August 2019:

https://ncses.nsf.gov/pubs/nsf19304/digest/employment

https://www.bls.gov/ooh/life-physical-and-social-science/

geoscientists.htm\#tab-2

https://www.census.gov/quickfacts/fact/table/US/PST045217
}

percentage of women. The other five disciplines had more balanced gender compositions (fig. 2.2).

Scientists of color are significantly underrepresented in the USGS: only 9 percent of the 3,115 research, development and senior scientists and 11 percent of the 6,123 scientists not in the RGE workforce in the 2002-2017 DEO dataset were of color. Thirty percent of scientists and engineers in the United States in 2017 were nonwhite (according to NSF data, as described above in the section on "Datasets") and 39 percent of the general U.S. population in 2015 was nonwhite (according to U.S. Census Bureau data as described in the section on "Datasets"). The U.S. Equal Employment Opportunity Commission (EEOC) defines seven categories for race and ethnicity. Figure 2.3 uses five categories for nonwhite scientists based on the EEOC categories and shows that Asians represented 5 percent of the RGE workforce; Hispanics or Latinos, 2 percent; and African Americans and American Indian/Alaska Native, less than 1 percent each. Nonwhite women (6 percent) were a smaller part of the female subset of the RGE workforce than nonwhite men (9 percent) in the male subset of the RGE workforce. This gender difference is largely due to a greater percentage of Asian men ( 5 percent) in the male subset than Asian women ( 3 percent) in the female subset of the RGE workforce (fig. 2.3).

Thirteen percent (609) of the 4,520 RGE scientists in the 1990-2017 FPPS dataset are veterans, and almost all (99 percent) are men. In addition to low demographic diversity, most RGE scientists are also spatially concentrated in only three States: more than half (54 percent) of all 4,520 RGE scientists in the 1990-2017 FPPS dataset had their most recent duty station in one of the three primary USGS locations in Colorado (22 percent), California (19 percent), and Virginia (13 percent). 


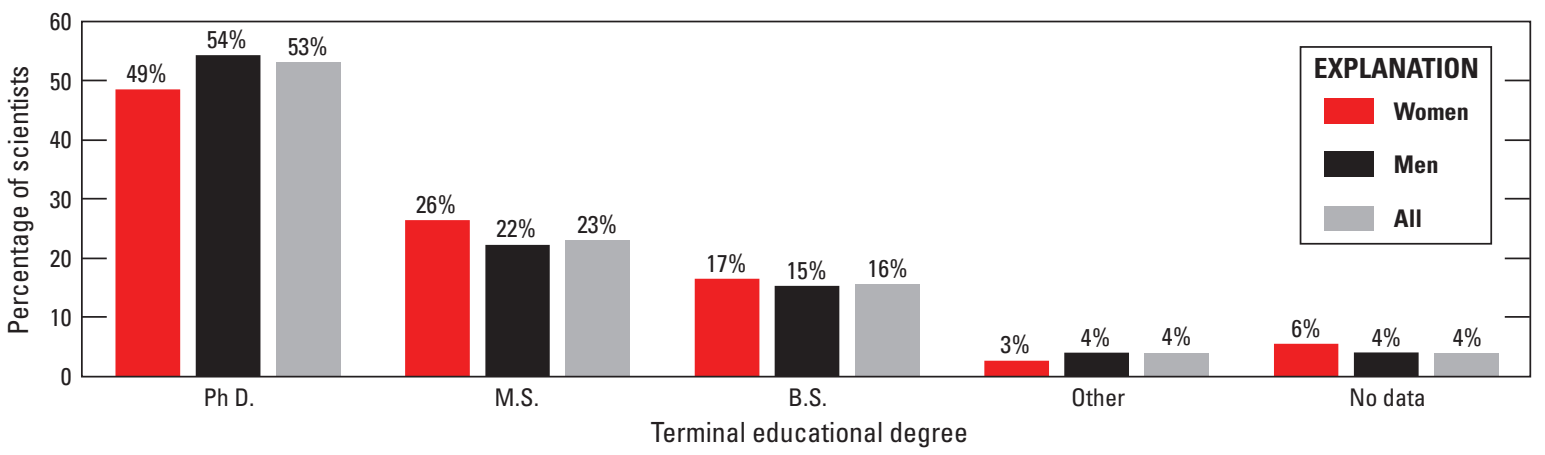

Figure 2.1. Bar graph showing percentages by gender of 4,520 U.S. Geological Survey research, development, and senior scientists holding different terminal educational degrees. The bars show the highest degrees attained as Ph.D., doctor of philosophy; M.S., master of science; B.S., bachelor of science; and other. The data are from the Federal Personnel and Payroll System (FPPS) dataset for 1990-2017.

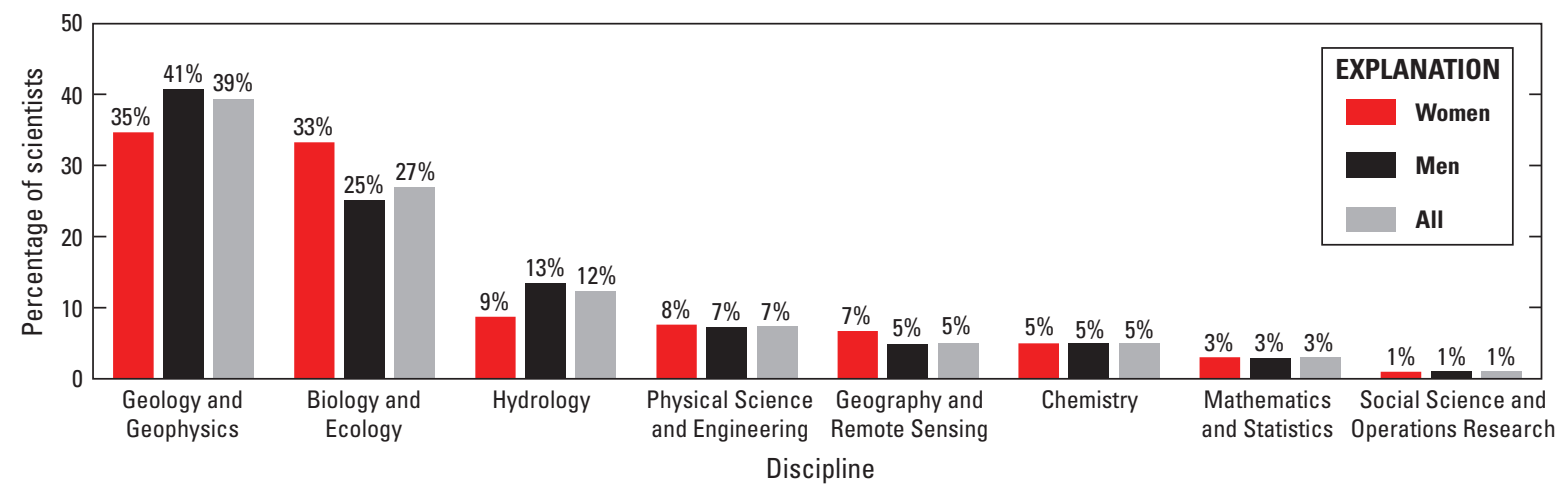

Figure 2.2. Bar graph showing percentages by gender of positions in eight scientific disciplines held by 4,520 U.S. Geological Survey research, development, and senior scientists. The data are from the Federal Personnel and Payroll System (FPPS) dataset for 1990-2017.

Finally, RGE retention patterns are also fairly uniform: After entering the RGE workforce, most (92 percent) of the RGE scientists in the 1990-2017 FPPS dataset remained active in RGE positions without interruption until their retirement or other permanent departure from their RGE positions, while 8 percent left and later reentered RGE positions at least once.

\section{Compositions of RGE Peer Review Panels}

The RGE Review Team received summary statistics from OSQI for the 126 RGE peer review panels convened during 2012-2016. Of the 582 panel members serving during 2012-2016, 72.6 percent were men and 27.4 percent were women, which roughly mirrors the gender composition of USGS RGE scientists in recent years (see below). Panels consisted of three to eight reviewers. Twenty-six (21 percent) of the panels consisted only of males; only one of these allmale panels reviewed only male scientists. None of the panels were all female. There were 1,458 scientists reviewed during this period, and 25 percent (369) of them were women. Of the 369 women up for review, 17.6 percent were evaluated by an all-male panel.

Data of this nature were not available prior to the implementation of the bureauwide RGE evaluation system in 2012, so the effects of this new system on panel composition could not be evaluated. Furthermore, the 2012-2016 dataset did not contain panel dates, so changes in panel composition over the last 5 years could also not be evaluated. Finally, while the dataset did include total numbers of men and women recommended for promotions by each panel, it did not provide grade levels for the scientists being reviewed. As shown below, grade levels have a strong influence on the probability of promotion, and it is important to include grade levels when evaluating the contributions of other factors on the probability of promotion, as was done for peer groups in the analysis presented below. Because this dataset on panel outcomes did not provide grade levels for the scientists being reviewed, it was not possible to determine if there was an influence of panel composition on the probability of promotion for men and women. 


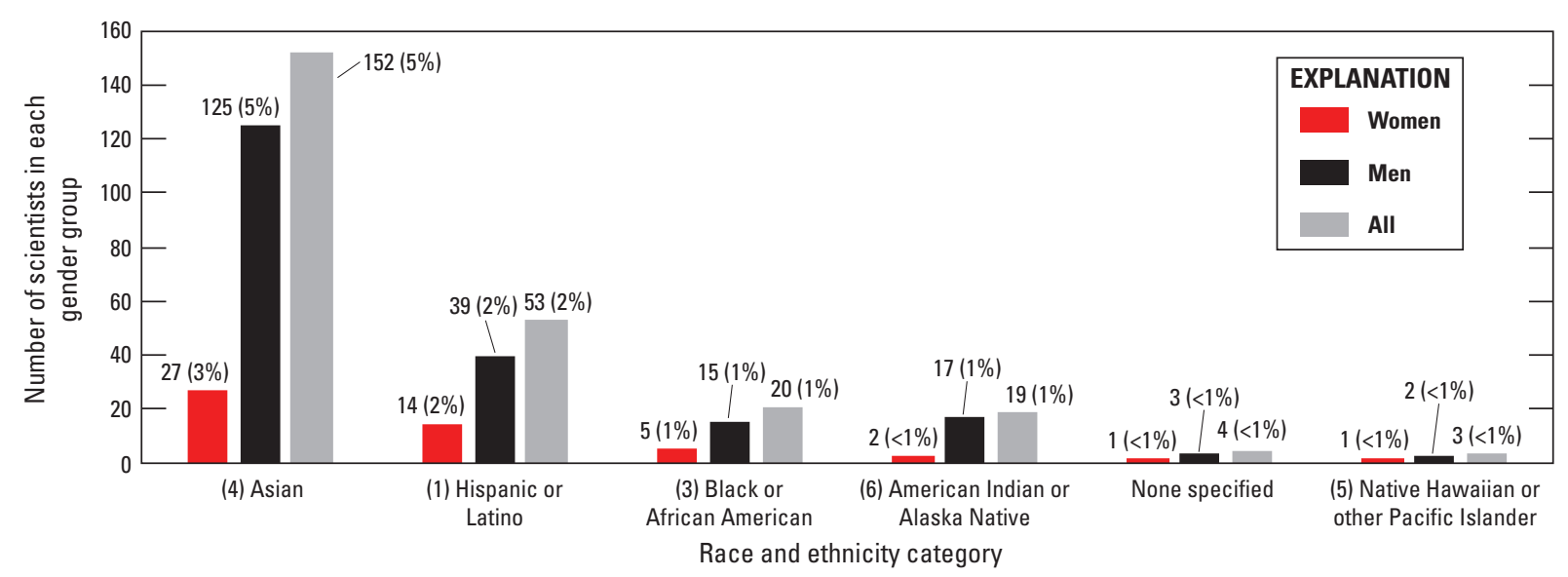

Figure 2.3. Bar graph showing numbers and percentages of nonwhite U.S. Geological Survey (USGS) scientists in 3,115 research, development, and senior scientist positions by gender in several race and ethnicity categories. Labels for bars show the number and percentage of scientists in each category. Percentages are given by gender subset as the percentage of 789 positions for women, 2,326 positions for men, or 3,115 positions for all. In order to show details for the nonwhite categories, no bars are shown for the 92 percent of positions occupied by white scientists. The categories are based on those defined by the U.S. Equal Employment Opportunity Commission (https://www.eeoc.gov/employers/ eeo1survey/2007instructions.cfm). The data are from the USGS Office of Diversity and Equal Opportunity (DEO) dataset for 2002-2017.

The RGE workforce has undergone substantial changes since 1990. The workforce changed abruptly in 1995 when there was a reduction in force and again in 1996 when 575 RGE scientists from the National Biological Survey were integrated into the USGS RGE workforce. Since 1996, most changes have been gradual, but persistent. With few exceptions, there is very little evidence for effects of the 2011-2012 change in the RGE process on the RGE workforce. The following sections highlight some of the most substantial changes and discuss the few instances where the 2011-2012 RGE process change might have had an effect on the RGE workforce.

\section{RGE Workforce Demographics}

Number of active RGE scientists per year: Since 1990, the USGS has on average had 1,474 active RGE scientists per year. The integration of 575 RGE scientists from the National Biological Survey in 1996 increased the number of RGE scientists to 1,728 in 1996. Since 1996, the number of RGE scientists has declined steadily by about 20 scientists per year to 1,264 in 2017 (fig. 2.4). The 2011-2012 change in the RGE review process had no discernible influence on this trend.

Scientific disciplines: RGE positions in the USGS can be grouped into eight informal disciplines (table 2.1). In 1990, the dominant disciplines were Geology and Geophysics (62 percent of all RGE scientists) and Hydrology (16 percent); the other six disciplines combined accounted for only 22 percent of the RGE workforce (fig. 2.5). Because of a reduction in force in October 1995, the USGS had a sharp decline in the number of geologists. This decline and the integration of the National Biological Survey in 1996 reduced the proportion of RGE scientists in Geology and Geophysics to 35 percent in 1996 and increased the proportion in Biology and Ecology from 2 percent in 1995 to 32 percent in 1996. While the numbers of active RGE scientists in Biology and Ecology, Physical Science and Engineering, and Social Science and Operations Research have remained fairly stable since 1996, numbers in other disciplines have declined. The loss of nearly 200 RGE scientists in Geology and Geophysics since 1996 accounts for about half of the overall decline in the number of RGE scientists in this time.

In 2017, 35 percent of RGE positions were in Biology and Ecology, 33 percent were in Geology and Geophysics, 14 percent were in Hydrology, 8 percent were in Physical Science and Engineering, and the remaining 10 percent were in the four smaller disciplines. According to the Bureau of Labor Statistics (as described in the section on "Datasets"), the overall number of jobs in 2016-2026 for occupations held by USGS RGE scientists is expected to increase at the national average rate for some positions ( $6-8$ percent for Economists, Wildlife Biologists and Zoologists, Chemists and Material Scientists, and Microbiologists) and above the national average for other positions (10-33 percent for Hydrologists, Environmental Scientists and Specialists, Geoscientists, and Mathematicians and Statisticians); thus, the loss of RGE scientists from the USGS is out of line with that forecast.

Gender composition: Male RGE scientists have consistently outnumbered female RGE scientists, but the number of men has steadily decreased by about 24 per year since 1996 while the number of women has steadily increased by about 5 per year since 1996 (fig. 2.6). Moreover, since 1996, the number of men declined in all eight disciplines, while the number of women increased in the four largest disciplines and remained fairly stable in the four smaller disciplines. These opposing trends mean that the overall decline in the number 


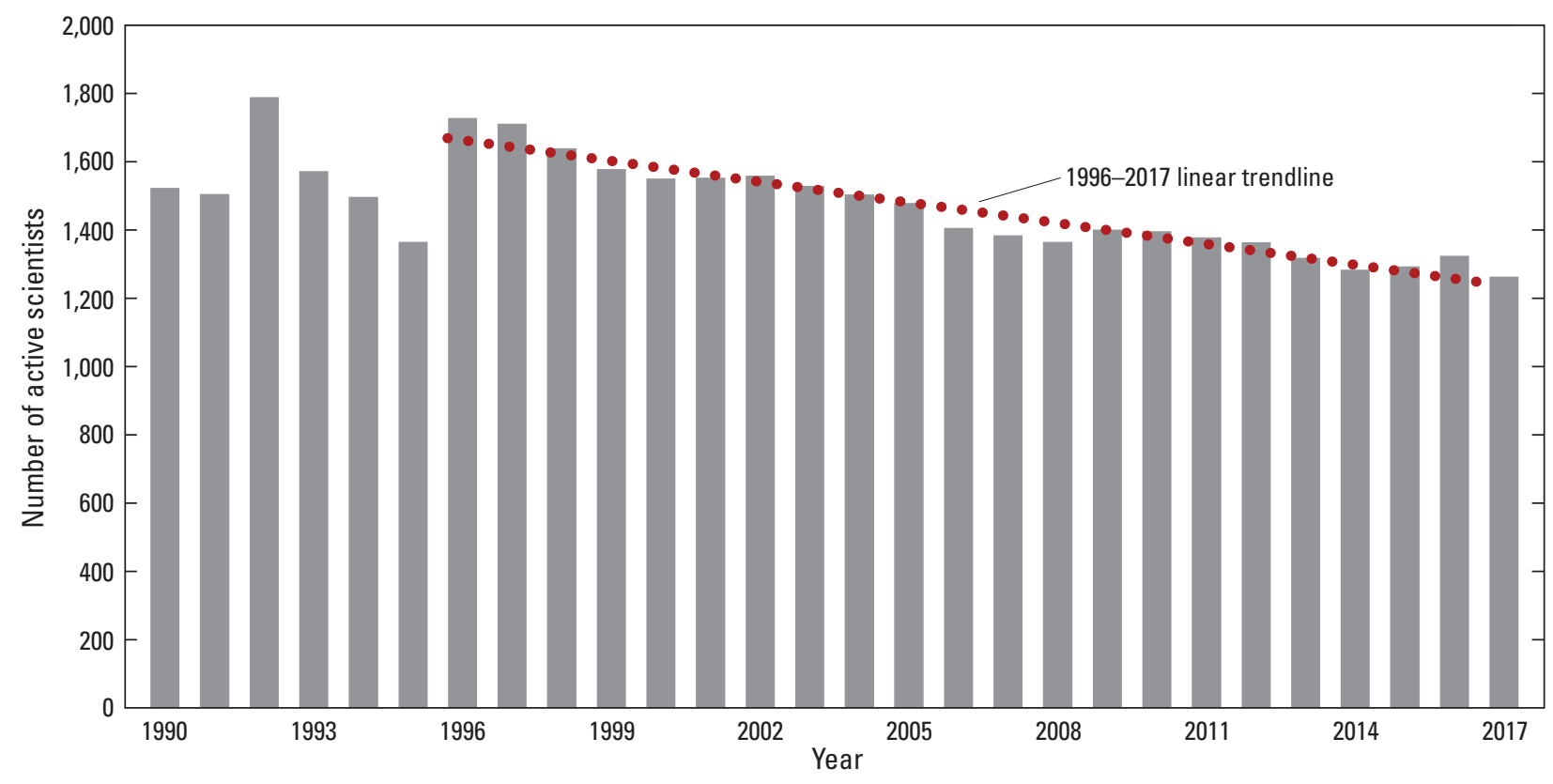

Figure 2.4. Bar graph showing the number of U.S. Geological Survey research, development, and senior scientists who were active in each year from 1990 through 2017. The trend from 1996 to 2017 shows a fairly steady decline. The data are from the Federal Personnel and Payroll System (FPPS) dataset for 1990-2017,

of RGE scientists is due to a decline in the number of men, not women. In 1990, only 12 percent of RGE scientists were women; by 2017, the percentage of women had more than doubled to 29 percent. If these trends continue, the numbers of male and female RGE scientists will be roughly equal in less than two decades.

Age composition: From 1990 to 2017, the average age of RGE scientists was 50 years, with a range of 22 to 92 years. The average age increased until 2007, then leveled out at 51-52 years. Age variability declined from 1990 (standard deviation $(\mathrm{SD})=10$ years, interquartile range $(\mathrm{IQR})=15$ years) to 1996 ( $\mathrm{SD}=8$ years, $\mathrm{IQR}=11$ years) and started rising again from 2007 to 2017 (in 2017, SD=11 years, IQR=18 years). The recent increase in age variability is due to an increase in both younger and older RGE scientists; that is, age diversity has been increasing. Female RGE scientists were on average younger than their male counterparts; the average age of male RGE scientists was 51 years while that of female scientists was only 46 years. While the average age of men and women increased from 1996 until about 2012, the age gap between men and women gradually narrowed from 7 years in 1990 to 4 years in 2011-2014, but then widened again to nearly 5 years (fig. 2.7A). The overall leveling out of the average ages of men and women and the increase in overall age diversity coincide approximately with the implementation of the bureauwide RGE process that started in 2012. It is unclear, however, how this process change might have affected the age distribution of the RGE workforce.

Grade composition: In addition to an age gap between men and women, there is also a persistent gender grade-level gap of nearly one full GS grade level. Data for ST scientists were included in calculations of the average grade by applying an artificial grade level of GS-16. For 1990-2017, the average GS grade level for female RGE scientists was 12.8 while that of male RGE scientists was 13.6. However, the grade gap has been decreasing as women's average grade levels have been increasing (fig. 2.7B).

Factors affecting the gender grade gap: Grade levels are positively associated with age, so one reason for the narrowing gap in average grade level between men and women may be the narrowing gap in average age between men and women. Another reason for the narrowing grade-level gap between men and women may be the narrowing gap in average grade level at entry into RGE positions. Until 2010, women usually entered RGE positions at lower GS levels (average difference 0.8 GS level). Since 2011, this difference has nearly disappeared (average difference 0.2 GS level), and overall variability in grade levels at entry has decreased; men and women alike now usually enter RGE positions at the GS-12 level (fig. 2.8).

Promotions: For 1990-2017, the average number of years for promotion from one GS level to the next increased with increasing GS level but was very similar for men and women. However, promotion from GS-12 to GS-14 took women on average 2 years longer than men (fig. 2.9).

The OSQI dataset of peer review panel outcomes for 1,184 scientists who were reviewed from 2012 to 2017 was used for an analysis of the probability of promotion across 13 RGE panel peer groups for men and women in grades GS-12 to GS-15. The purpose was to determine if there was statistical evidence of systematic gender bias or if gender bias was more prevalent within certain grade levels. 
A. Number of active scientists for the four larger disciplines

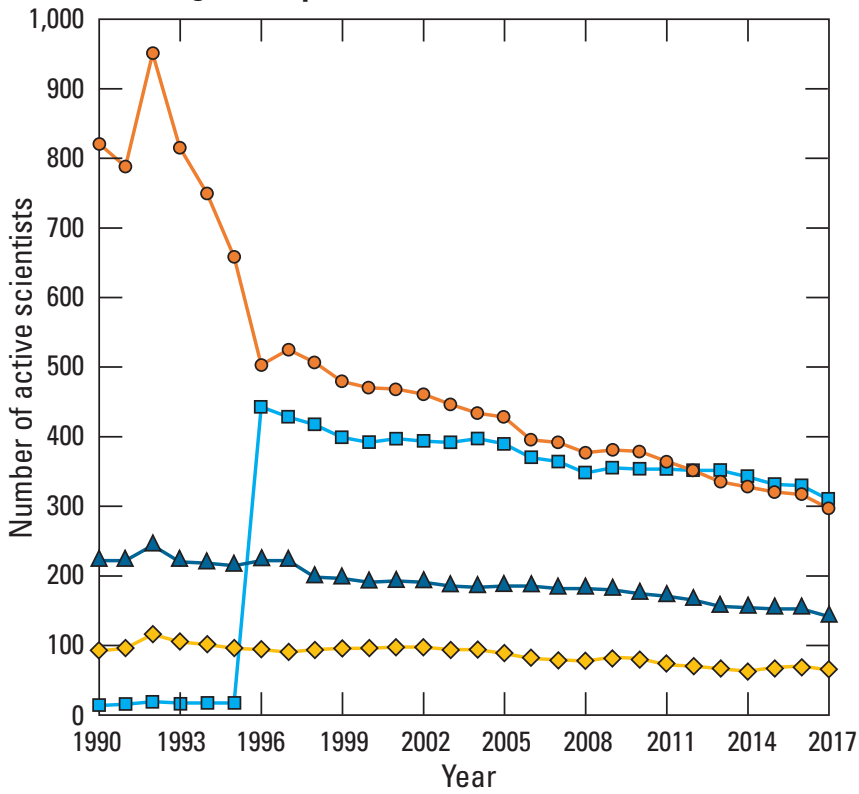

EXPLANATION

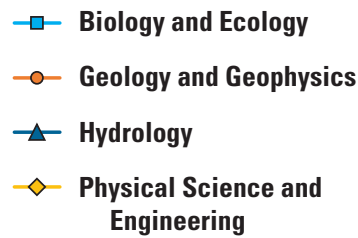

B. Number of active scientists for the four smaller disciplines

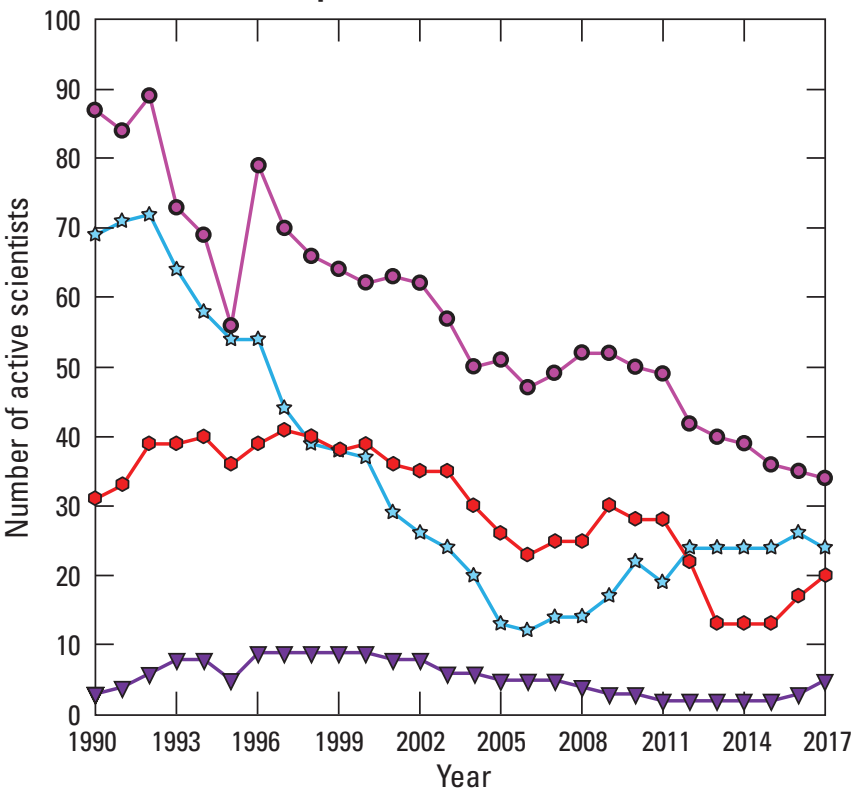

EXPLANATION

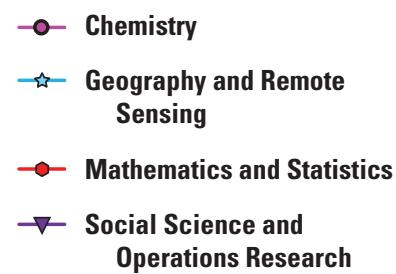

Figure 2.5. Line graphs showing the number of U.S. Geological Survey research, development, and senior scientists who were in each of eight disciplines in each year from 1990 through 2017. The graphs have different scales because four disciplines had significantly more members than the other four. $A$, Number of active scientists for the four larger disciplines; $B$, Number of active scientists for the four smaller disciplines.

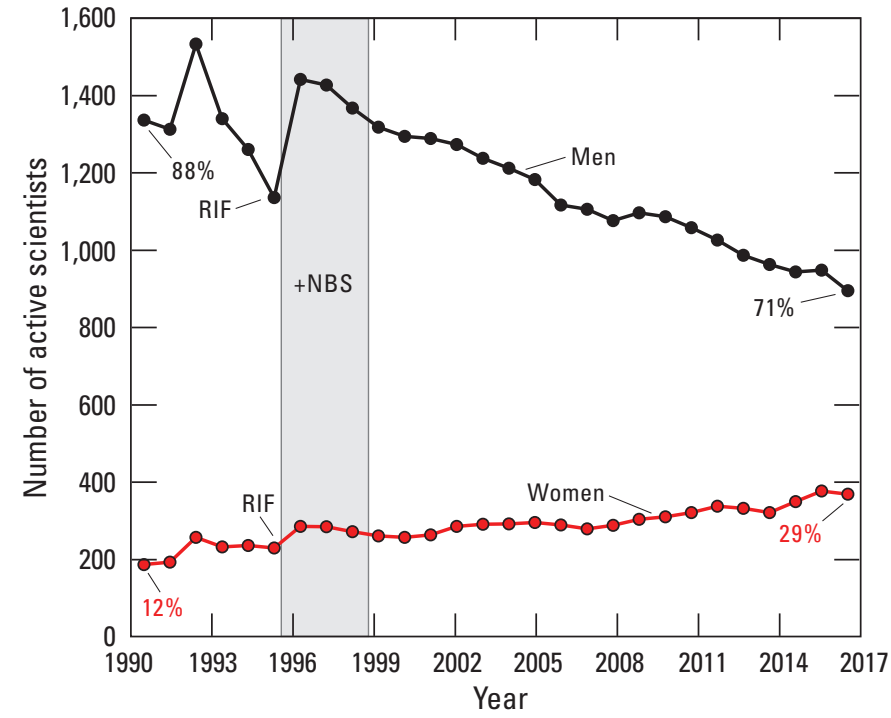

Figure 2.6. Line graph showing the number of male and female U.S. Geological Survey employees in research, development, and senior scientist positions who were active in each year from 1990 through 2017. The gray rectangle labeled "+NBS" indicates the effect of the integration of the National Biological Survey employees in 1996. The 1995 points labeled "RIF" indicate effects of a reduction in force. 
A. Average age for each year

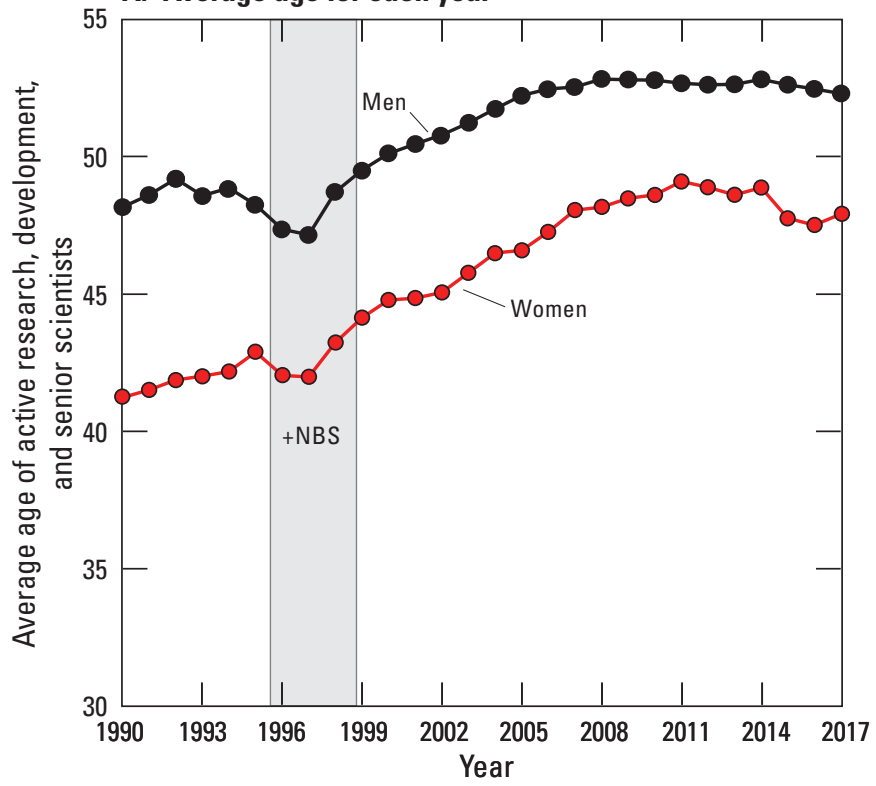

B. Average grade level for each year

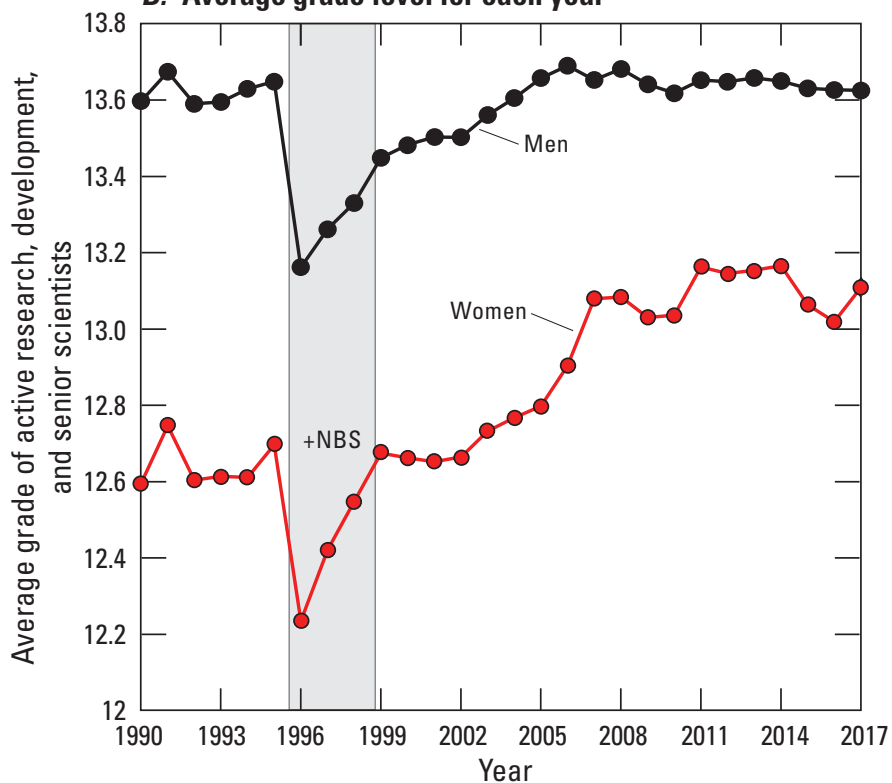

Figure 2.7. Line graphs showing the annual average age and average grade level of U.S. Geological Survey employees in research, development, and senior scientist positions who were active in each year from 1990 through 2017. The gray rectangle labeled "+NBS" indicates the effect of the integration of the National Biological Survey employees in 1996. A, Average age for each year; $B$, Average grade level for each year. Grades are from the General Schedule (GS) described by the Classification Act of 1949 for Federal civilian employees. Data for senior scientists were included in calculations of the average grade by applying an artificial grade level of GS-16.

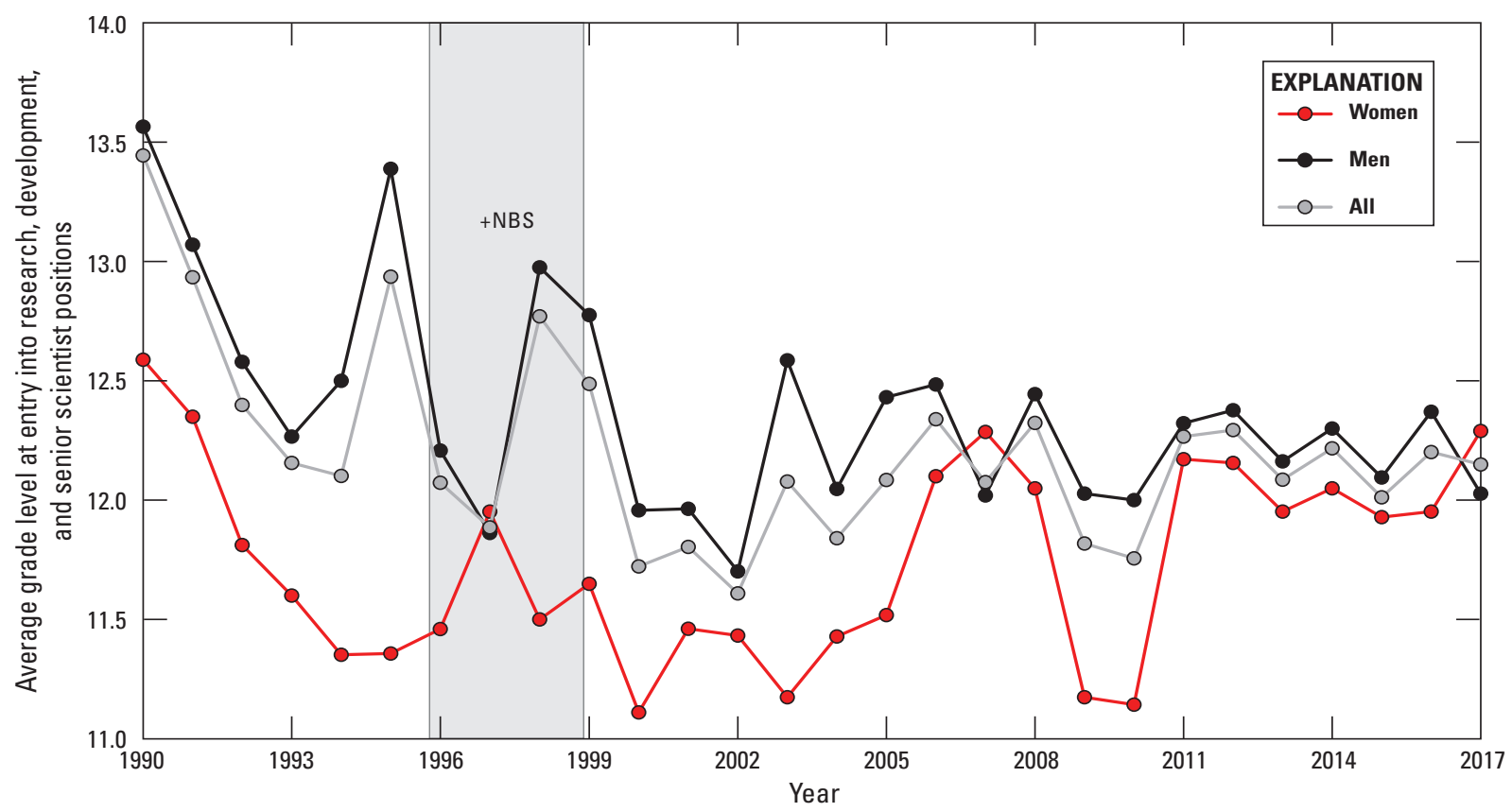

Figure 2.8. Line graph showing the average grade level at entry into U.S. Geological Survey research, development, and senior scientist positions for female, male, and all scientists who were active in each year from 1990 through 2017. Grades are from the General Schedule (GS) described by the Classification Act of 1949 for Federal civilian employees. Data for senior scientists were included in calculations of the average grade by applying an artificial grade level of GS-16. The gray rectangle labeled "+NBS" indicates the effect of the integration of the National Biological Survey employees in 1996. 


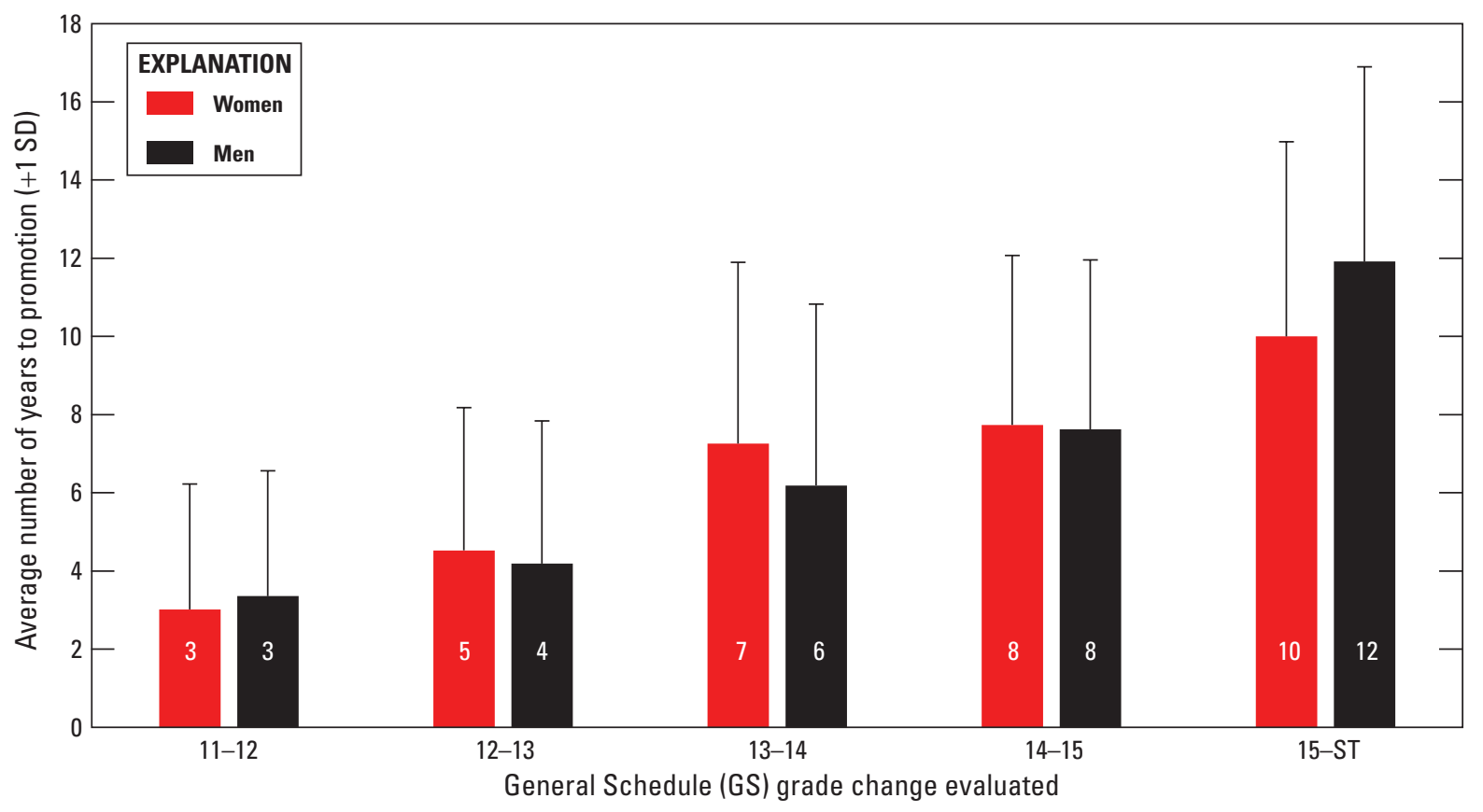

Figure 2.9. Bar graph showing the number of years to promotion from one General Schedule (GS) level to the next for female and male research, development, and senior scientists in the U.S. Geological Survey during 1990-2017. The numbers of years to promotion do not indic ate the likelihood of promotion. The data for promotion from GS-15 to senior scientist (ST) positions are included for completeness. The full performance level for a research grade position is GS-15, and very few scientists are likely to be promoted to an ST position, which is governed by different hiring rules and guidelines. The bars show extensions indicating one positive standard deviation (SD).

The peer groups are discussed below and data for them are shown in figure $2.10 A-F$. The peer groups differ from the disciplines and occupational series listed in table 2.1 and were named as follows for this analysis (listed in order of decreasing number of members): (1) Wildlife, (2) Geohazards, (3) Fisheries and Aquatic Organisms, (4) Ecology,

(5) Hydrology, (6) Framework Geology and Geophysics,

(7) Energy and Minerals, (8) Biogeochemistry, (9) Climate and Land Surface Change, (10) Coastal and Marine, (11) Geochemistry, (12) Geographic Information Science and Remote Sensing, and (13) Equipment Development.

When data from all peer groups were combined, logistic regression indicated a decreasing probability of promotion as grade level increases, but no clear systematic differences in the likelihood of promotion for women and men (fig. 2.9). Although the probability of promoting to the GS-15 level was estimated to be higher for men ( 30 percent) than women (23 percent), the sample size for women was too low to interpret this difference as evidence of systematic bias.

When the OSQI data were examined in subsets for individual panel peer groups, however, there were some instances of potential gender bias. There was some evidence of systematic gender bias in the Framework Geology and Geophysics Peer Group in favor of women and in the Geohazards Peer
Group in favor of men (fig. 2.10B, C). Evidence of potential gender bias in favor of men in Biogeochemistry was limited to GS-14 and GS-15 ranks (fig. 2.10D). No evidence of gender bias was seen in six peer groups: Fisheries and Aquatic Organisms, Climate and Land Surface Change, Hydrology, Ecology, Energy and Minerals, and Wildlife (fig. 2.10F) Peer Groups. There were insufficient data to allow meaningful analysis of the remaining four peer groups: Coastal and Marine, Equipment Development, Geochemistry, and Geographic Information Science and Remote Sensing. As mentioned above, we were unable to obtain data about the gender composition of the peer review panels evaluating each scientist. Because of this lack of data, we were unable to include panel composition in this analysis of promotion probability for men and women.

Although the probability of promotion declines steadily from GS-12 through GS-14, the trend is different for both men and women at GS-15 (fig. 2.10A). The decreasing probability of promotion as grade level increases explains the increasing number of years to higher level promotions observed in the FPPS dataset. This increase is expected: it becomes increasingly harder to advance to higher GS grade levels. Furthermore, the similarity in the likelihood of promotion for women and men at each grade level across all peer groups is consistent with the finding of similar numbers of 


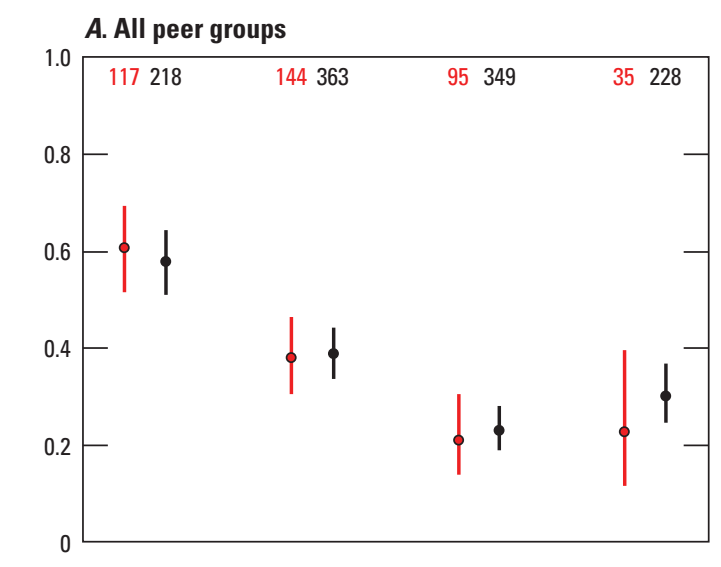

B. Framework Geology and Geophysics Peer Group
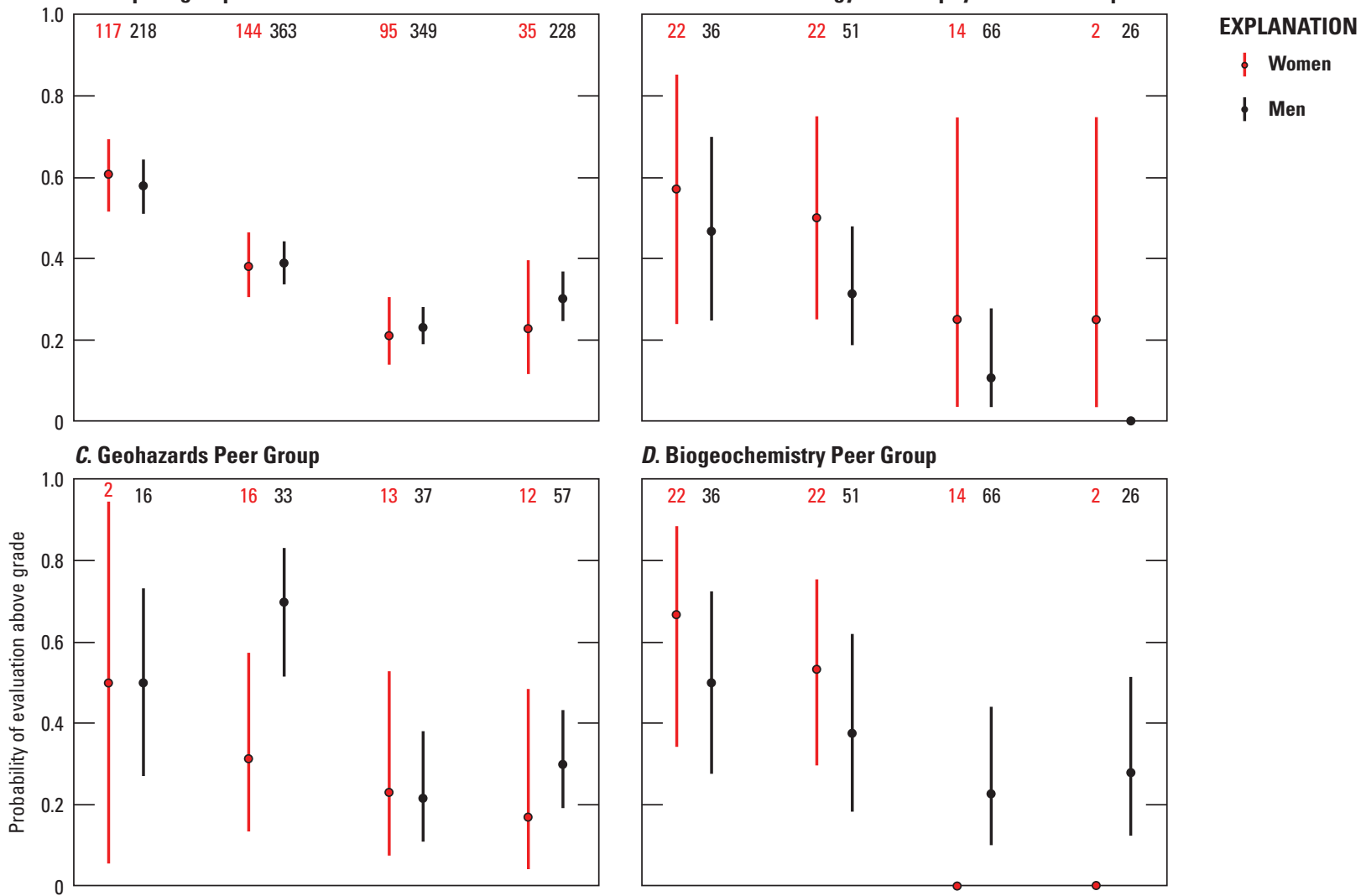

D. Biogeochemistry Peer Group
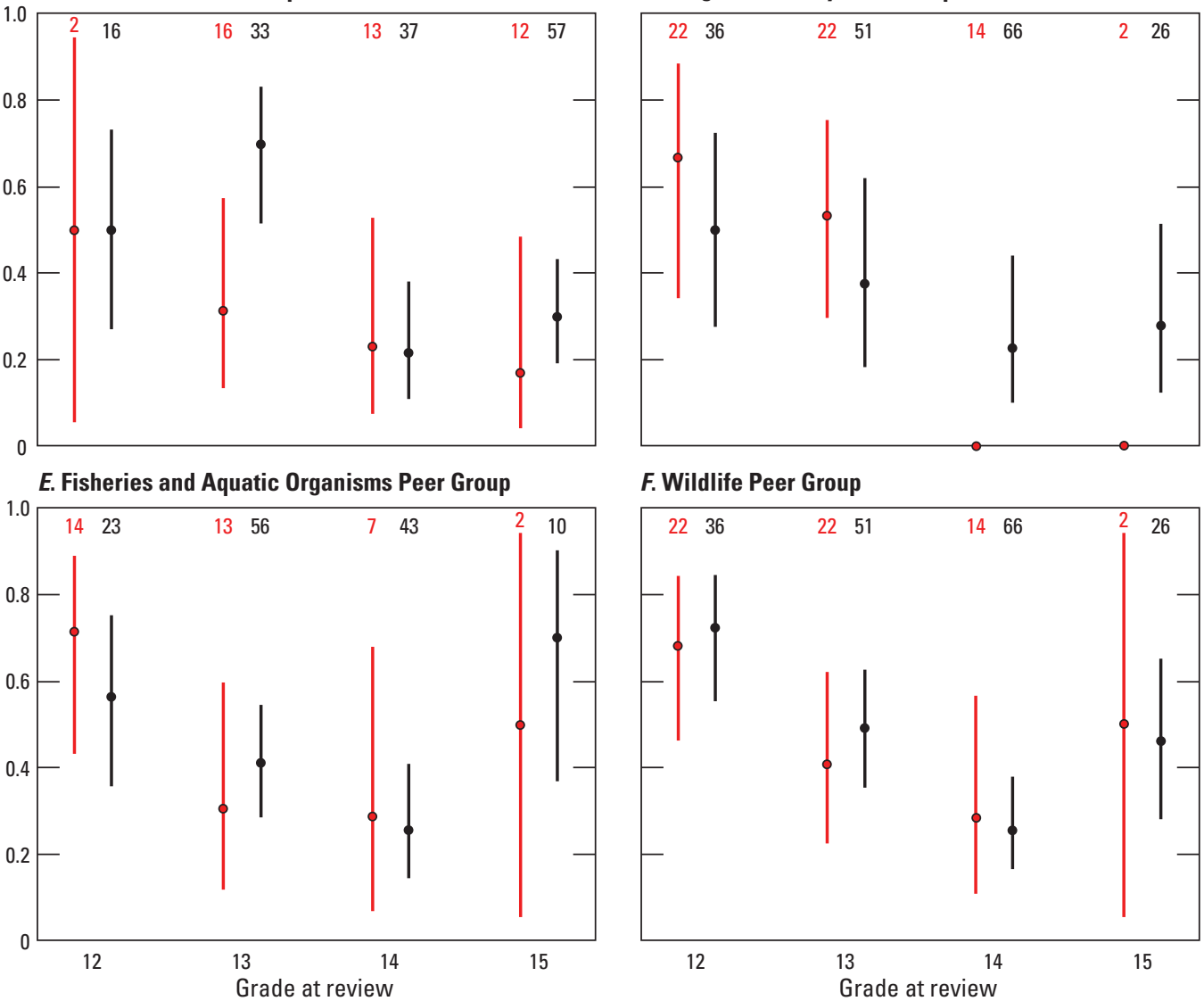

F. Wildlife Peer Group

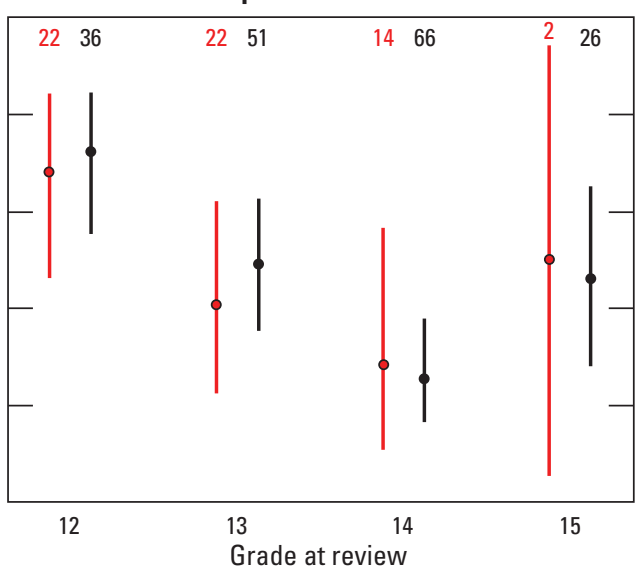

Figure 2.10. Graphs comparing the probability of evaluation above grade (odds of promotion being recommended) resulting from peer review panel evaluations during 2012-2017 for General Schedule grades GS-12 to GS-15 and among men and women in research and development scientist positions across all 13 U.S. Geological Survey peer groups and for five selected individual peer groups. $A$, All peer groups; $B$, Framework Geology and Geophysics Peer Group; $C$, Geohazards Peer Group; $D$, Biogeochemistry Peer Group; E, Fisheries and Aquatic Organisms Peer Group; F, Wildlife Peer Group. Numbers at top of graphs are numbers of scientists in each grade (GS-12 to GS-15); black lines and numbers represent data for men, red lines and numbers represent data for women. Data points at 0 probability in parts $B$ and $D$ indicate that scientists were found to be performing within grade and were not promoted. Data for senior scientists were included in calculations by applying an artificial grade level of GS-16. 
years needed by women and men to advance from one GS level to the next in the FPPS dataset. In general, this indicates that differences in promotion rates may contribute much less to the persistent grade gap between men and women than age, time between evaluations, and grade level at entry. However, gender bias in promotion may contribute to the grade gap in some peer groups and at higher grade levels. Peer review panels and OSQI staff need to remain vigilant against any kind of systematic bias in panel outcomes, including gender bias.

Funding sources: One concern many research and development scientists have is a perceived difference in grade and promotion between scientists working in cost centers that are largely funded by appropriated dollars versus those that are largely supported by reimbursable funding. Reimbursable funding sources provided more than half of total center funding in 27 percent of 149 cost centers in the FBMS dataset (during 2012-2017); 75 percent of these centers were water science centers (fig. 2.11).

Data on funding sources are available for 1,879 (42 percent) of the 4,520 research, development, and senior scientists active between 1990 and 2017. Only 298 of these scientists were identified as working in highly reimbursable cost centers, and they represented 16 percent of the 1,879 scientists for whom funding source data were available. If that percentage is typical of the group for which there are no data on funding sources, then it is likely that most research, development, and senior scientists worked in centers funded mostly by congressional appropriations (fig. 2.12).

Although it takes research, development, and senior scientists in highly reimbursable centers on average longer to be promoted from one GS grade level to the next (fig. 2.13), these differences are generally small (on average less than 1 year), indicating that funding source does not play a large role in their promotion success. This conclusion is also reflected in the nearly identical average grade levels for research, development, and senior scientists in the two types of centers (about GS-13 in both).

\section{The Current RGE Workforce: Patterns and Challenges}

Though less numerous than in the past, the current research, development, and senior scientists still make up a vital component of the scientific USGS workforce. Not only are these scientists responsible for upholding the scientific credibility and impact of the USGS, but they also serve many other functions. For example, in 2017, 32 percent of these scientists supervised other USGS employees while many others served as mentors to the next generation of USGS scientists. Many research, development, and senior scientists also manage projects and programs, procure reimbursable funding, and assist numerous stakeholders with difficult scientific questions. Numerous pending retirements and a continued lack of diversity are current challenges facing this component of the USGS workforce.

Retirement eligibility: In 2017, 32 percent of research, development, and senior scientists were eligible for retirement. By 2027, 56 percent of these scientists who were active in 2017 will be eligible for retirement, most in higher grade levels (fig. 2.14). Between September 2017 and May 2019, the number of senior scientists declined by 28 percent (from 47 to 34) mostly by retirements. As of the end of FY 2019, 35 senior scientists were eligible to retire ( 87.5 percent).

Although the proportion of research, development, and senior scientists eligible for retirement increases at approximately the same steady rate in eight disciplines, it starts at a higher percentage (44 percent in 2017, compared to 32 percent for all other disciplines combined) and increases more rapidly in Hydrology than in any of the other disciplines (fig. 2.15). Three-quarters of the Hydrology research, development, and

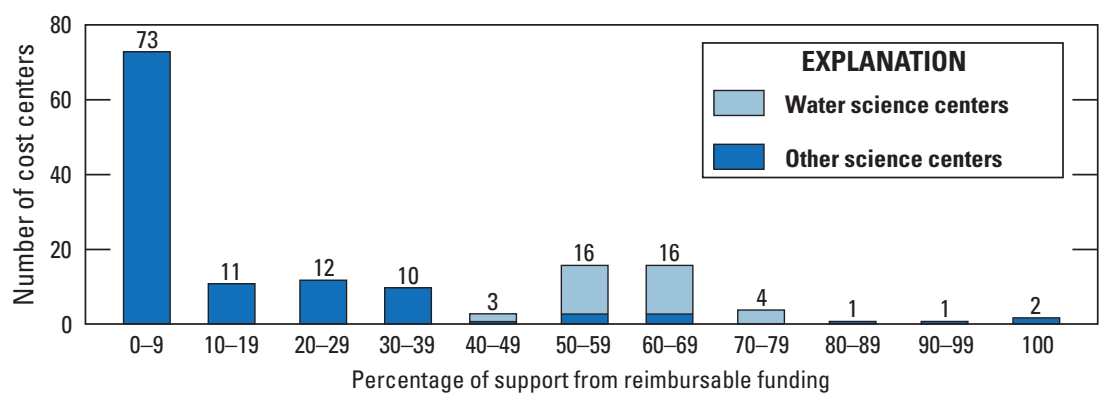

Figure 2.11. Bar graph showing the percentages of support from reimbursable funding for 149 U.S. Geological Survey cost centers during 2012-2017. Data are from the USGS Financial and Business Management System (FBMS) dataset. Numbers above bars are numbers of cost centers. Note that water science centers make up 75 percent of the mostly reimbursable cost centers. The remaining 25 percent of highly reimbursable cost centers include Astrogeology, International Programs (Water), Upper Midwest Environmental Science Center, Western Fisheries Regional Center, Geophysics (Water), and Western Ecological Regional Center. 
senior scientists active in 2017 will be eligible for retirement in just one decade (by 2028), whereas it would take at least 5 additional years to reach this level of retirement eligibility in any of the other disciplines.

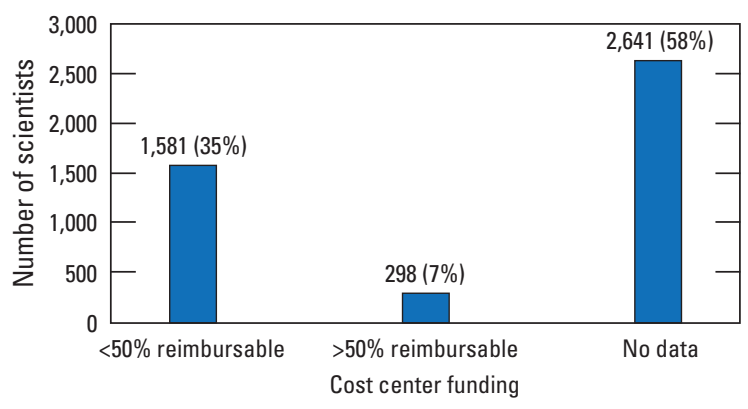

Figure 2.12. Bar graph showing the numbers of research, development, and senior scientists working in U.S. Geological Survey cost centers with less than or more than 50-percent reimbursable funding during 1990-2017. No cost center funding data were available for 2,641 scientists, who made up 58 percent of the 4,520 scientists in these positions who were active between 1990 and 2017. The 298 scientists working in highly reimbursable cost centers represented 16 percent of the 1,879 scientists for whom funding source data were available. Data are from the Federal Personnel and Payroll System (FPPS) dataset and the Financial and Business Management System (FBMS) dataset.
Without substantial recruitment efforts, the declining trend in numbers of research, development, and senior scientists since 1996 is likely to continue for a third consecutive decade, and the loss of high-level scientific expertise in Hydrology might be especially severe. Recruitment and mentoring over the next 10 years along with the changes in the RGE process recommended by the RGE Review Team will play an important role in sustaining vibrant and productive populations of research, development, and senior scientists in the face of these looming retirements.

Diversity: Today's USGS workforce of research, development, and senior scientists has a more balanced number of men and women than it had a few decades ago, but overall diversity continues to remain low and inequalities persist. Most significantly, scientists of color in 2017 still made up only 7 percent of this component of the workforce. Furthermore, despite the narrowing gender gap and despite women and men having similar promotion rates and similar likelihoods of being promoted, substantial gender differences persist. In 2017, women still made up less than a third (29 percent; see fig. 2.6) of the research, development, and senior scientists. Furthermore, the imbalance between numbers of men and women continues to be substantially more pronounced at higher GS grade levels, with an approximately 9-percent decline in percentage of women from one GS grade level to the next higher GS grade level (fig. 2.16). At the end of fiscal year 2017, only 3 of 47 senior scientists were women (6 percent). Due to retirements and no new recruitments, these numbers decreased to 2 female and 32 male senior scientists by June 2019 .

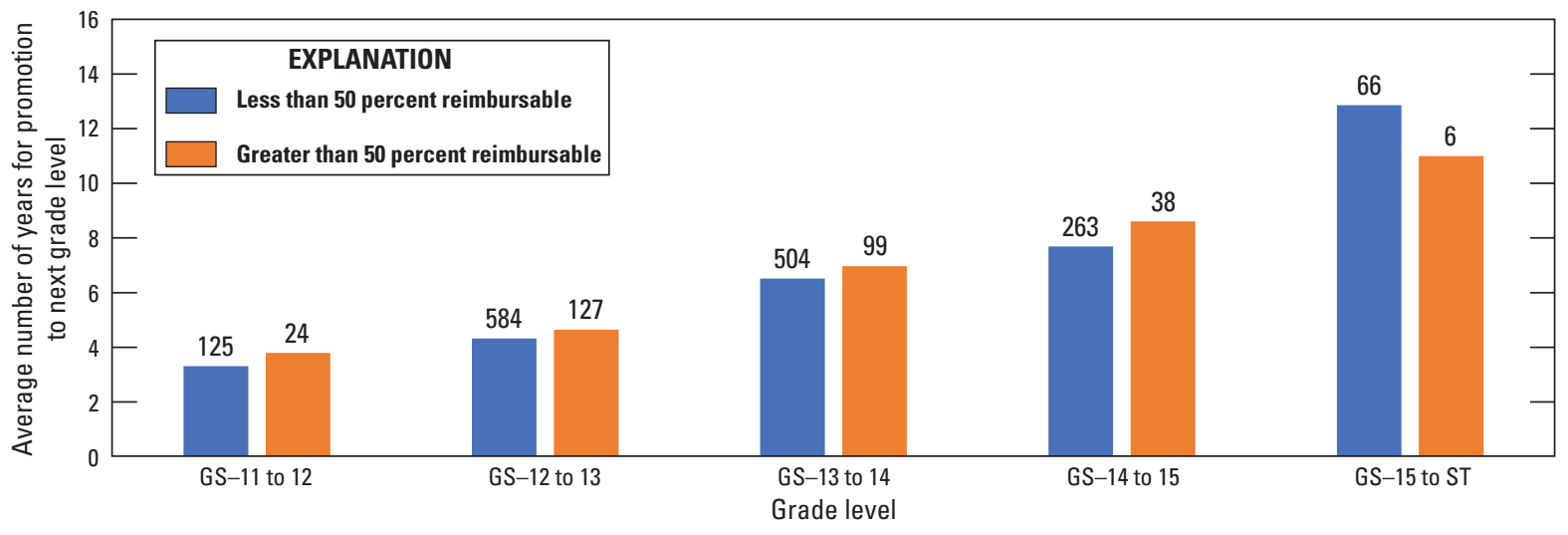

Figure 2.13. Bar graph showing the average number of years to promotion from one General Schedule (GS) level to the next for research, development, and senior scientists in U.S. Geological Survey (USGS) cost centers with less than or more than 50-percent reimbursable funding during 2000-2017. The data for promotion from GS-15 to senior scientist (ST) positions are included for completeness. Numbers above bars indicate the number of scientists for which data were graphed. Funding data are from the Financial and Business Management System (FBMS) dataset, and promotion data are from the Federal Personnel and Payroll System (FPPS) dataset. 


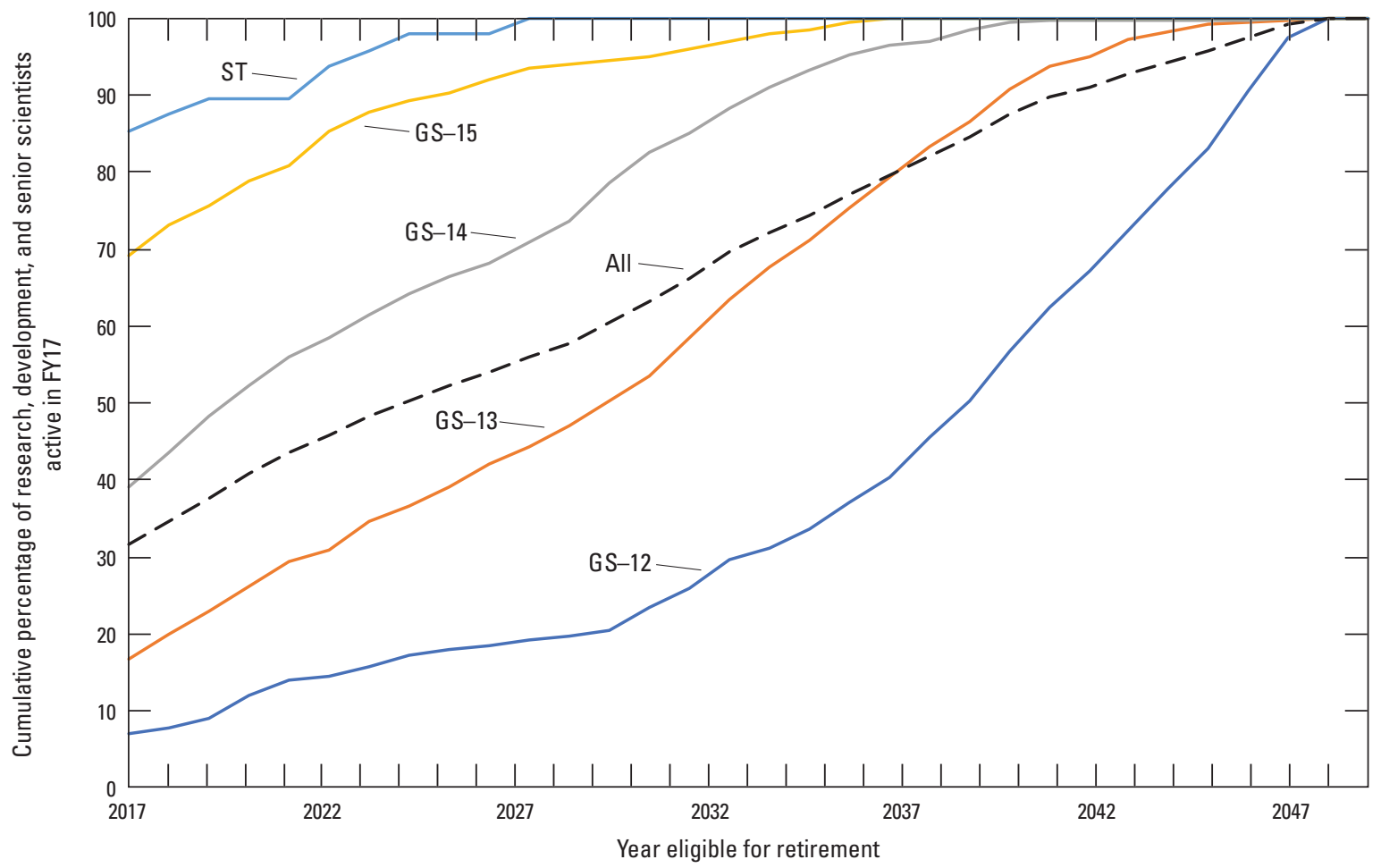

Figure 2.14. Line graph showing the cumulative percentage of research, development, and senior scientists active in the U.S. Geological Survey in fiscal year 2017 (FY17) becoming eligible for retirement over the next three decades, by General Schedule (GS) and senior scientist (ST) grade level. Data are from the Federal Personnel and Payroll System (FPPS) dataset for 1990-2017,

In consequence, a greater percentage of women research, development, and senior scientists active in 2017 had a grade level of GS-12 (29 percent of all women) than of GS-14 (22 percent), whereas for men, it was the reverse; 16 percent of all men were GS-12, and 29 percent were GS-14. Over half (53 percent) of men had GS grade levels of 14 or higher, while only a third (33 percent) of women had GS grade levels of 14 or higher (fig. 2.17). At the highest GS grade levels, the proportional difference was even more pronounced: the proportion of men with GS-15 and senior scientist positions (24 percent of all men) was more than twice that of women (11 percent of all women).

If the long-term trends described above persist, the gradelevel differences between men and women may slowly disappear over the next few decades, but it will likely take longer at higher grade levels, especially for senior scientist positions. Targeted efforts to recruit more women and especially more racial and ethnic minorities into research, development, and senior scientist positions and to mentor them may help shorten the time it will take to achieve a greater diversity in this component of the USGS workforce that is more reflective of the U.S. population as well as a better grade balance among women and men.

\section{Data Limitations}

The greatest limitation for the RGE Review Team's quantitative assessment of the status and trends of the part of the USGS workforce subject to RGE rules was that data had to be collected from several sources (which are described above in this appendix 2). The datasets from these sources were not easily integrated and did not contain the data needed to answer all questions posed by the team. For example, the Federal Personnel and Payroll System (FPPS) dataset for 1990-2017 did not contain information about the number of times and the dates on which scientists were reviewed by a peer review panel and thus could not be used to assess patterns and trends in panel outcomes.

The dataset for 2012-2017 from the USGS Office of Science Quality and Integrity (OSQI) contained outcome information on individual scientists but did not contain information on the evaluating panel that would allow us to look for relationships between panel composition and the likelihood of a candidate being promoted. As this panel information did not include years before 2012, the OSQI dataset could not be used to assess long-term trends in panel outcomes and changes in outcomes due to the implementation of the bureauwide RGE 


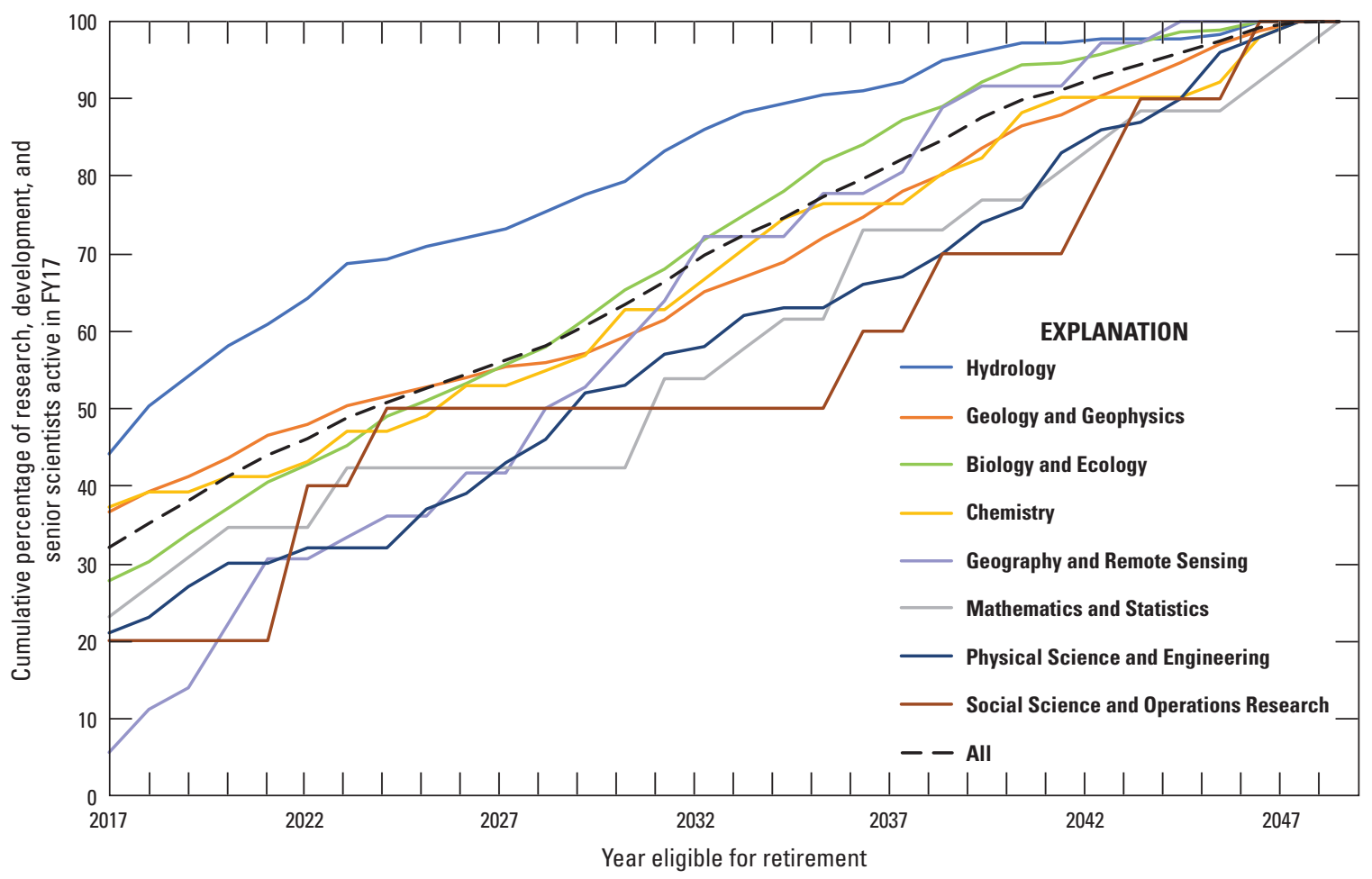

Figure 2.15. Line graph showing the cumulative percentage of research, development, and senior scientists active in the U.S. Geological Survey in fiscal year 2017 (FY17) becoming eligible for retirement over the next three decades, by discipline. Data are from the Federal Personnel and Payroll System (FPPS) dataset for 1990-2017,

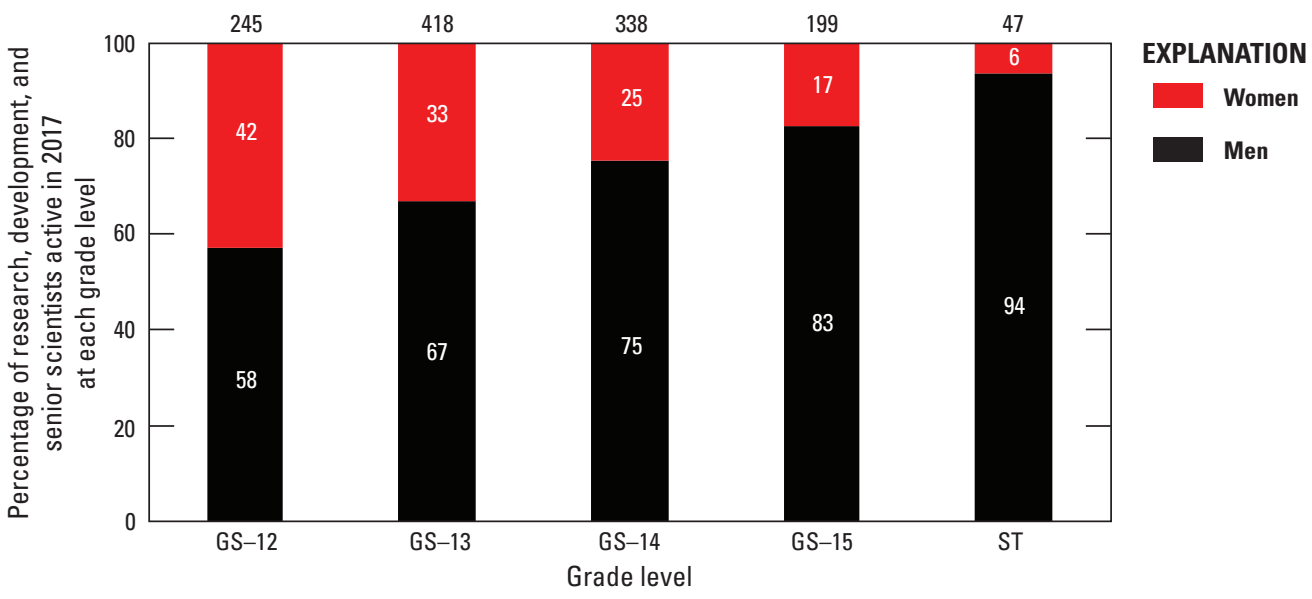

Figure 2.16. Graph showing the percentages of male and female U.S. Geological Survey scientists in research, development, and senior scientist positions who were active in 2017 in each General Schedule (GS) grade level and in senior scientist (ST) positions. Numbers above bars indicate the total number of scientists in each grade level. Data are from the Federal Personnel and Payroll System (FPPS) dataset for 1990-2017, 


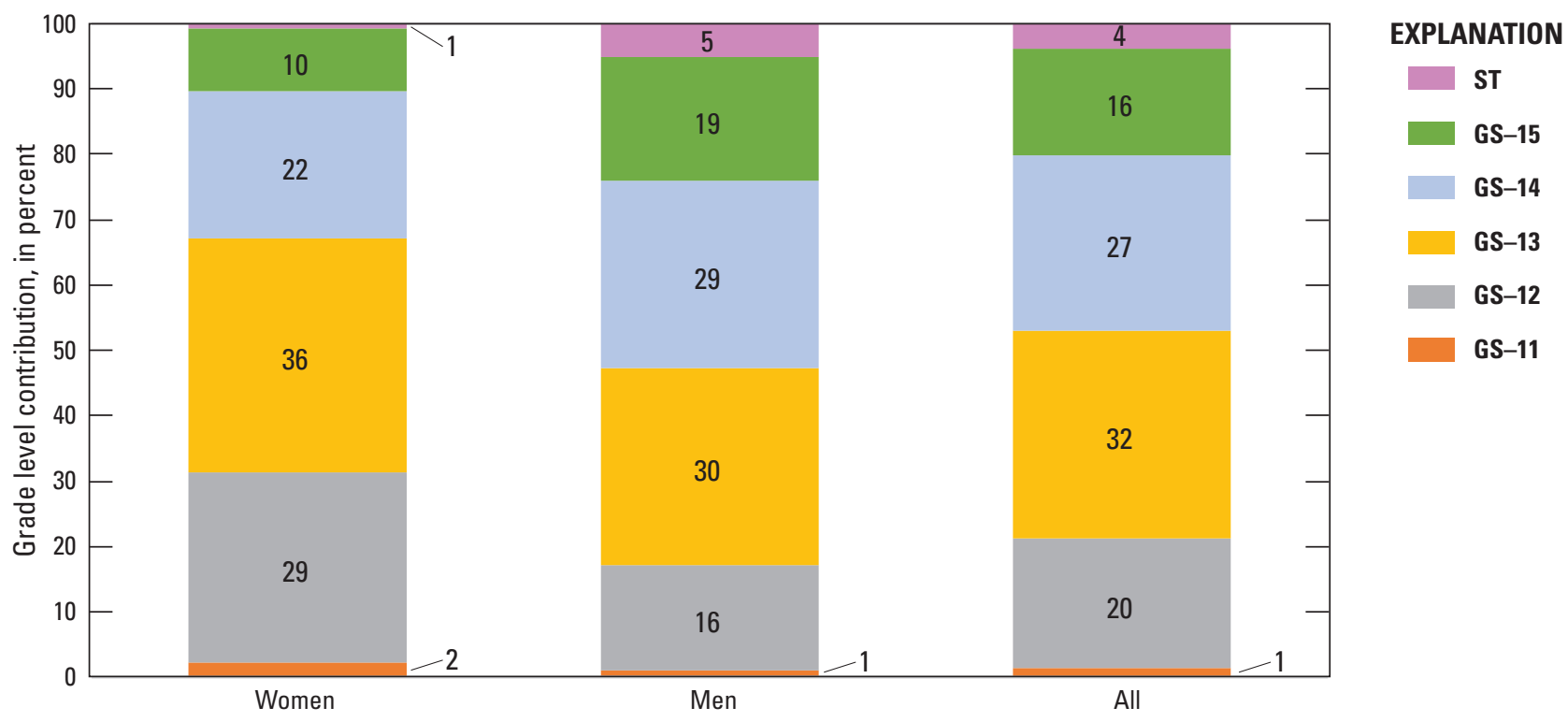

Figure 2.17. Bar graph showing General Schedule (GS) and senior scientist (ST) grade-level distributions for female, male, and all U.S. Geological Survey scientists in research, development, and senior scientist positions who were active at the end of fiscal year 2017. Data are from the Federal Personnel and Payroll System (FPPS) dataset for 1990-2017.

process in 2012. Also, the number of scientists was too small to conduct meaningful analyses of gender bias in 4 of the 13 RGE peer groups.

Finally, it was difficult to combine the OSQI and FPPS datasets because the OSQI dataset did not include the common identification (ID) numbers (common employee ID) assigned to employees in the FPPS dataset and many scientist names were given slightly differently in the datasets (for example, Theodore in the FPPS dataset and the dataset from the USGS Office of Diversity and Equal Opportunity (DEO), but Ted in the OSQI dataset). In addition, 48 percent of employees in the FPPS database had no common ID numbers, and some employees changed their names. These name changes had to be identified manually in order to avoid double counting. Because of the inconsistent availability of common employee IDs, the use of names was necessary to combine datasets, but this limited access to these datasets to just two members of the RGE Review Team because of concerns about personally identifiable information.

Other limitations were the lack of a long-term organizational workforce database and the lack of RGE peer group continuity in the USGS. The USGS organizational units, from divisions to disciplines to mission areas to science centers, have changed numerous times in recent decades. A significant change was the integration of the National Biological Survey into the USGS starting in 1996. Similarly, the FPPS database changed from the previous Pay/Pers system to the current FPPS system in the 1990's, and tools available for analysis changed as well; for example, from Oracle's Hyperion Financial Management to the current Oracle Business Intelligence Enterprise Edition (OBIEE). These changes prevented us from compiling the consistent long-term dataset needed for this assessment. Finally, peer groups have also changed over time, and scientists sometimes change their peer group affiliation. Moreover, no peer group affiliation or peer review panel information was available from the former disciplines before the change to the bureauwide RGE process. Scientists subject to the RGE process self-select into peer groups (such as Biogeochemistry or Framework Geology), and, in many cases, scientists having the same position titles choose different peer groups; therefore, the position titles included in the FPPS database could not be used to determine the correct peer groups. Because of this inconsistency, the RGE Review Team was able to assess peer group patterns and trends only for actions taken after the change to the bureauwide RGE process.

Grouping OPM occupational series (such as Botany, Geology, Chemical Engineering) into eight informal scientific disciplines designated for this study (table 2.1) allowed the RGE Review Team to assess differences in long-term trends and retirement projections among disciplines, but these disciplines do not correspond closely to USGS organizational units and are thus of limited utility for workforce management and planning. Nevertheless, these informal disciplines may be the best way to track disciplinary changes because, unlike peer group affiliation and organization, they can provide long-term continuity. 


\section{Appendix 3. Graphic Summary of Results of Surveys of Three Groups of Stakeholders About the Research Grade Evaluation Process in the U.S. Geological Survey}

In accordance with the charge to the Research Grade Evaluation (RGE) Review Team of the U.S. Geological Survey (USGS), surveys of four groups of stakeholders were conducted to understand how USGS personnel view the RGE system overall. An initial survey of members of the Executive Leadership Team of the USGS was conducted by individual interviews, which took place in person when possible.

Some of the responses to the interviews (not provided here) informed questions for the other three surveys, which were developed and administered by USGS social scientist Steve Gillespie. The RGE Review Team proposed questions, and Steve worked them into formats informed by his expertise. The three surveys were conducted in March-April 2018. The three groups surveyed were (1) research, development, and senior scientists; (2) members of RGE peer review panels, and (3) supervisors of scientists subject to the RGE process. Several questions were common on all three surveys, and additional questions were specific to each stakeholder group. This appendix contains graphic summaries of the results of these three surveys. The conclusions from the surveys are discussed in the text section, "Surveys of Stakeholders."

\section{The Groups}

\section{RGE Scientists}

Random sample of 150 RGE scientists

Response rate $=87 \%$

Non-response bias is small

Note: 78 volunteer responses were also received, but are not included in the results shown

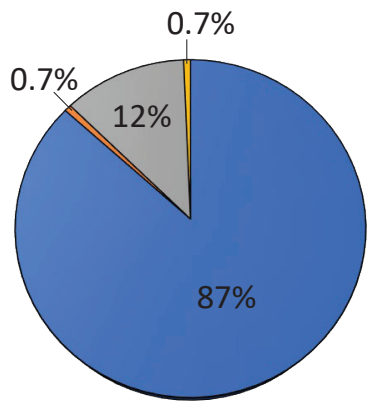

\section{Panelists}

Random sample of 75 RGE scientists who had served on panels

Response rate $=93 \%$

Non-response bias is small

Note: 41 volunteer responses were also received, but are not included in the results shown

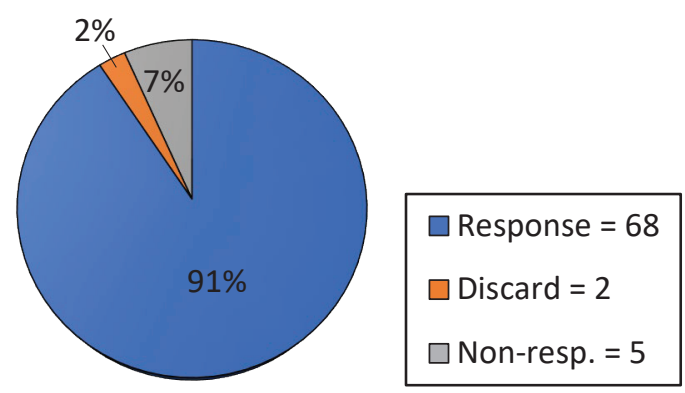

\section{Supervisors}

Random sample of 75 supervisors of RGE scientists

Response rate $=81 \%$

Non-response bias is probably downward and small

Note: 25 volunteer responses were also received, but are not included in the results shown

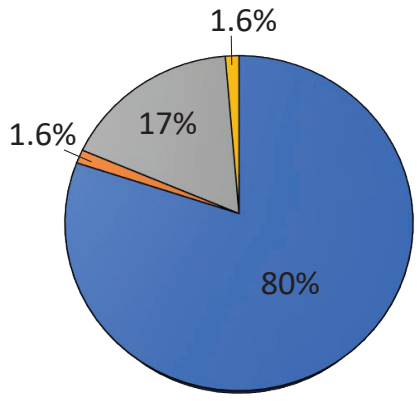

$\square$ Response $=60$

$\square$ Discard $=1$

$\square$ Non-resp. $=13$

$\square$ Refusal = 1 


\section{Questions and Responses From All Three Stakeholder Groups}

1. What goals does the USGS RGE process serve?

- For USGS: Properly grade research scientists

- For individual scientists: Provide feedback and support in developing and reaching personal and professional goals

- For the scientific workforce: Assure fairness, consistency, and transparency across the bureau

- For bureau management: Monitor and assess the scientific productivity overall

- For bureau management: Identify areas of excellence and skills gaps, align workforce planning with USGS and DOI [U.S. Department of the Interior] research goals and needs

- For bureau reputation: Enhance the reputation of USGS as an unbiased provider of scientific information and as a bestplace for scientists to work

Respondents were asked to rank on a 5-point scale from critical to not important:

1A: How important is it that the RGE process meets each goal?

1B: How well do you think each goal is currently being met?

\section{Importance of Goals of RGE Process (Scientists)}

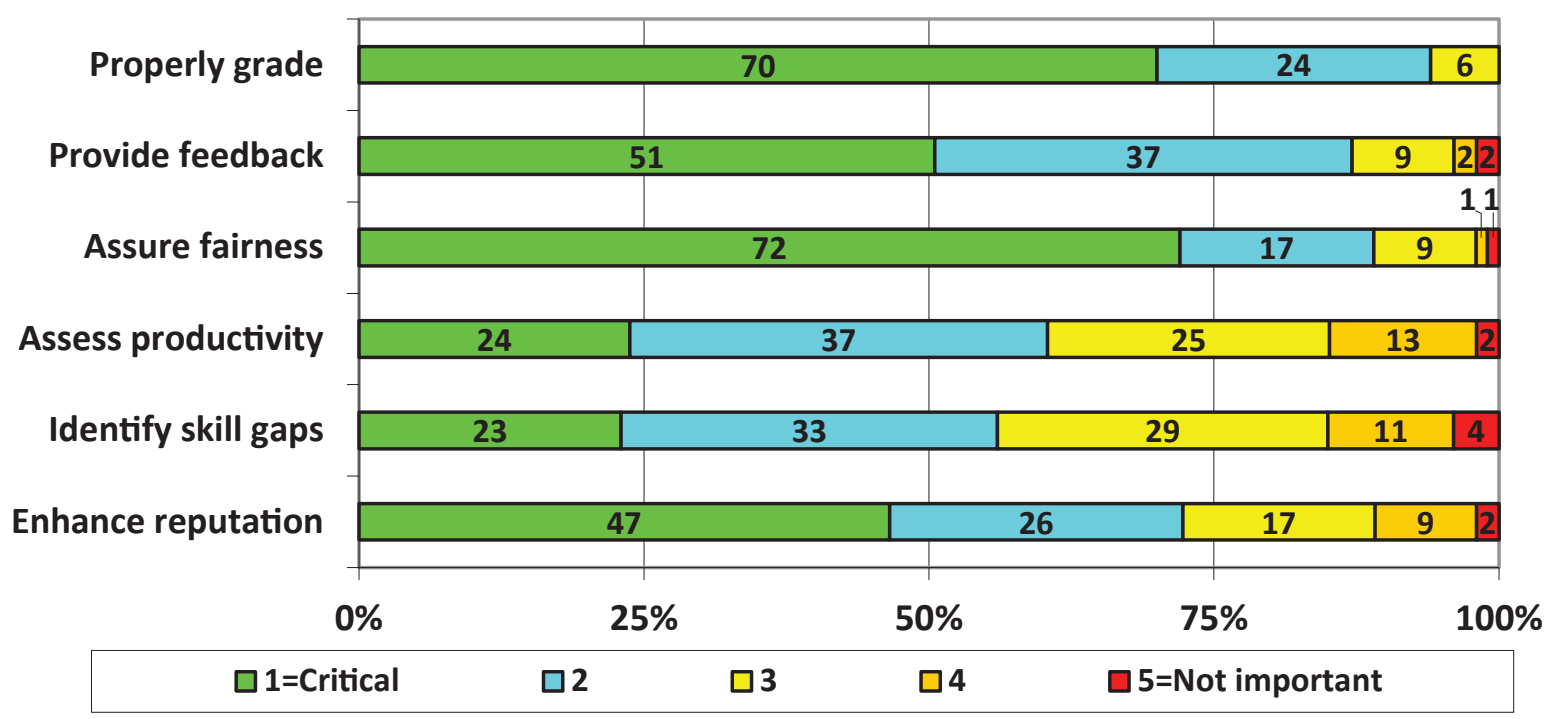

How Well Goals Being Met (Scientists)

[No graph provided] 
Importance of Goals of RGE Process (Panelists)
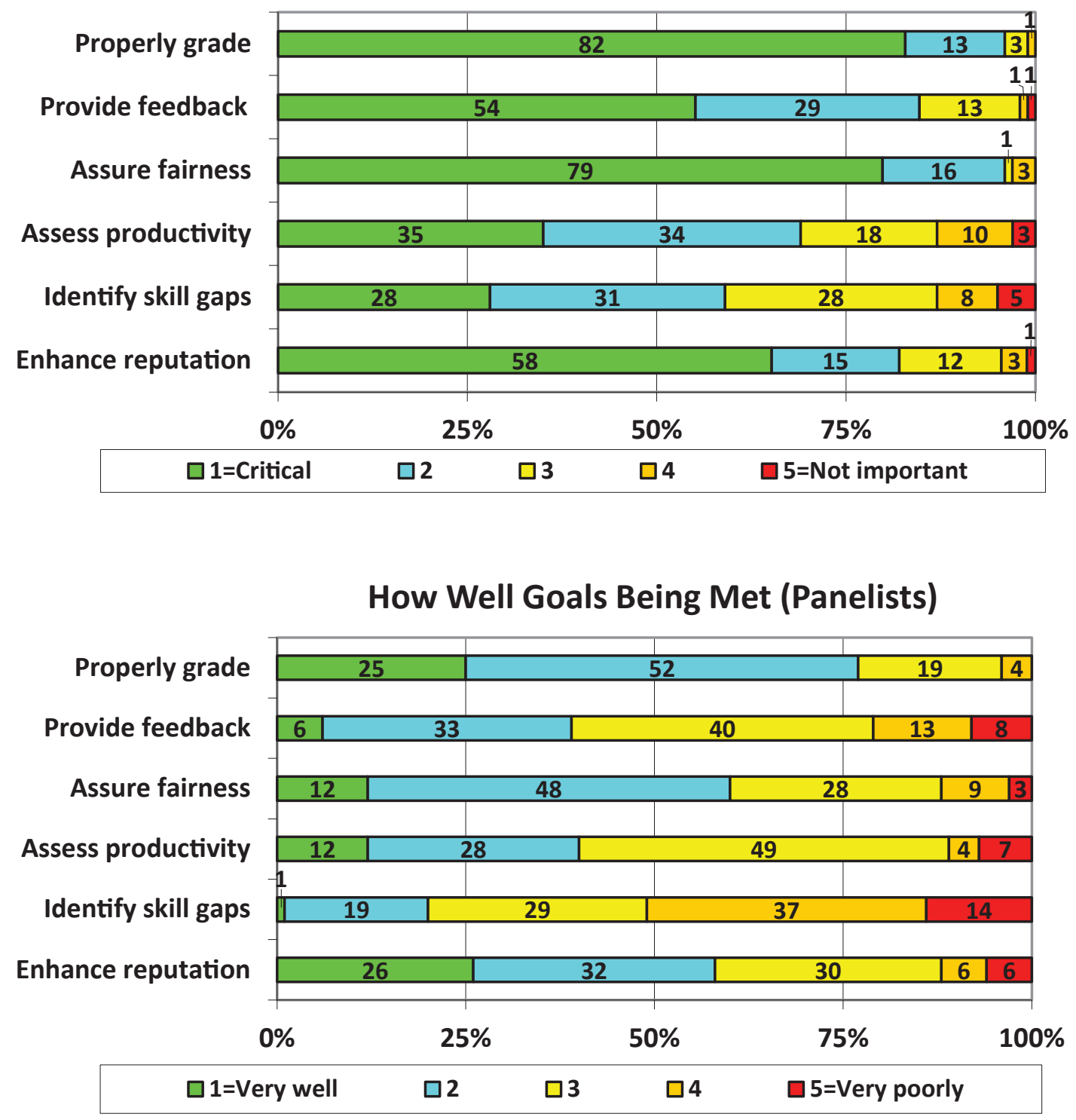

Importance of Goals of RGE Process (Supervisors)

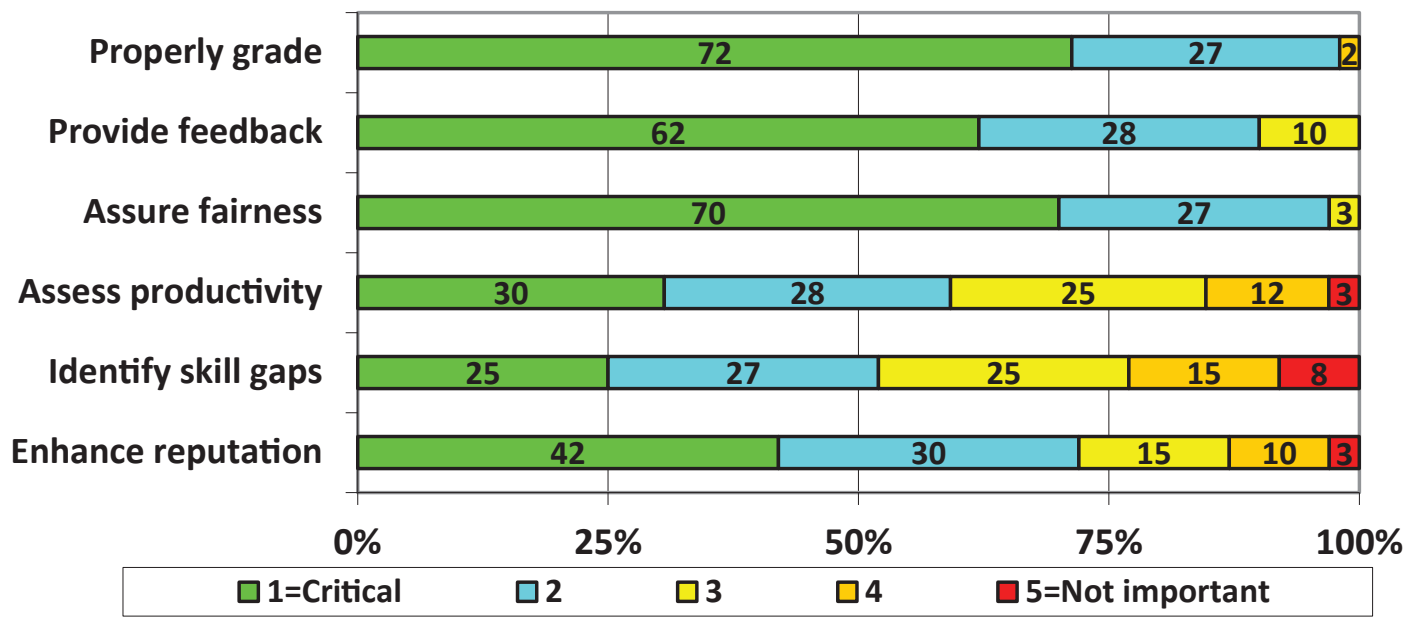




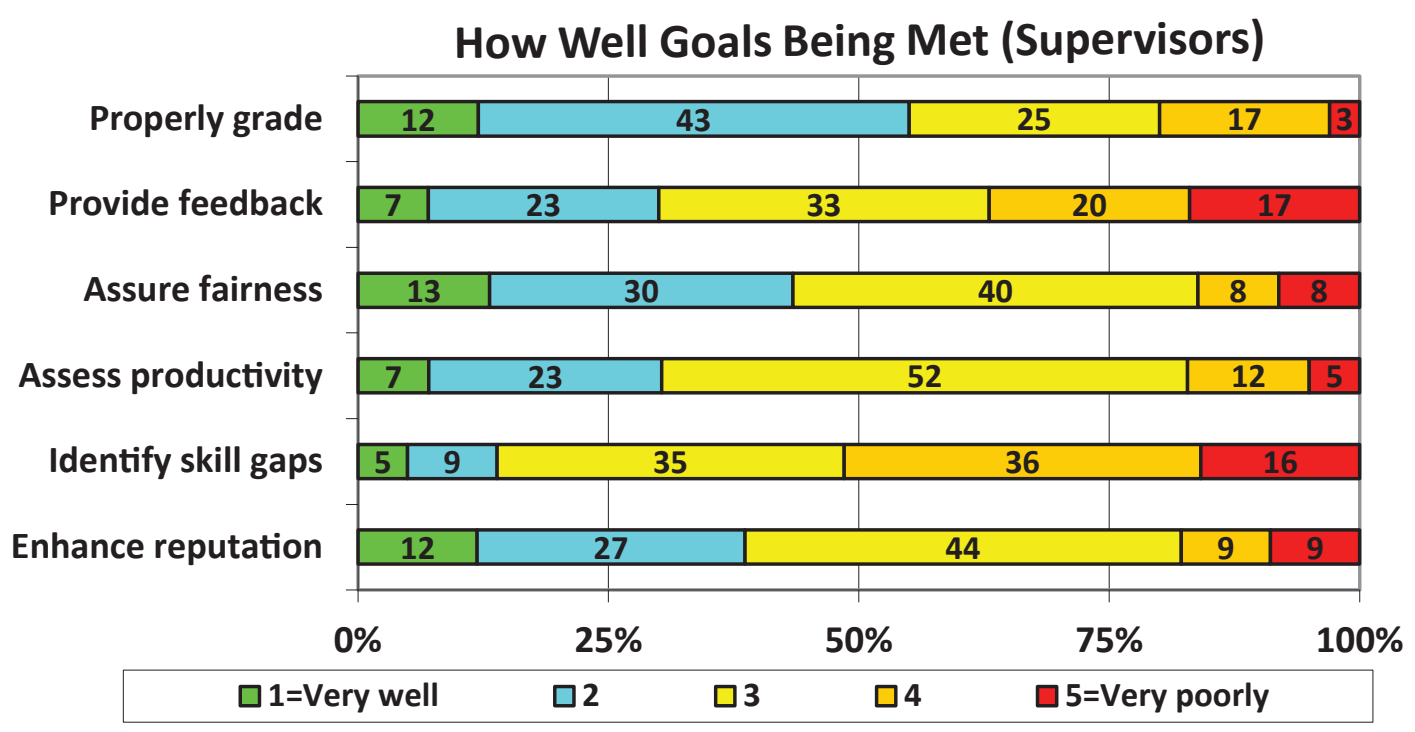

2. To what extent do you agree or disagree with each of the following statements about the existing USGS RGE review process?

- Standards for review are transparent (reported for panelists only)

- Standards for review are fair (reported for panelists only)

- Standards for review and assessment are applicable to all research and development scientists, regardless of area of expertise

- Panelists are knowledgeable experts in their field

- The feedback from the RGE panel is valuable

- Panel decisions are generally consistent from year to year

- The mandatory 4-year cycle ensures that scientists continue to perform at or above the grade level to which they are assigned

- The review process strikes a fair balance between the quantity of a scientist's publications and presentations and the quality of their work

- The review process provides a fair assessment of the quality and impact of the work done by a scientist

- RGE standards limit the kind of science RGE scientists can do

- RGE standards discourage scientists from taking other roles such as leadership or outreach

- RGE standards place a higher premium on peer-reviewed publication vs other types of science communication

- The RGE standards value publications in outside journal over USGS publications

- The RGE review process as a whole works well

- The benefits of the USGS RGE review process as a whole justify the costs in time, effort, and dollars

Respondents were asked to agree or disagree on a 5-point scale with 3 meaning neutral and 5 meaning strongly disagree. 


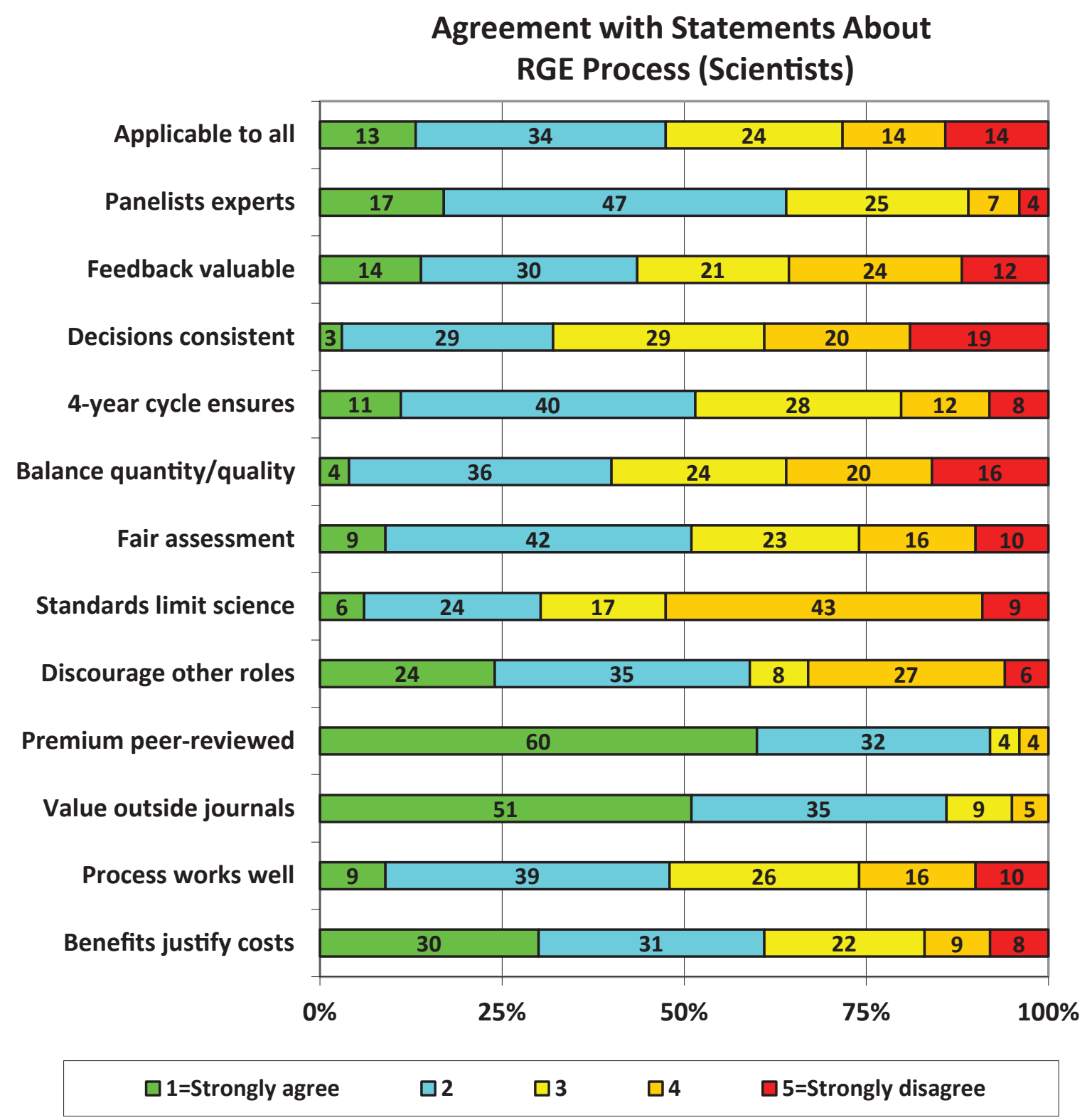




\section{Agreement with Statements About \\ RGE Process (Panelists)}

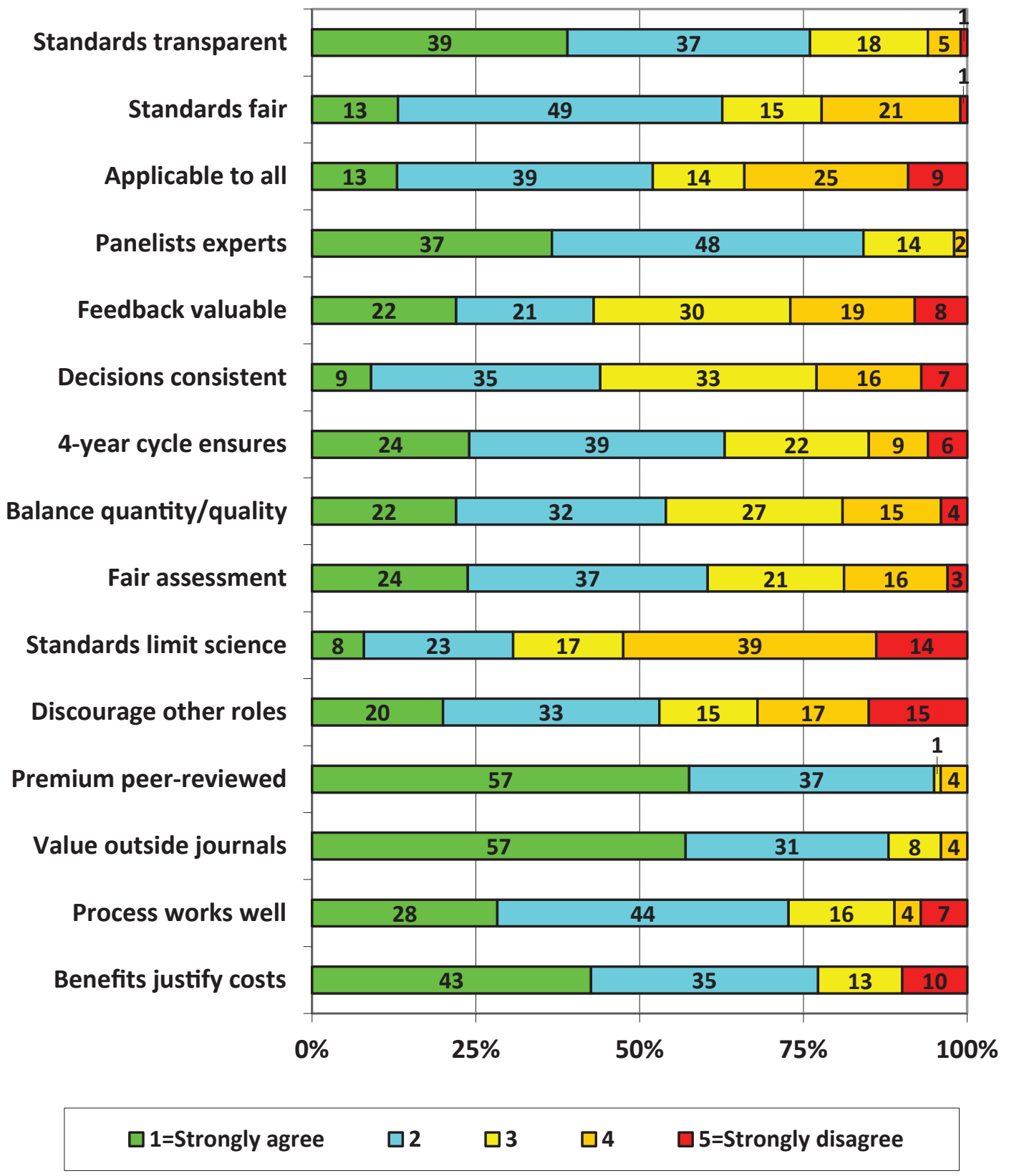




\section{Agreement with Statements About \\ RGE Process (Supervisors)}

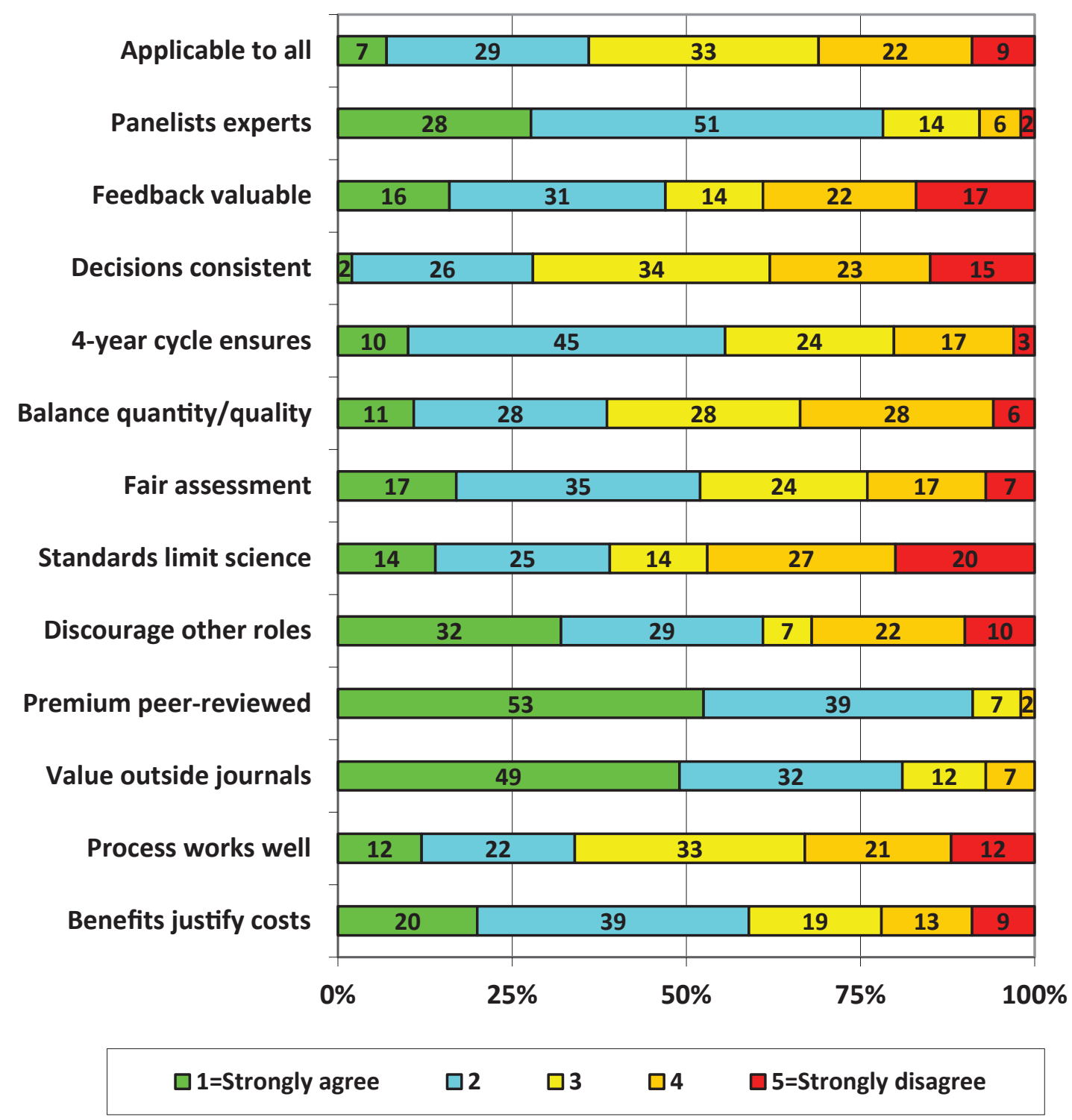


3. How satisfied are you with the various components of the current RGE process?

- 4-year review cycle

- OSQI [Office of Science Quality and Integrity of the USGS] provided training in preparation of RDSR [Research and Development Scientist Record] Packets

- Scientific peer groups as an organizational basis for RGE

- Panel selection and training

- Two-panel system

- Criteria for review (existing four factors)

- Feedback from panel

- Input from supervisor or center director

- Communication with RGE staff

- Appeal process

- The timeliness of the process

Respondents were asked to rank on a 5-point scale:

3A: How important is each component for the proper functioning of the RGE process?

3B: How well do you think each component is currently working?

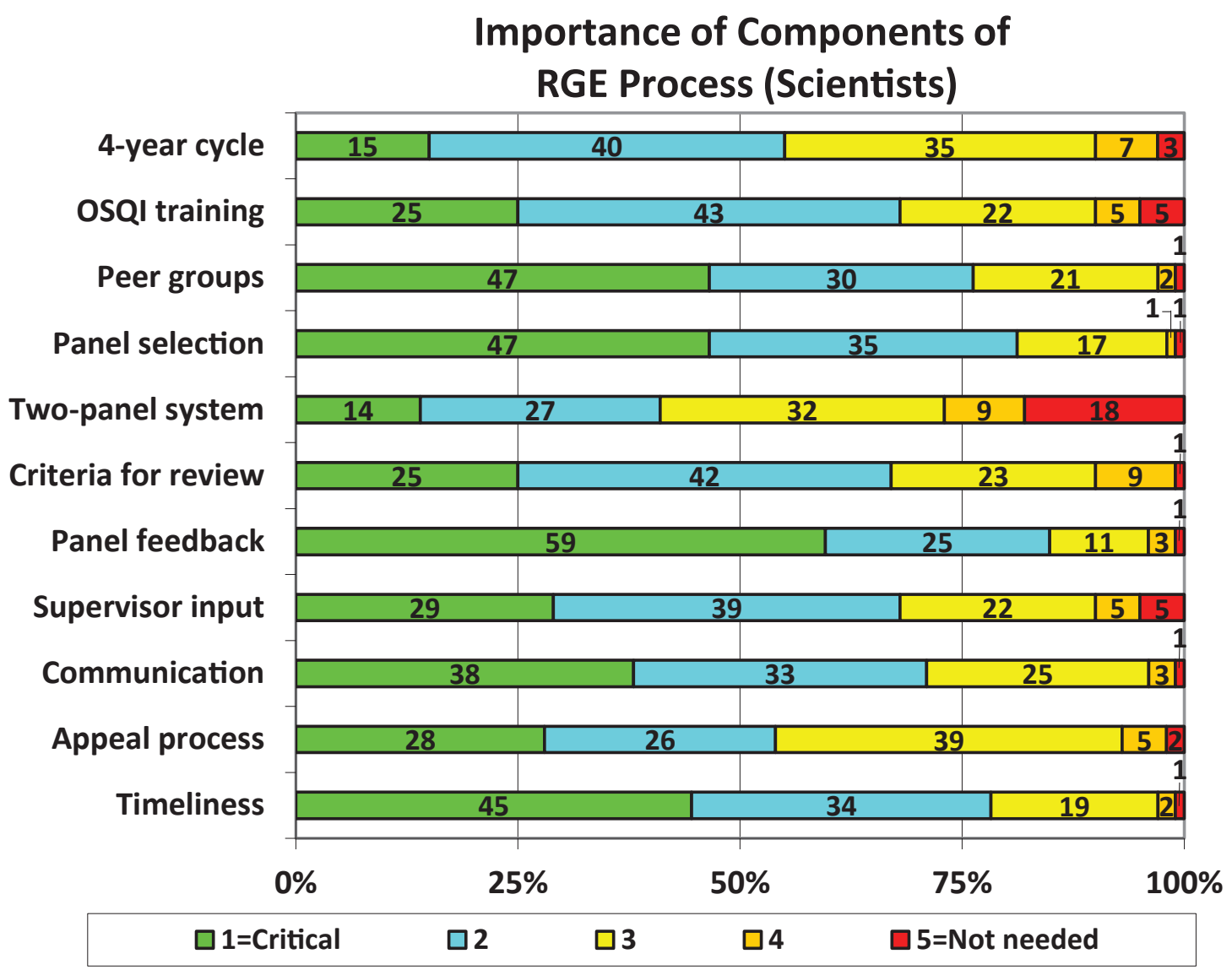




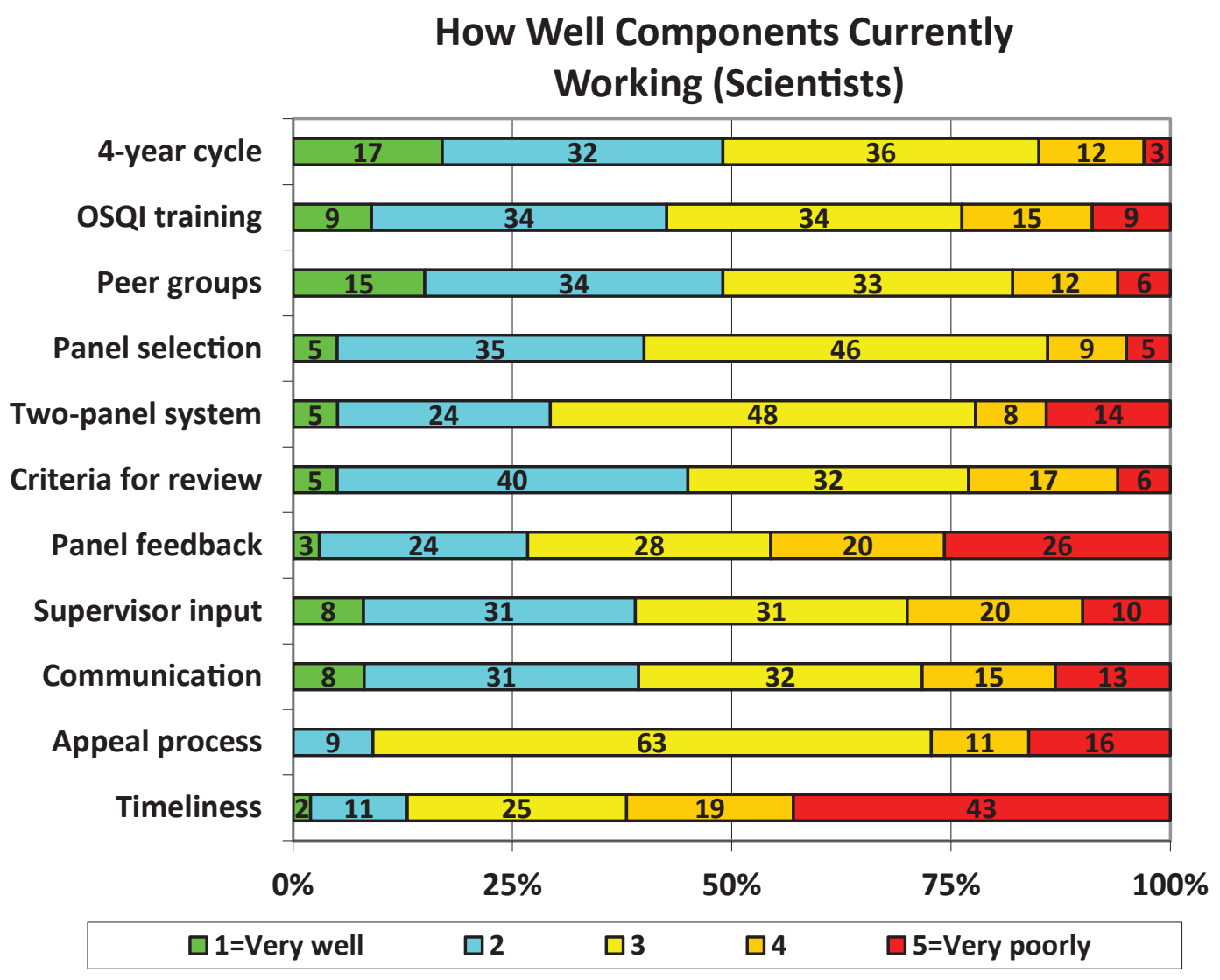

Importance of Components of RGE
Process (Panelists)

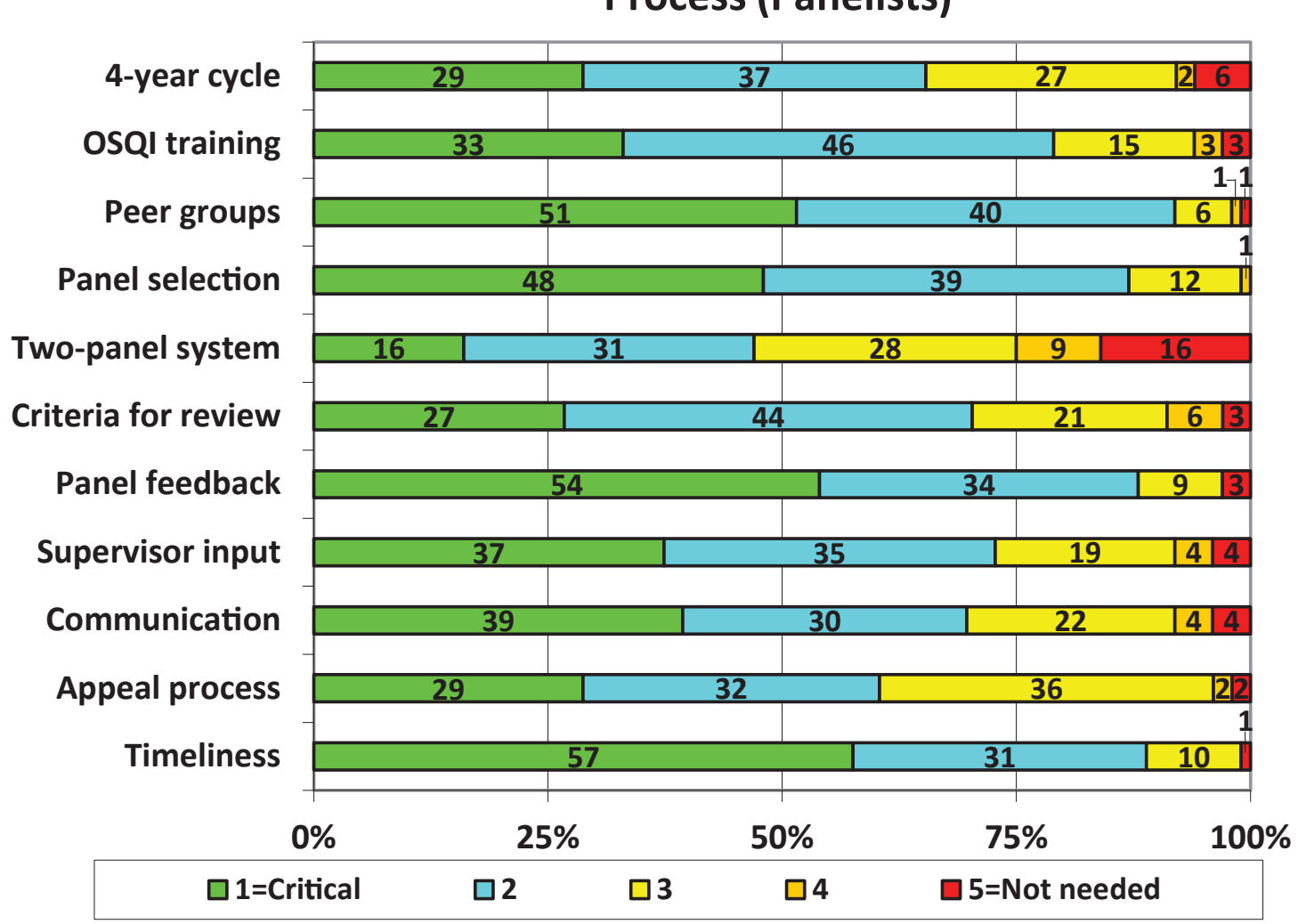




\section{How Well Components Currently \\ Working (Panelists)}

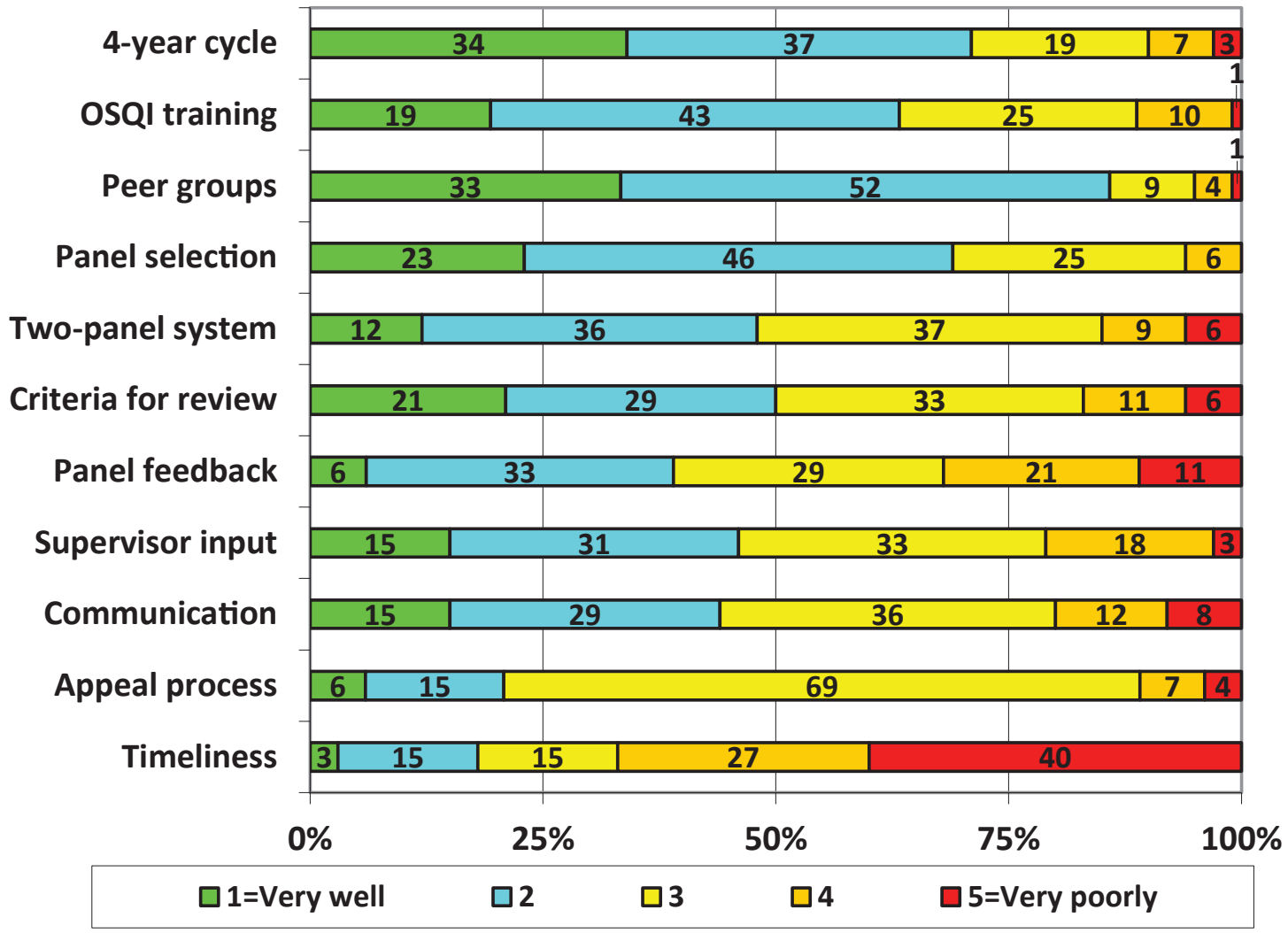

\section{Importance of Components of RGE Process (Supervisors)}

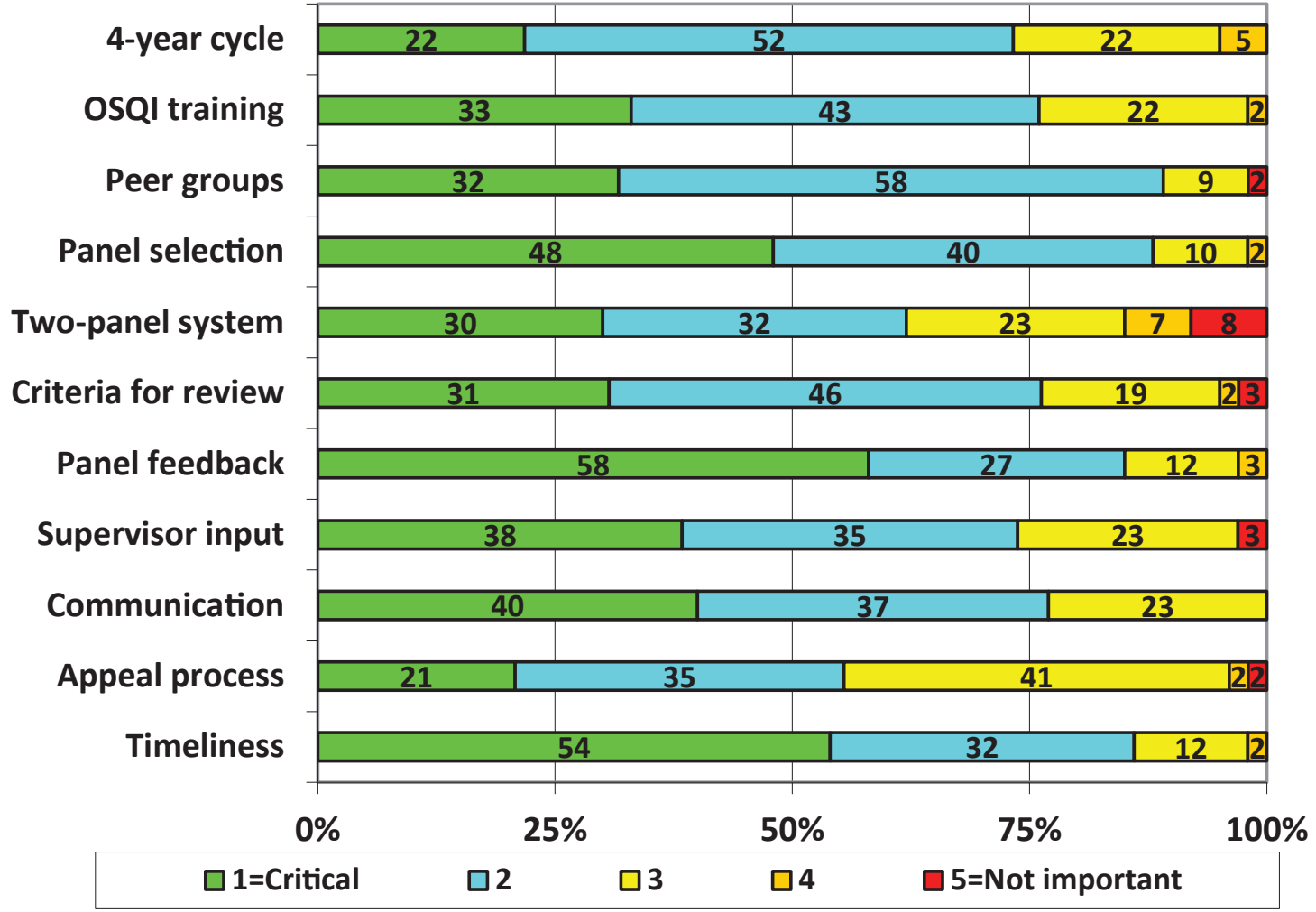




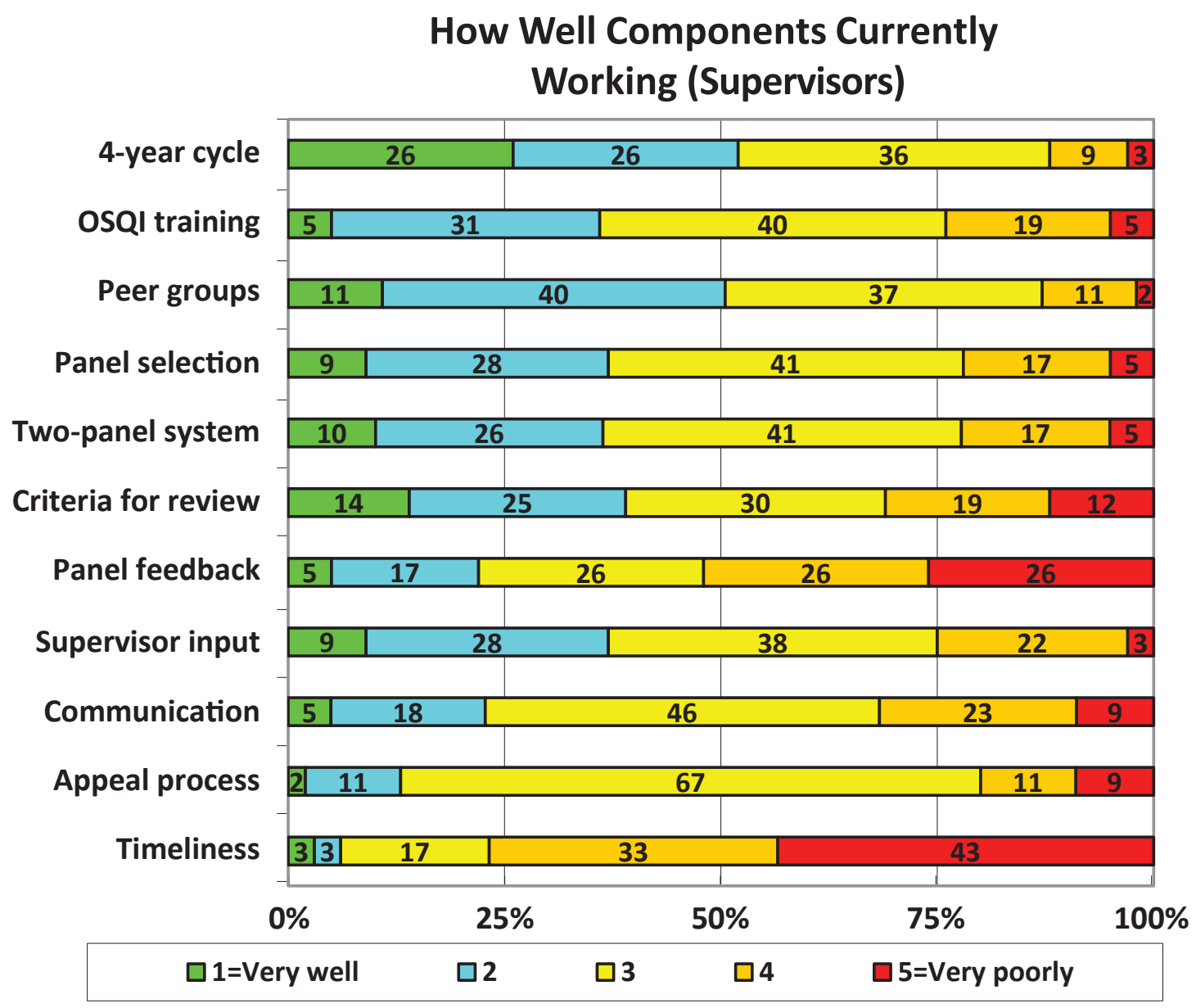


4. How does the RGE review process affect each of the following?

- Research productivity

- Center morale

- Quality of scientific papers

- Quantity of scientific papers

- Willingness of scientists to support stakeholders (through meetings, briefings, white papers, etc.)

- Willingness of scientists to take on non-research tasks

Respondents were asked to rank on a 5-point scale ranging from increases to decreases. No impact was also an option.

\section{Effect of RGE Review Process (Scientists)}

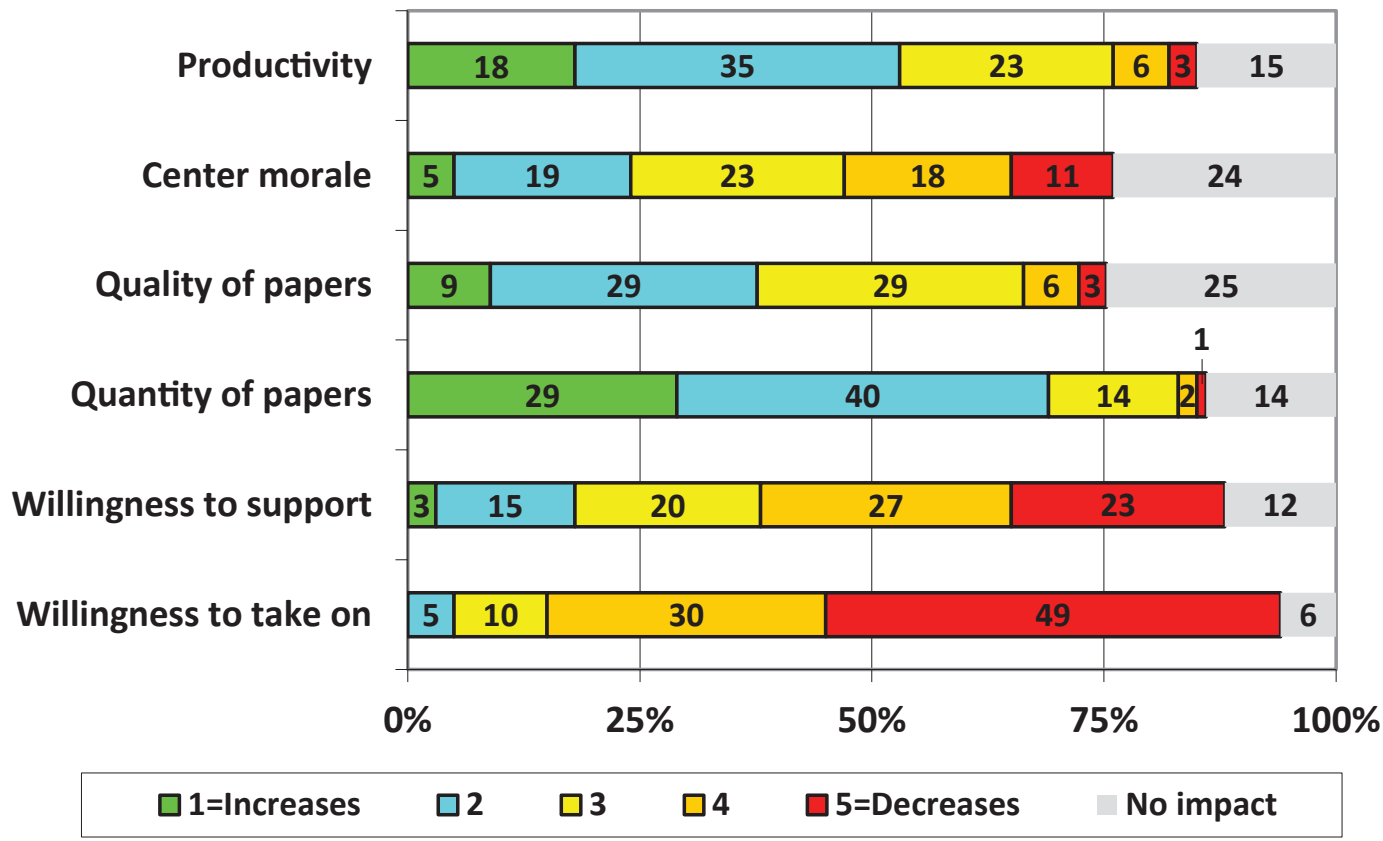




\section{Effect of RGE Review Process (Panelists)}

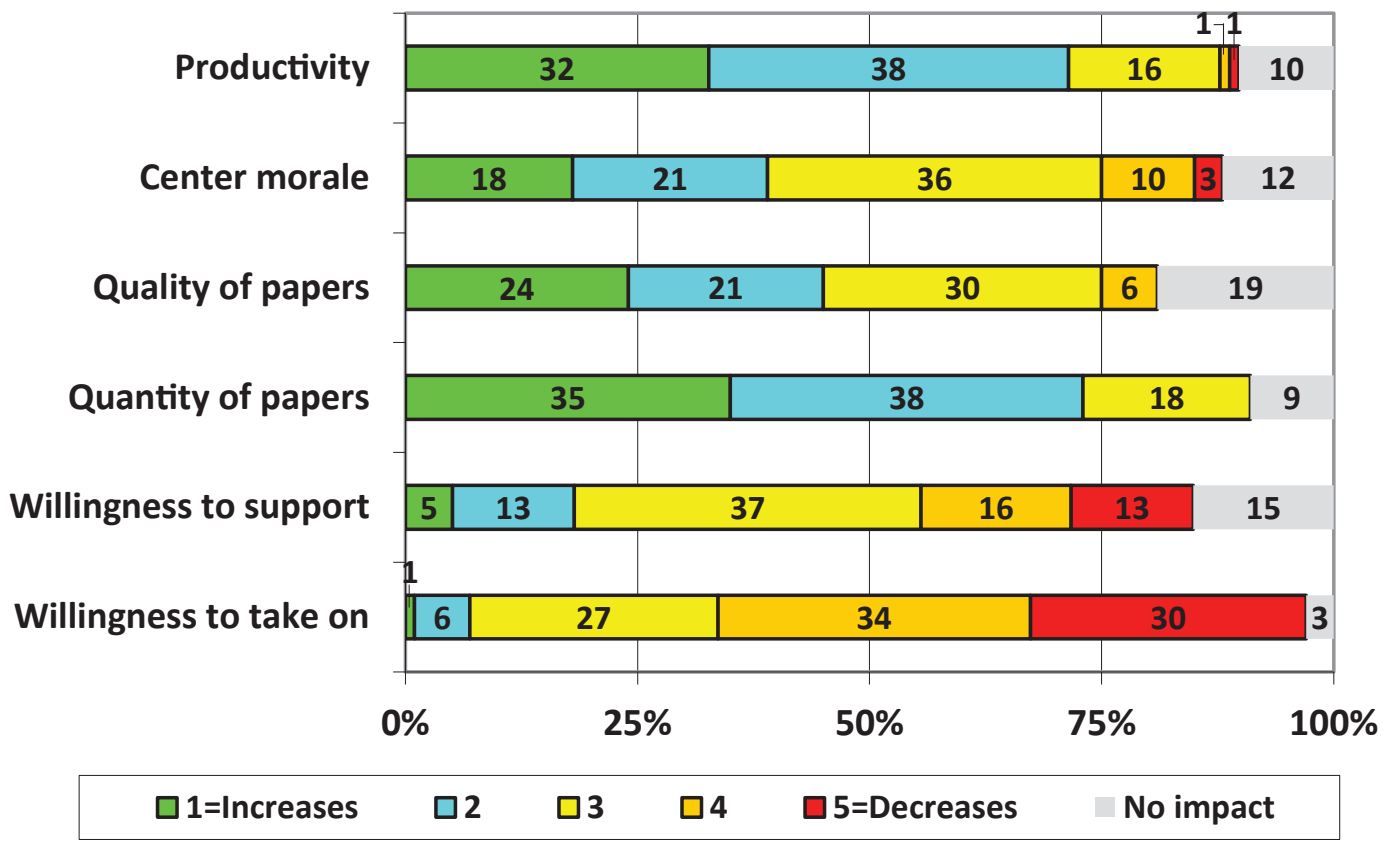

\section{Effect of RGE Review Process \\ (Supervisors)}

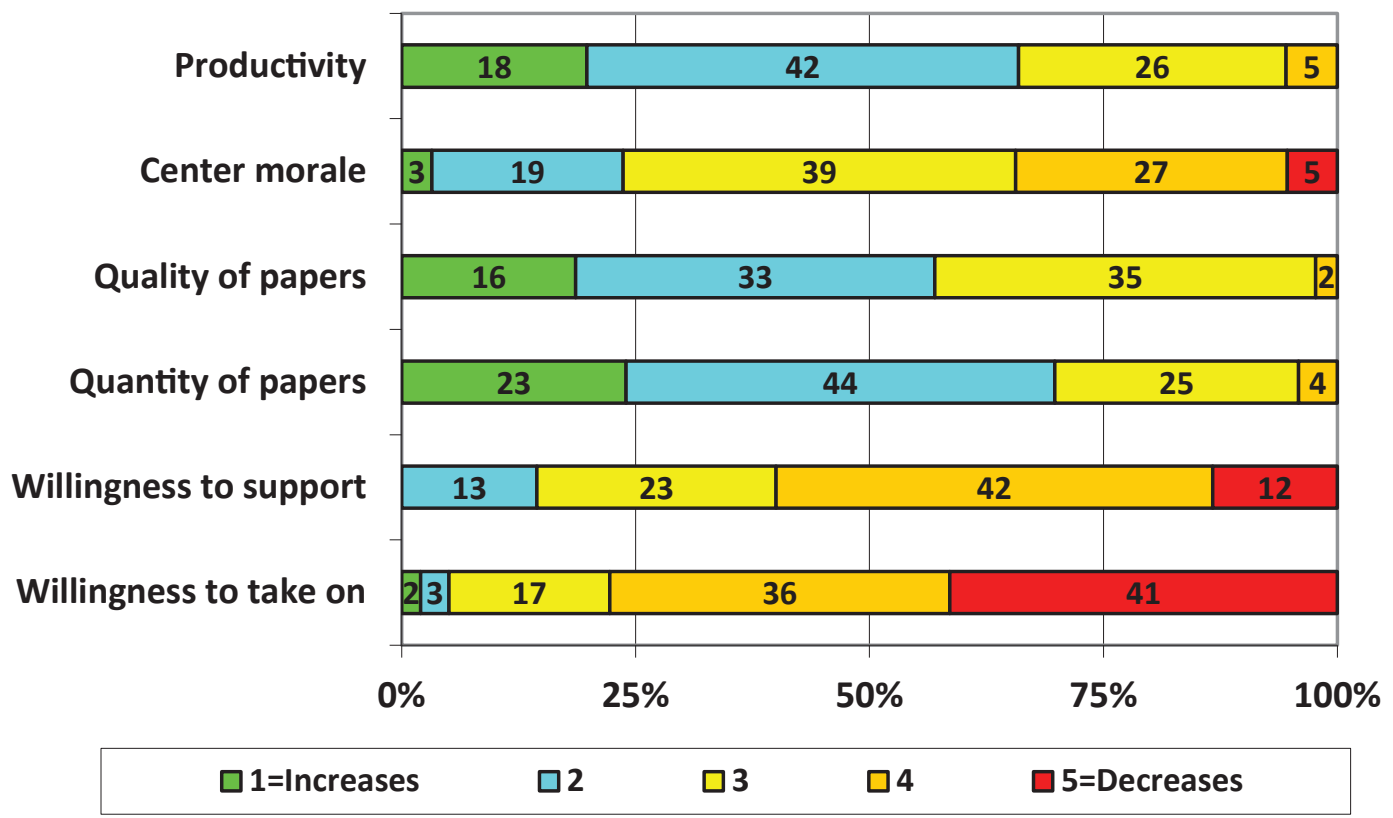




\section{Questions and Responses for Scientists Only}

Scientists were asked to answer the following questions based on the most recent evaluation.

S1. Considering your most recent review, to what extent do you agree with the following statements?

- The review was well timed to showcase my work

- The peer group I was reviewed by was appropriate

- The scoring criteria were subjective

- The scoring criteria were adequate to judge my work

- I felt discriminated against in the process

- I know how to appeal the RGE decision

- I know how to change my review cycle

Respondents were asked to agree or disagree on a 5-point scale with 3 meaning neutral and 5 meaning strongly disagree.

\section{Agreement with Statements}

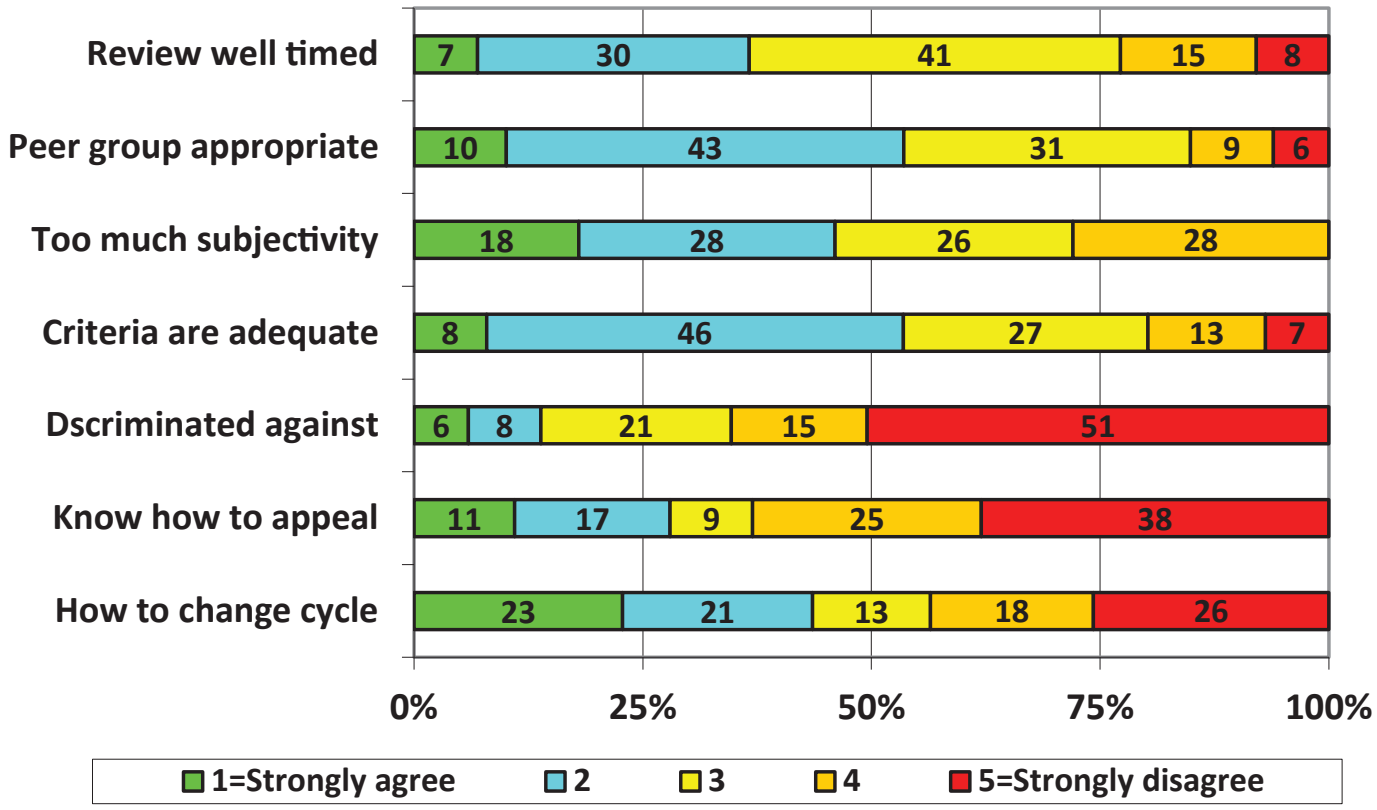


S2. Considering your most recent review:
a) Did you have sufficient time to prepare?
b) Did the results match your expectations?
c) Was the feedback provided sufficient?
d) Was the feedback provided helpful?

Sufficient Time to Prepare?

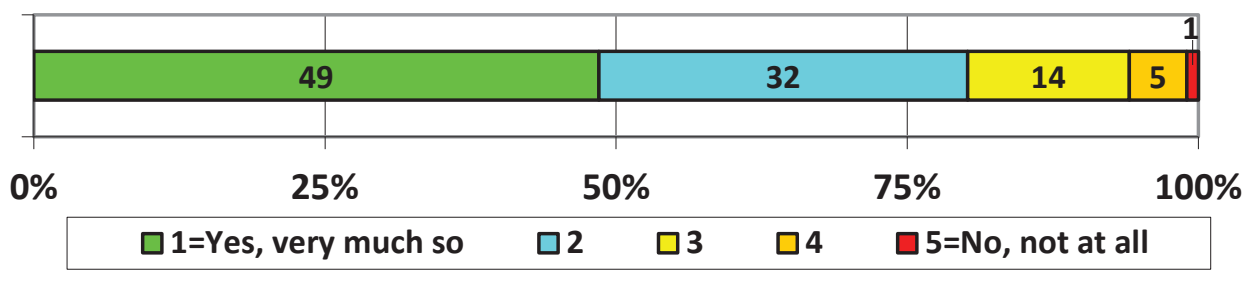

Results Match Expectations?

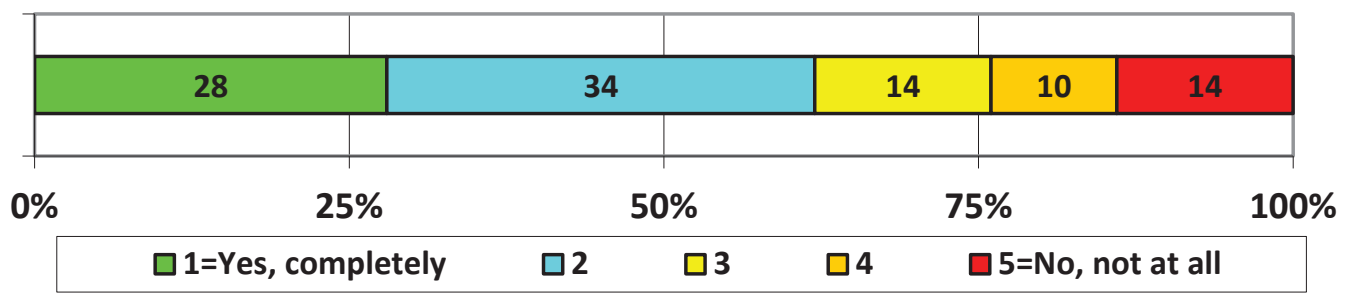

Feedback from RGE Review

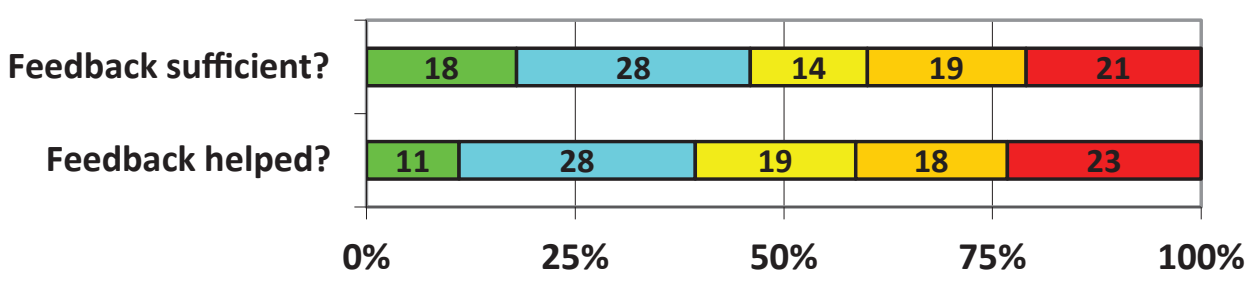

$\square 1=$ Yes, completely $\square 2 \quad \square 3 \quad \square 4 \quad \square 5=$ No, not at all


To better understand how scientists learn about the RGE process, they were asked:

S3a) How well do you feel you understand the RGE Process?

S3b) How did you learn about the RGE Process?

\section{How Well Understand RGE Process}

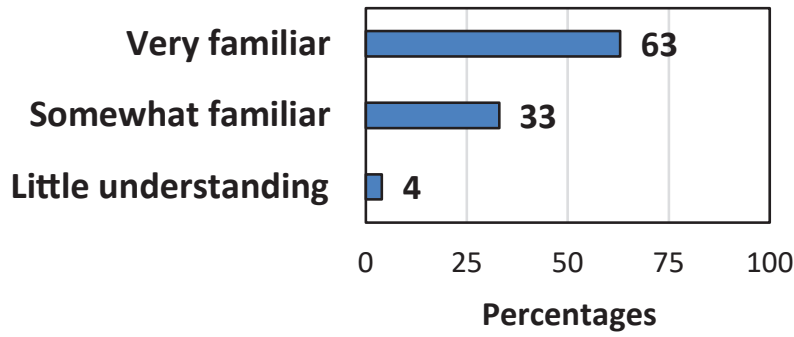

\section{How Learn About RGE Process}

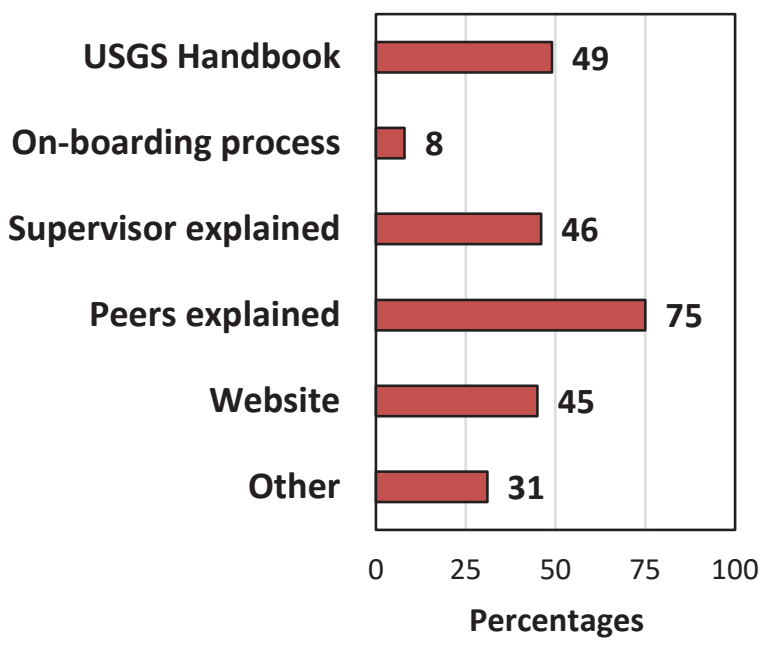

S3c) How helpful was the guidance you received for the RGE Process from peers, RGE Staff, or Center [or Mission Area] leadership?

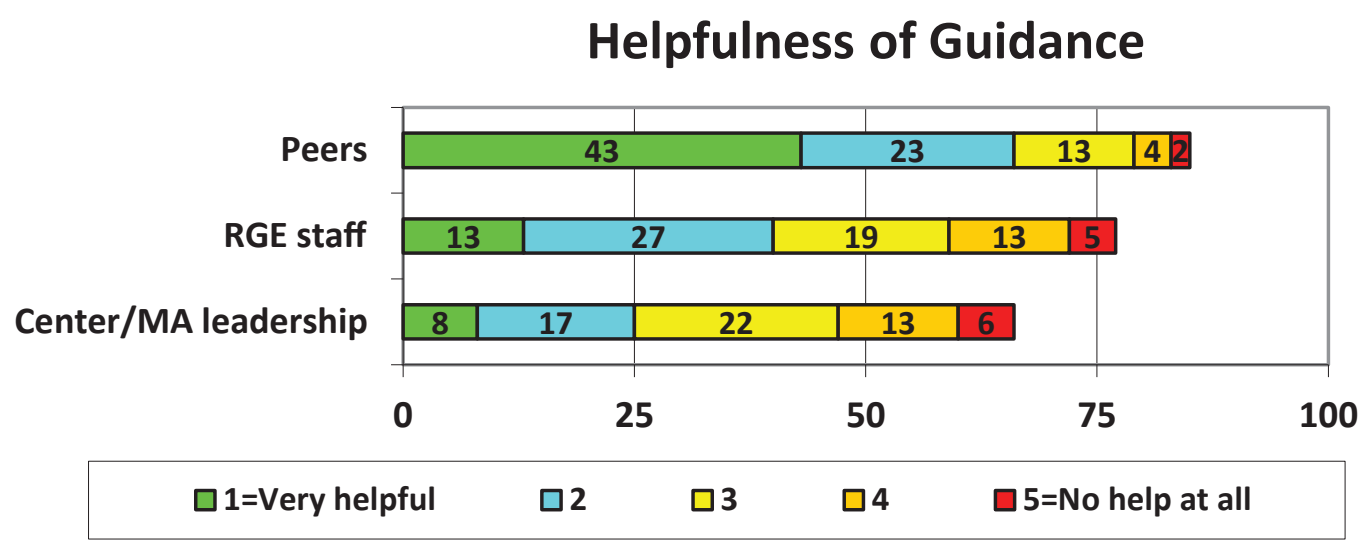


Finally, scientists were asked about their attitudes about the RGE process.

S4. Which of these statements describe your feelings about the RGE process. Choose all that apply:

- I don't have any control of the outcome

- I appreciate the feedback on my scientific work

- The review process is a waste of time

- RGE review represents an opportunity for promotion

- The process takes time away from my research

\section{Attitudes About RGE Review}

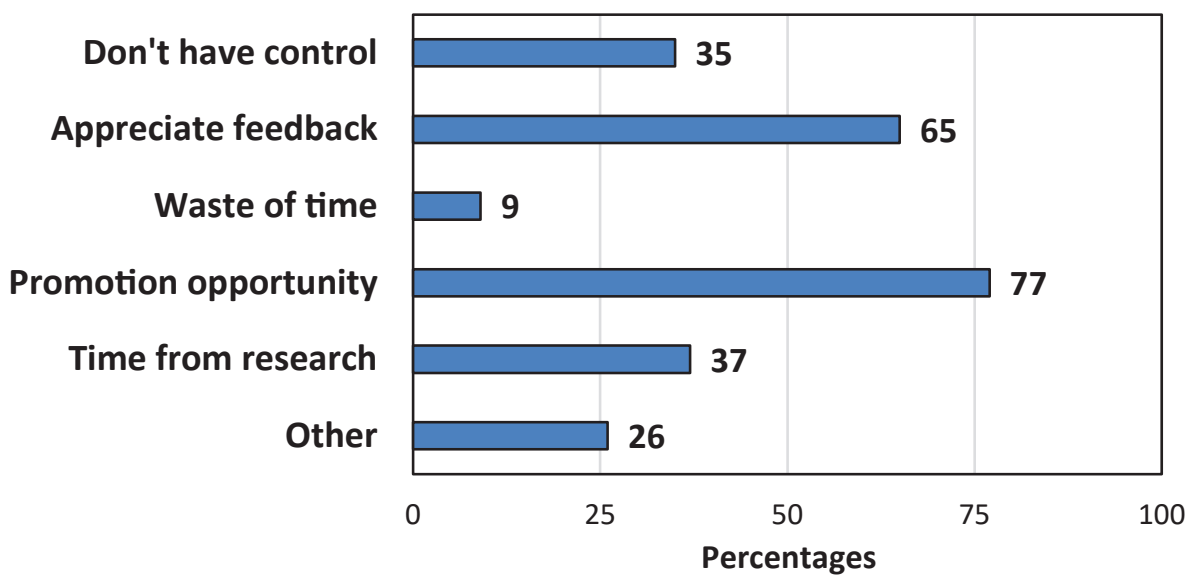




\section{Questions and Responses for Panelists Only}

P1. With respect to your most recent panel, rate your satisfaction with the following:

- The amount of time you had to prepare

- Training received before the panel meeting

- The overall workload of the panel

- The preparation of your fellow panelists

- The expertise of your fellow panelists

- The diversity of your fellow panelists

- How well your expertise matched the needs of the panel

- The role and execution of the panel chair

- The role and execution of primary reviewers

- The role and execution of the RGE coordinator

- The role and execution of the HR [Human Resources] representative

- The opportunity for robust discussion

- The opportunity to air and hear divergent opinions

- The fairness/lack of bias of the panel

- The process of writing the feedback

- The quality of the panel feedback

Respondents were asked to rank their satisfaction on a 5-point scale with 3 meaning neutral and 5 meaning very dissatisfied. 


\section{Satisfaction with Most Recent Panel}

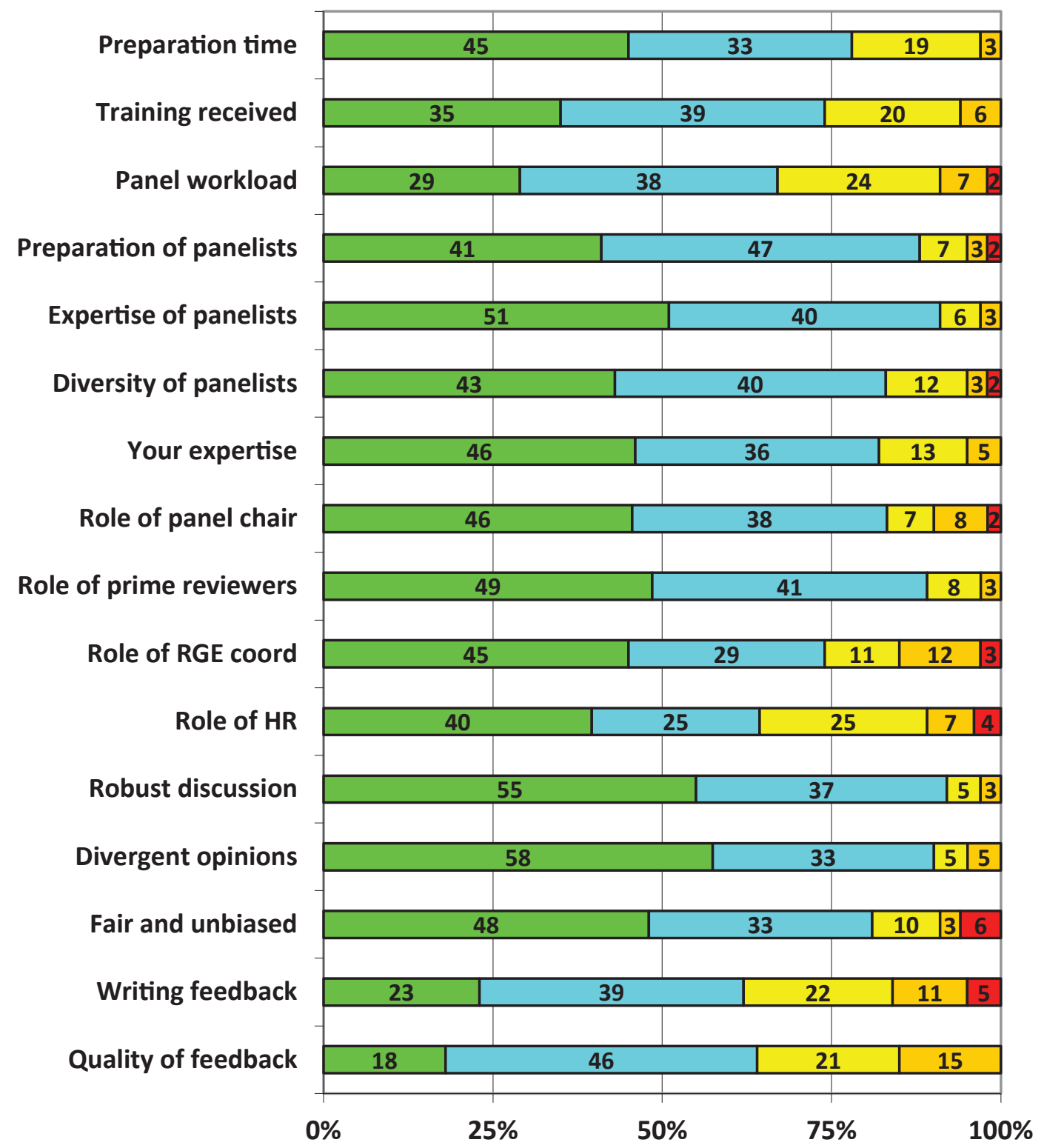

$\square$ 1=Very satisfied $\square 2 \quad \square 3 \quad \square 4 \quad \square 5=$ =ery dissatisfied




\section{Questions and Responses for Supervisors Only}

Supervisors were asked to discuss how the RGE processes affect the management of their staff.

Su1. What training methods do scientists in your center have available to learn about the RGE processes? Check all that apply:

- The USGS RGE Handbook

- The USGS RGE website

- An onboarding-training at the center level

- Supervisors explain the process to new RGE scientists

- Peers explain the process to new RGE scientists

- Other

\section{Training Methods Used}

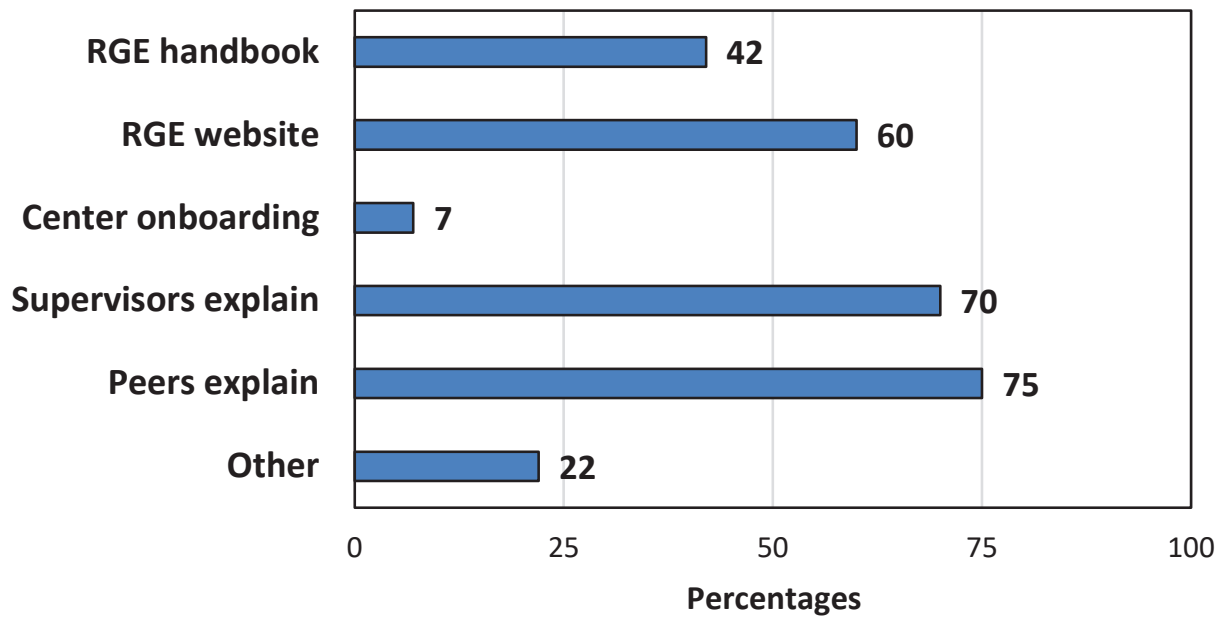

Su2. With respect to promotion, does the RGE process change promotions within your staff? For example, are scientists promoted more quickly or more slowly than they would have been based purely on annual performance reviews? Are scientists promoted, or not, when they otherwise would have been based on annual reviews?

\section{Effect of RGE Process on Promotion}

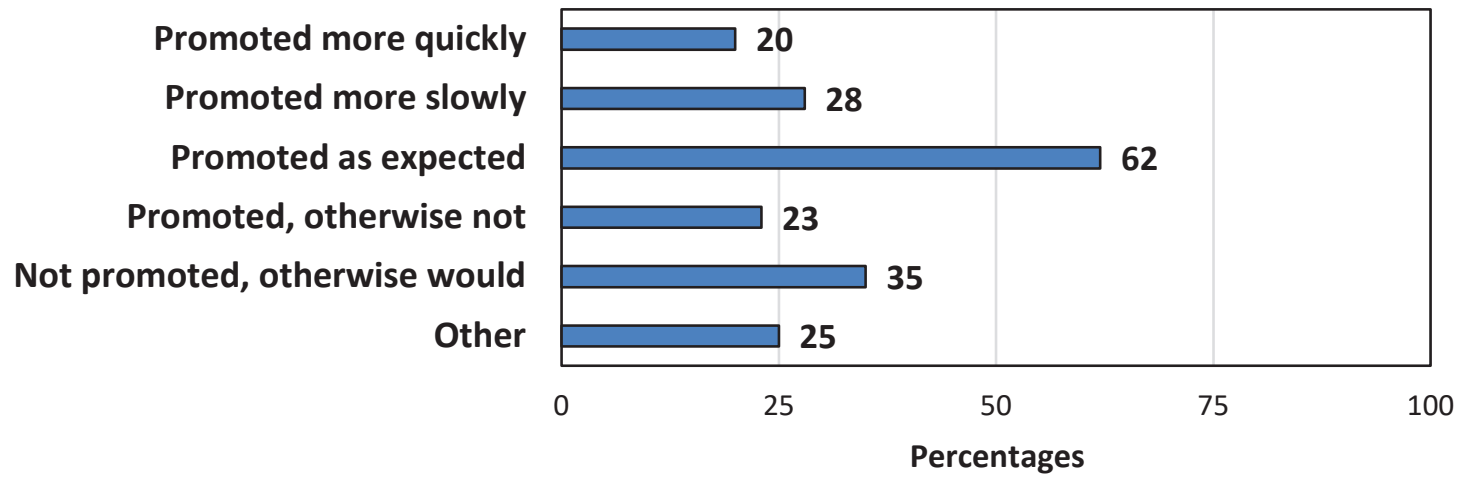




\section{Appendix 4. Benchmarking Information From a Comparison of Methods Used To Evaluate Research Scientists}

In March 2018, the U.S. Geological Survey (USGS) hosted a meeting of Federal science agencies that employ research scientists. The four tables in this appendix compare data on the various systems used by 11 agencies to evaluate research scientists. The submitted data have not been edited.

Agencies (from row 1 to row 11): USGS, U.S. Geological Survey; EPA, U.S. Environmental Protection Agency; USFS, U.S. Department of Agriculture Forest Service; ARS, U.S. Department of Agriculture Agricultural Research Service; USDA-ERS, U.S. Department of Agriculture Economic Research Service; FDA, U.S. Food and Drug Administration; VA, U.S. Department of Veterans Affairs; CDC, Centers for Disease Control and Prevention; NIST, National Institute of Standards and Technology; NOAA, National Oceanic and Atmospheric Administration; ARL, U.S. Army Research Laboratory.

Evaluation systems (from row 1 to row 11): RGE, research grade evaluation; APMS, Alternative Personnel Management System. The three agencies using the APMS category have separate systems: NOAA and NIST are within the OPM Pay for Performance, Alternative Personnel Management System, and Commerce Alternative Personnel System (https://www.commerce.gov/hr/practitioners/caps), respectively, and ARL is within the Department of Defense's Pay for Performance system (https://www.arl.army.mil/www/default.cfm?page=529).

Other terms: CV, curriculum vitae; FOIA, Freedom of Information Act; GS, General Schedule; HR, Human Resources; hr, hour; N/A, not applicable; OPM, U.S. Office of Personnel Management; RDSR, Research and Development Scientist Record; SME, subject matter expert; SOP, standard operating procedure; ST, senior scientist; —, no data. 
Table 4.1. Data on general and overall processes for evaluating research scientists.

\begin{tabular}{|c|c|c|c|c|c|c|c|c|c|}
\hline \multirow[b]{2}{*}{ Agency } & \multicolumn{9}{|c|}{ General/Overall Processes } \\
\hline & Process & \# Scientists & Grades & Frequency of review & $\begin{array}{l}\text { Office overseeing the } \\
\text { process }\end{array}$ & $\begin{array}{l}\text { Alterations to OPM } \\
\text { guidance }\end{array}$ & $\begin{array}{l}\text { Submission of } \\
\text { materials }\end{array}$ & Promotion process & Additional notes \\
\hline USGS & RGE & 1100 & GS11+ & 4 years $\mid \mathrm{ST}=6$ years & $\begin{array}{l}\text { Office of Science Quality } \\
\text { and Integrity - permanent } \\
\text { RGE staff }\end{array}$ & $\begin{array}{l}\text { Yes - additional language } \\
\text { written for scoring } \\
\text { criteria }\end{array}$ & - & $\begin{array}{l}\text { Result communicated to } \\
\text { Center Director. CD has } \\
\text { discretion to promote or } \\
\text { not. Most promote }\end{array}$ & - \\
\hline EPA & RGE & - & GS14-15 & Promotion only & - & $\begin{array}{l}\text { Added guidelines: } \\
\text { how does your work } \\
\text { impact the mission of } \\
\text { the agency; how does } \\
\text { it impact policy. Also } \\
\text { added value for service, } \\
\text { chairing, leading, writ- } \\
\text { ing policy, providing } \\
\text { expertise }\end{array}$ & $\begin{array}{l}\text { Moving to all } \\
\text { electronic }\end{array}$ & - & $\begin{array}{l}\text { New hires also undergo modi- } \\
\text { fied review - no ad-hoc mem- } \\
\text { bers. Since supervisors serve } \\
\text { as gatekeepers to the process, } \\
\text { packets are usually strong }\end{array}$ \\
\hline USFS & RGE & 450 & GS11+ & $\begin{array}{l}1 \text { st }- \text { within } 3 \text { years } \\
11-13-4 \text { years } \\
14+-5 \text { years } \\
\text { ST }- \text { not rereviewed }\end{array}$ & - & $\begin{array}{l}\text { Created a detailed } \\
\text { supplement based on } \\
\text { OPM guidance }\end{array}$ & - & $\begin{array}{l}\text { Recommendations go } \\
\text { to supervisors. At 15/ST } \\
\text { level, recommendations } \\
\text { go to Deputy Chief }\end{array}$ & $\begin{array}{l}\text { After panel closes, the panel } \\
\text { discusses feedback for the } \\
\text { scientist - effectiveness of } \\
\text { the packet, career advice, } \\
\text { kudos. This is delivered } \\
\text { outside of the formal process. } \\
\text { Evaluation of } 10 \text { years of data } \\
\text { shows: promotions slower } \\
\text { with higher grade; set time } \\
\text { for review is effective; no } \\
\text { gender bias }\end{array}$ \\
\hline ARS & RGE & 1500 & GS11+ & $\begin{array}{l}11 / 12-3 \text { years } \\
13-4 \text { years } \\
14-5 \text { years } \\
15-7 \text { years }\end{array}$ & $\begin{array}{l}\text { RGE office. They have a } \\
\text { budget for travel for pan- } \\
\text { els. Advisory committee } \\
\text { meets quarterly to update } \\
\text { processes }\end{array}$ & - & $\begin{array}{l}\text { Use database to } \\
\text { keep track. Use } \\
\text { SharePoint to } \\
\text { share materials to } \\
\text { panelists }\end{array}$ & $\begin{array}{l}\text { Decisions binding. } \\
\text { Promotions within } 2 \text { pay } \\
\text { periods. Pay is whatever } \\
\text { is highest (research } \\
\text { grade or other) for mixed } \\
\text { positions }\end{array}$ & $\begin{array}{l}\text { Panelists get } 6-7 \text { weeks with } \\
\text { materials. Employee knows } \\
\text { outcome within } 1-2 \text { days. ID } \\
\text { of panelists is confidential, } \\
\text { even to FOIA. They ask } \\
\text { panelists to seek outside com- } \\
\text { ments by phone only. Save } \\
\text { draft report, initial scores, } \\
\text { panel notes, and oral report } \\
\text { notes for } 3 \text { years. Panels } \\
\text { evaluate hires at GS13+ }\end{array}$ \\
\hline USDA - ERS & RGE & 120 & GS12+ & $\begin{array}{l}12 / 13 \text { reviews volun- } \\
\text { tary, but expect one in } \\
\text { year } 1 \text { or } 2 \text {, and expect } \\
\text { every } 3-4 \text { years for } \\
13 \mathrm{~s} \text {; every } 5 \text { years for } \\
14 \mathrm{~s}-15 \mathrm{~s}\end{array}$ & - & - & - & $\begin{array}{l}\text { Panels are in the spring, } \\
\text { decisions by June, promo- } \\
\text { tion within } 2 \text { pay periods }\end{array}$ & $\begin{array}{l}\text { GS } 12 \text { is reviewed within the } \\
\text { division; } 3 \text { peers, chair, and } \\
\text { HR. } 13+\text { are agency reviews }\end{array}$ \\
\hline
\end{tabular}


Table 4.1. Data on general and overall processes for evaluating research scientists. - Continued

\begin{tabular}{|c|c|c|c|c|c|c|c|c|c|}
\hline \multirow[b]{2}{*}{ Agency } & \multicolumn{9}{|c|}{ General/Overall Processes } \\
\hline & Process & \# Scientists & Grades & Frequency of review & $\begin{array}{l}\text { Office overseeing the } \\
\text { process }\end{array}$ & $\begin{array}{l}\text { Alterations to OPM } \\
\text { guidance }\end{array}$ & $\begin{array}{l}\text { Submission of } \\
\text { materials }\end{array}$ & Promotion process & Additional notes \\
\hline FDA & RGE & - & GS13+ & $\begin{array}{l}\text { Promotion only, recom- } \\
\text { mendation by supervi- } \\
\text { sor or self-nomination }\end{array}$ & - & $\begin{array}{l}\text { 14-page chart describes } \\
\text { scoring for each level, } \\
\text { including added lan- } \\
\text { guage for B and D }\end{array}$ & - & $\begin{array}{l}\text { Result is a recommenda- } \\
\text { tion to HR - HR does the } \\
\text { classification. They have } \\
30 \text { days to complete }\end{array}$ & $\begin{array}{l}\text { There are } 2 \text { reports: Chair } \\
\text { writes an evaluation that } \\
\text { includes recommendation and } \\
\text { career advice, this goes to sci- } \\
\text { entist. HR writes classification } \\
\text { evaluation, which does not go } \\
\text { to scientist }\end{array}$ \\
\hline VA & RGE & - & GS12+ & $\begin{array}{l}2 \text { years. Up to } 13 \text {, in } \\
\text { field offices. } 14+\text { is } \\
2 \text {-step process }\end{array}$ & $\begin{array}{l}\text { Office of R\&D \& VHA } \\
\text { HR Servicing Office }\end{array}$ & $\begin{array}{l}\text { Added guidance for } \\
\text { reviewers of pre-clinical, } \\
\text { clinical, biomedical or } \\
\text { health services investiga- } \\
\text { tors }\end{array}$ & $\begin{array}{l}\text { Currently by e-mail; } \\
\text { hope to move to a } \\
\text { SharePoint portal }\end{array}$ & $\begin{array}{l}\text { Panel recommendations } \\
\text { at GS14 require concur- } \\
\text { rence by VHSO and final } \\
\text { approval by the Chief } \\
\text { R\&D Officer; GS15s } \\
\text { require final approval } \\
\text { from the Under Secretary } \\
\text { of Health or designee }\end{array}$ & $\begin{array}{l}\text { Panel meets twice/year and } \\
\text { composition depends on } \\
\text { needed expertise }\end{array}$ \\
\hline $\mathrm{CDC}$ & RGE & - & GS12+ & $\begin{array}{l}\text { Promotion only. Timing } \\
\text { is self-selected }\end{array}$ & - & - & - & - & $\begin{array}{l}\text { Panels are managed at center } \\
\text { level. Chair serves } 2-3 \text { years. } \\
\text { HR reviews before the com- } \\
\text { mittee. Standing committee } \\
\text { meets monthly }\end{array}$ \\
\hline NIST & APMS & 1800 & $\begin{array}{l}\text { Pay Bands } \\
(3-5)\end{array}$ & $\begin{array}{l}\text { Promotion only - no } \\
\text { review of PB-5 sci- } \\
\text { entists }\end{array}$ & $\begin{array}{l}\text { Each lab has its own } \\
\text { authority }\end{array}$ & $\mathrm{N} / \mathrm{A}$ & - & $\begin{array}{l}\text { Decided at lab level. Bud- } \\
\text { get is part of the decision } \\
\text { process }\end{array}$ & $\begin{array}{l}\text { All cases are reviewed in the } \\
\text { fall. Troublesome cases are } \\
\text { referred to spring panels }\end{array}$ \\
\hline NOAA & APMS & 1000 & $\begin{array}{l}\text { Pay Bands } \\
(3-5)\end{array}$ & $\begin{array}{l}\text { Pilot underway for } \\
\text { promotion only, PB-5 }\end{array}$ & $\begin{array}{l}\text { Each lab has its own } \\
\text { authority }\end{array}$ & N/A & - & - & $\begin{array}{l}\text { No system in place. Piloting } \\
\text { an RGE type process for } \\
\text { PB-5. Lower levels to stay } \\
\text { local for now }\end{array}$ \\
\hline ARL & APMS & 1700 & $\begin{array}{l}\text { Pay Bands } \\
(3-5)\end{array}$ & $\begin{array}{l}\text { Annual performance } \\
\text { review }\end{array}$ & Local management & $\begin{array}{l}\text { Scored on three factors } \\
\text { - each worth } 6 \text { points: } \\
\text { complexity of work; } \\
\text { impact on ARL; } \\
\text { recognition }\end{array}$ & - & 15 points - $\mathrm{PB}-4$ & $\begin{array}{l}\text { Do not need to meet all } \\
\text { subfactors for each factor. For } \\
\text { example: } 3 \text { of } 5 \text { subfactors is } \\
\text { a score of } 5\end{array}$ \\
\hline
\end{tabular}


Table 4.2. Data on level 1 panels used for evaluating research scientists.

\begin{tabular}{|c|c|c|c|c|c|c|c|c|c|c|c|c|}
\hline \multirow[b]{2}{*}{ Agency } & \multicolumn{12}{|c|}{ Level 1 Panel } \\
\hline & $\begin{array}{l}\text { Number of } \\
\text { panelists }\end{array}$ & $\begin{array}{c}\text { Number of } \\
\text { packets }\end{array}$ & $\begin{array}{l}\text { Length of } \\
\text { meeting }\end{array}$ & $\begin{array}{l}\text { Method of } \\
\text { meeting }\end{array}$ & Scoring & $\begin{array}{c}\text { Panel } \\
\text { formation }\end{array}$ & Information & External & HR rep? & RGE role & $\begin{array}{l}\text { Voting } \\
\text { members }\end{array}$ & Panel vote/role \\
\hline USGS & $5-7$ & 15 & $2-3$ days & In person & $\begin{array}{l}\text { Subfactors scored } \\
\text { individually. } \\
\text { Factor score= } \\
\text { minimum sub- } \\
\text { factor score }\end{array}$ & Peer groups & $\begin{array}{l}\text { RDSR packet, } \\
\text { primary } \\
\text { reviewer in- } \\
\text { terviews with } \\
\text { supervisor } \\
\text { and others }\end{array}$ & No & Yes & Yes & Scientists only & $\begin{array}{l}\text { Consensus } \\
\text { advisory }\end{array}$ \\
\hline EPA & 6 & 1 & - & Some virtual & $\begin{array}{l}\text { No scoring - vote } \\
\text { up or down on } \\
\text { promotion }\end{array}$ & $\begin{array}{l}4 \text { EPA, } 3 \text { in } \\
\text { the same } \\
\text { discipline, } \\
\text { plus two ad } \\
\text { hoc }\end{array}$ & - & $\begin{array}{l}\text { Two -profes- } \\
\text { sional } \\
\text { services } \\
\text { contract }\end{array}$ & - & - & Scientists only & $\begin{array}{l}\text { Yes or no - } \\
\text { majority }\end{array}$ \\
\hline USFS & 6 & 1 & - & Mostly virtual & $\begin{array}{l}\text { Yes - scores submit- } \\
\text { ted in advance of } \\
\text { meeting. Must } \\
\text { reach consensus } \\
\text { at meeting with } \\
3 \text { agree and 4th } \\
\text { within }+/-1 \\
\text { (point) }\end{array}$ & $\begin{array}{l}\text { One subject } \\
\quad \text { matter } \\
\text { expert, one } \\
\text { peer, two } \\
\text { nonpeers, } \\
\text { chair, HR }\end{array}$ & $\begin{array}{l}\text { Scientists } \\
\text { narrative } \\
\text { addresses } \\
\text { accomplish- } \\
\text { ments and } \\
\text { impacts. } \\
\text { Panel } \\
\text { consultations } \\
\text { conducted } \\
\text { before meet- } \\
\text { ing }\end{array}$ & - & Yes & - & - & $\begin{array}{l}\text { Consensus } \\
\text { advisory }\end{array}$ \\
\hline ARS & 7 & 10 & 1 day & In person & - & $\begin{array}{l}2 \text { peer groups/ } \\
\text { panel, } 5 \\
\text { scientists } \\
\text { - each is } \\
\text { primary } \\
\text { reviewer for } \\
2 \text { packets }\end{array}$ & $\begin{array}{l}\text { Packets are } \\
\text { space-lim- } \\
\text { ited. Factor } \\
4 \text { is } 3 / 4 \text { of } \\
\text { total. Re- } \\
\text { search leader } \\
\text { must sign for } \\
\text { accuracy }\end{array}$ & No & Yes & Yes & All & $\begin{array}{r}\text { Consensus } \\
\text { binding }\end{array}$ \\
\hline USDA - ERS & 7 & 5 & - & In person & - & $\begin{array}{l}5 \text { peers plus } \\
\text { chair } \\
\text { (director or } \\
\text { deputy) HR }\end{array}$ & $\begin{array}{l}\text { Require outside } \\
\text { letters. Do } \\
\text { not allow } \\
\text { phone calls. } \\
\text { Limit } \\
\text { exhibits to } \\
3 \text { for GS12, } \\
\text { and } 6 \text { for all } \\
\text { others }\end{array}$ & No & Yes & - & $\begin{array}{l}\text { Scientists plus } \\
\text { chair }\end{array}$ & - \\
\hline FDA & $4-20$ & $2-3$ & - & - & - & $\begin{array}{l}\text { Regular peer } \\
\text { review done } \\
\text { at center } \\
\text { level only. } \\
\text { Standing } \\
\text { committee } \\
\text { (3-4 years } \\
\text { of service) }\end{array}$ & $\begin{array}{l}\text { Primary review- } \\
\text { er interviews } \\
\text { employee } \\
\text { and supervi- } \\
\text { sor }\end{array}$ & - & - & - & - & $\begin{array}{l}\text { Majority } \\
\text { advisory }\end{array}$ \\
\hline
\end{tabular}


Table 4.2. Data on level 1 panels used for evaluating research scientists. - Continued

\begin{tabular}{|c|c|c|c|c|c|c|c|c|c|c|c|c|}
\hline \multirow[b]{2}{*}{ Agency } & \multicolumn{12}{|c|}{ Level 1 Panel } \\
\hline & $\begin{array}{l}\text { Number of } \\
\text { panelists }\end{array}$ & $\begin{array}{l}\text { Number of } \\
\text { packets }\end{array}$ & $\begin{array}{l}\text { Length of } \\
\text { meeting }\end{array}$ & $\begin{array}{l}\text { Method of } \\
\text { meeting }\end{array}$ & Scoring & $\begin{array}{c}\text { Panel } \\
\text { formation }\end{array}$ & Information & External & HR rep? & RGE role & $\begin{array}{l}\text { Voting } \\
\text { members }\end{array}$ & Panel vote/role \\
\hline VA & $\begin{array}{l}\text { Local panel } \\
\quad 3-4\end{array}$ & $1-2$ & $\sim 1 \mathrm{hr}$ & Local decision & $\begin{array}{l}\text { Each reviewer } \\
\quad \text { submits scores \& } \\
\text { critiques }\end{array}$ & $\begin{array}{l}3 \text { reviewers at } \\
\text { the same } \\
\text { or higher } \\
\text { grade }\end{array}$ & $\begin{array}{l}\text { Complete packet } \\
\text { for GS14+ }\end{array}$ & $\begin{array}{l}\text { May recruit } \\
\text { SMEs from } \\
\text { other VA's }\end{array}$ & Encouraged & - & $\begin{array}{l}\text { Scientists plus } \\
\quad \text { chair }\end{array}$ & $\begin{array}{l}\text { Consensus } \\
\text { advisory }\end{array}$ \\
\hline $\mathrm{CDC}$ & $5-7$ & $5-6$ & $1 \mathrm{hr}$ & - & - & $\begin{array}{l}\text { 3-5 scientists. } \\
\text { One must } \\
\text { be from } \\
\text { outside the } \\
\text { center. HR } \\
\text { and Chair }\end{array}$ & $\begin{array}{l}\mathrm{CV} \text {, narrative, } \\
\text { publications, } \\
\text { accomplish- } \\
\text { ments }\end{array}$ & - & Yes & - & $\begin{array}{l}\text { Scientists plus } \\
\text { chair. No } \\
\text { one can } \\
\text { vote on } \\
\text { someone } \\
\text { above their } \\
\text { grade }\end{array}$ & - \\
\hline NIST & \multicolumn{12}{|c|}{ No agencywide process. Evaluations are done within lab or working groups } \\
\hline NOAA & \multicolumn{12}{|c|}{ No agencywide process. Evaluations are done within lab or working groups } \\
\hline ARL & \multicolumn{12}{|c|}{ Details vary across agency } \\
\hline
\end{tabular}


Table 4.3. Data on level 2 panels used for evaluating research scientists.

\begin{tabular}{|c|c|c|c|c|c|c|c|c|}
\hline \multirow[b]{2}{*}{ Agency } & \multicolumn{8}{|c|}{ Level 2 Panel } \\
\hline & Role of $2 \mathrm{~d}$ panel & $\begin{array}{c}\text { Number of panel } \\
\text { members }\end{array}$ & Number of packets & Panel formation & External members & Voting members & HR rep? & Panel role \\
\hline USGS & $\begin{array}{l}\text { Re-review all potential } \\
\text { promotions to } 14 \text { or } \\
15 \text {, and all below } \\
\text { grade }\end{array}$ & $10-20$ & 50 & Bureauwide & No & Scientists only & $\begin{array}{l}\text { Yes, classification } \\
\text { specialist }\end{array}$ & Consensus advisory \\
\hline EPA & N/A & - & - & - & - & - & - & - \\
\hline USFS & N/A & - & - & - & - & - & - & - \\
\hline ARS & N/A & - & - & - & - & - & - & - \\
\hline USDA - ERS & $\mathrm{N} / \mathrm{A}$ & - & - & - & - & - & - & - \\
\hline FDA & $\begin{array}{l}\text { Agency level review } \\
\text { for regulatory } \\
\text { work only - no HR } \\
\text { involvement }\end{array}$ & - & - & - & - & - & - & - \\
\hline VA & $\begin{array}{l}\text { Centralized evaluation } \\
\text { of all GS14+ for } \\
\text { uniform application } \\
\text { of the RGEGs }\end{array}$ & $10-15$ & $\begin{array}{l}3 \text { reviewers/packet; } \\
10-20 \text { packets per } \\
\text { cycle }\end{array}$ & $\begin{array}{l}\text { VA PhD, MD, Associ- } \\
\text { ate Chiefs of Staff } \\
\text { for Research, HR } \\
\text { tech. advisor }\end{array}$ & No & Scientists only & Yes, HR class. & Consensus advisory \\
\hline $\mathrm{CDC}$ & N/A & - & - & - & - & - & - & - \\
\hline NIST & N/A & - & - & - & - & - & - & - \\
\hline NOAA & N/A & - & - & - & - & - & - & - \\
\hline ARL & N/A & - & - & - & - & - & - & - \\
\hline
\end{tabular}


Table 4.4. Data on guidance, training, and challenges for people involved in evaluating research scientists.

\begin{tabular}{|c|c|c|c|c|c|}
\hline \multirow{2}{*}{ Agency } & \multicolumn{4}{|c|}{ Guidance and training } & \multirow{2}{*}{ Challenges } \\
\hline & For scientists & For panels & For supervisors & About scoring / evaluation & \\
\hline USGS & $\begin{array}{l}\text { Training on RDSR preparation is } \\
\text { available by reading prepared slides } \\
\text { then Q\&A }\end{array}$ & $\begin{array}{l}\text { Training on panel is available by } \\
\text { reading prepared slides then } \\
\text { Q\&A. RGE Staff brief panels at } \\
\text { start of each meeting }\end{array}$ & No formal training & - & How to handle mixed positions. How to evaluate impact \\
\hline EPA & - & $\begin{array}{l}\text { New panel members must observe } \\
\text { a panel before serving }\end{array}$ & - & - & - \\
\hline USFS & $\begin{array}{l}\text { Manual for training scientists. They } \\
\text { have limits to number of things to } \\
\text { address and length. Limits increase } \\
\text { with grade }\end{array}$ & $\begin{array}{l}\text { Written guidelines for panelists } \\
\text { include list of things to focus } \\
\text { on, how to evaluate stature and } \\
\text { impact. Nor formal training }\end{array}$ & No, but considering it & - & $\begin{array}{l}\text { Struggle with how to identify and evaluate impact. One measure } \\
\text { they use is who contacted the scientists for expertise }\end{array}$ \\
\hline ARS & $\begin{array}{l}\text { Case writeup and panel operations } \\
\text { webinars provided the summer } \\
\text { before case is due, recorded and } \\
\text { posted on intranet for future refer- } \\
\text { ence }\end{array}$ & $\begin{array}{l}\text { In-person day and a half for new } \\
\text { panelists; refresher webinars } \\
\text { provided quarterly ( } 90 \text { minutes) }\end{array}$ & $\begin{array}{l}\text { Covered briefly but } \\
\text { investigating ways to } \\
\text { expand/enhance }\end{array}$ & $\begin{array}{l}\text { Covered in both types of training/ } \\
\text { webinars, for scientists and panel- } \\
\text { ists }\end{array}$ & $\begin{array}{l}\text { Addressing the misconceptions that this process is a perfor- } \\
\text { mance and/or career guidance tool; many managers and } \\
\text { employees still believe that it is }\end{array}$ \\
\hline USDA - ERS & - & $\begin{array}{l}\text { Training required. Full day. } \\
\text { Example packets used }\end{array}$ & - & $\begin{array}{l}\text { They have ranked journals by tier. } \\
\text { Technical work is more valued } \\
\text { than journal articles. Note different } \\
\text { kinds of accomplishments: } \\
\text { knowledge discovery, knowledge } \\
\text { synthesis and assessment, modeling } \\
\text { - survey design - data development, } \\
\text { leadership, special assignments }\end{array}$ & $\begin{array}{l}\text { Balancing internal vs external journal articles. Weighing the } \\
\text { importance of presentations and special assignments }\end{array}$ \\
\hline FDA & Have an SOP document for packet & - & - & - & $\begin{array}{l}\text { Some are asking for reviews for potential hires -they are trying } \\
\text { to stop that. One challenge of promotion only panel is that } \\
\text { scientists can file a grievance if they are unhappy with result. } \\
\text { Committee members are public knowledge, so their notes can } \\
\text { be subpoenaed }\end{array}$ \\
\hline
\end{tabular}
be subpoenaed

\begin{tabular}{|c|c|c|c|c|}
\hline VA & Guidelines and instructions & $\begin{array}{l}\text { Reviewer trains with long-time } \\
\text { panel members }\end{array}$ & No & $\begin{array}{l}\text { Driven by factor } 4 \text { and research } \\
\text { contribution. For GS15's we expect } \\
\text { more leadership/advisory roles at }\end{array}$ \\
\hline
\end{tabular}

Very few HR specialists feel comfortable classifying research appointments because they may not have done one in the past. This is a major challenge. Also the majority of our scientists/reviewers are associated with universities so they are very familiar with tenure and promotions which can be both a blessing and a curse

\begin{tabular}{|c|c|c|c|c|c|}
\hline CDC & - & $\begin{array}{l}\text { Sample documents and packets for } \\
\text { training }\end{array}$ & - & - & - \\
\hline NIST & $\begin{array}{l}\text { Would like to see mentoring required } \\
\text { in science positions }\end{array}$ & - & - & - & $\begin{array}{l}\text { New mindset among younger scientists is driving change. Not } \\
\text { sure where this will lead }\end{array}$ \\
\hline NOAA & - & - & - & - & $\begin{array}{l}\text { There is concern that lab-level committees are not adequate and } \\
\text { that agency-level committees do not have the expertise to } \\
\text { evaluate scientists. They are working on a pilot for an RGE- } \\
\text { type process }\end{array}$ \\
\hline ARL & - & No training & - & - & $\begin{array}{l}\text { Observation: women are leaving research roles for management. } \\
\text { No explanation yet }\end{array}$ \\
\hline
\end{tabular}





\section{Appendix 5A. Research Scientist Record Template \\ U.S. GEOLOGICAL SURVEY \\ Research Scientist Record}

This template is used by U.S. Geological Survey (USGS) scientists whose positions are classified on the basis of a work assignment that is more than 25 percent directed to research activities. These positions are subject to the Research Grade Evaluation (RGE) process to determine the appropriate position classification level as the scientist moves from entry level to full performance level (GS-15; that is, grade 15 of the General Schedule described by the Classification Act of 1949 for Federal civilian employees). The RGE process is defined in the U.S. Office of Personnel Management's (OPM's) "Research Grade Evaluation Guide" of 2006 (RGE Guide). Instructional information in blue should be removed in final document.

\section{PART I. BACKGROUND INFORMATION}

Name:

Date Prepared:

Cost Center:

Region or Mission Area:

Classification Title, Series, and Grade:

Date of Entrance to Federal Service:

Date of Last Promotion:

Date of Last Research Grade Evaluation by a Peer Review Panel:

Supervisor:

Provide up to five keywords that characterize your research:

\section{WORK ENVIRONMENT}

(Limit 1 page) The first sentence in this paragraph should explain where the position is located organizationally and include the duty station, if different from the location of the organization. Example: The position is located in the Hydrological Services Division of the Regional Office. The incumbent serves as primary investigator or project chief for complex, multiyear hydrologic studies.

In addition, provide a concise description of the purpose of the position and your work environment. Include collaboration and major sources of funding, if relevant.

If applicable, document other major (non-research) responsibilities or assignments and include the percentage of time spent on such duties. Such duties may include the following:

- Technical assistance related to the assignment; committee assignments; technology transfer; consultations

- Facility or laboratory management (including compliance with the U.S. Geological Survey Quality Management System (QMS))

- Special assignments (for example, safety officer responsibilities)

- Substantive supervisory duties (for example, supervising staff in an organizational unit) 


\section{TOP THREE CONTRIBUTIONS}

(Limit 1 page) Briefly describe what you consider to be your top three contributions. Tie each to the relevant factor or factors (see below for factor descriptions). Note: there will be space in the factor narratives to elaborate on these contributions. Listing them upfront is intended to set the stage for reviewing the factor narratives.

\section{PART II. FACTOR NARRATIVE STATEMENTS}

Each of these four narratives addresses one of the four factors that are scored in this process. Researchers are strongly urged to read OPM guidelines, including scoring guidelines, to understand what is being evaluated for each factor. These begin on page 8 of the OPM RGE Guide.

\section{Factor 1. Research Assignment}

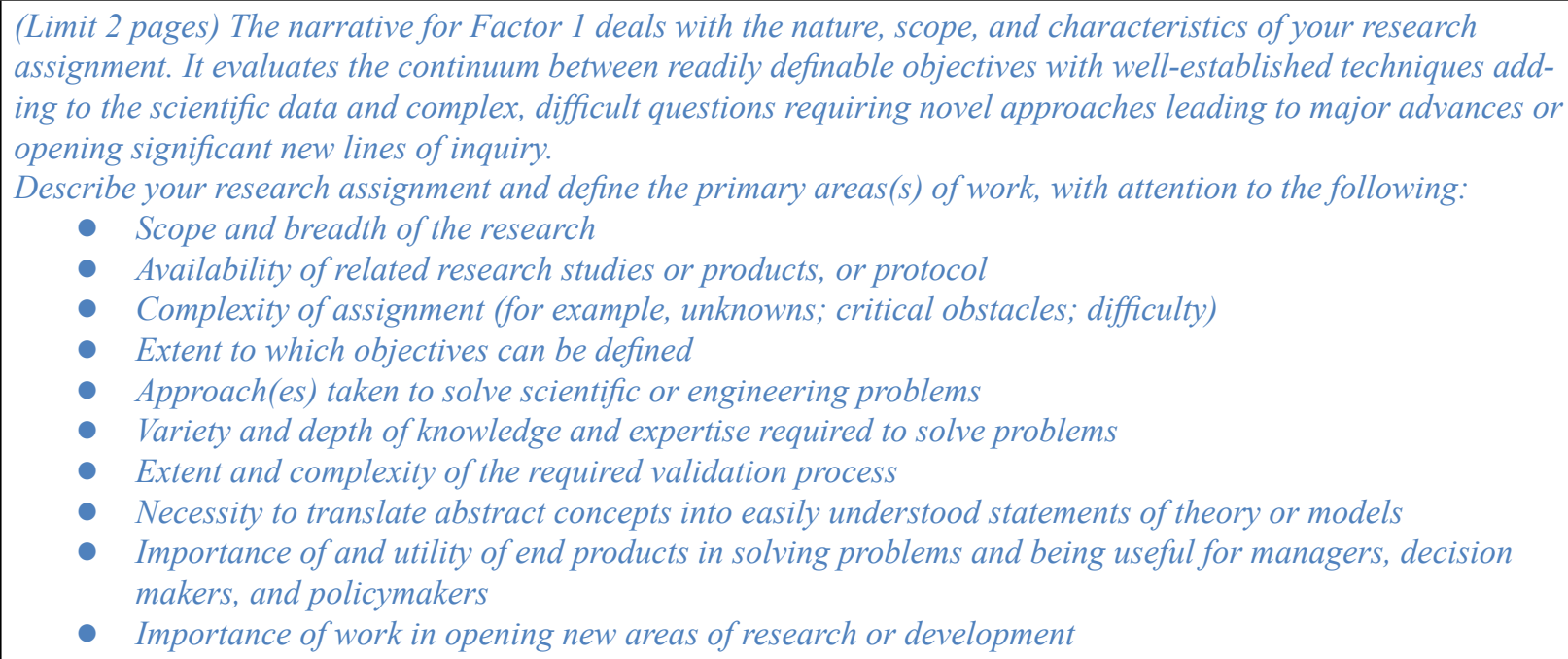

Do not describe each individual study or project but rather focus on the major themes of your research program. Individual study/project titles and funding sources can be listed in appendix A of this Research Scientist Record and can be referenced in the narrative.

\section{Factor 2. Supervisory Controls}

(Limit 1 page) The narrative for Factor 2 addresses your level of independence. Do you work on projects as assigned under close supervision, which is where most everyone starts, or do you define and pursue your own research projects with little or no supervisory control?

Describe your relationship with your supervisor and your current level of independent performance. Specify the following:

- Your supervisor's role (for example, science center director, supervisory scientist)

- How work is assigned (for example, consider the nature of guidance provided, employee's freedom in choosing a course of action)

- How independently work is performed

- Technical and administrative guidance and control exercised by supervisor

- How work is reviewed and the acceptance of your research results, conclusions, and final products

- Freedom to represent your research program to other organizations and agencies, policymakers, and the public

Use caution in distinguishing between consultation and supervisory control and guidance. 


\section{Factor 3. Guidelines and Originality}

(Limit 2 pages) The narrative for Factor 3 speaks to the originality of the research you are engaged in. Are you applying well-known techniques and procedures or adapting old methods to new problems or creating an entirely new protocol to attack a research problem?

Describe the creative thinking, analysis, synthesis, evaluation, judgment, resourcefulness, and insight needed to perform your work. Identify existing scientific guides (or knowledge) and indicate the degree of applicability (for example, how available or useful are technical handbooks, periodicals, reports, patent disclosures, guidance from technical specialists?). Also describe the intrinsic difficulty in applying available guides to your current assignment.

Address the following topics:

- Original and independent creation of research subjects, analysis, reasoning, evaluation, and judgment

- Originality in interpreting findings and translating findings into a form usable by others

Describe originality (for example, technical judgment, creativity, resourcefulness) needed to fill in, adapt, or extend theories, methods, and techniques.

If you use established techniques for your field, describe how you are applying those techniques to complex and original questions or problems.

Reference information contained in appendixes as appropriate.

\section{Factor 4. Contributions, Impact, and Stature}

(Limit 6-8 pages) The narrative for Factor 4 is the largest piece to the evaluation, and it addresses your research contributions, the impacts of your research, and your stature as a researcher or expert in your field.

When describing your contributions, do not simply state that you have produced $x$ number of scientific papers and do not list every single paper here (use appendixes B and C of this Research Scientist Record for these lists). Instead, describe how your work has contributed to your scientific field and society. Focus on outcomes, rather than outputs. Use examples from the products listed in the appendixes to support your description.

When describing the impact of your work, include how your work has had an impact on scientific and (or) societal issues; if your work has set new research directions for yourself or others; if you have developed new methods, techniques, or tools to be used by others; and how your work has driven management or policy outcomes. You may reference papers or presentations and other supporting materials included in the appendixes. Note that appendix E of this Research Scientist Record offers a place to put a wide variety of materials that may speak to your impact and stature.

When describing your stature, provide evidence of stature such as requests for expert advice or consultation by other professionals or managers; requests to exercise leadership on research teams or projects; invitations to serve on advisory boards or to lead committees, workshops, and symposia; invitations to present your work or address scientific or professional organizations; recognition by other professionals or groups; and honors or awards. Reference information contained in appendixes as appropriate.

\section{PART III. REFERENCES}

List name and contact information for your supervisor and center director and other references (five or more are recommended) for use by the primary reviewer. Select peers, cooperators, and end users who can support your leadership, impact, and stature as described in the above narratives. 


\section{PART IV. APPENDIXES}

You are encouraged to number the items listed in the appendixes so that you can easily refer to them in the text; for example, A1, A2, B1, B2, and so on. Only include appendixes relevant to you, but do not change the letter please.

A. List of Active or Recently Completed (Since Last Review) Projects; include title, funding source, amount, and dates

B. Bibliography

Published reports

Papers approved for publication; they must have approval by the Bureau approving official (BAO)

Unpublished technical reports

C. Presentations

Invited presentations

Contributed presentations since last promotion

D. Letters of Support; limit of five

E. Exhibits (such as testimonials, recognitions, media coverage)

F. Awards (include descriptions 1-2 sentences long)

G. Editorships, Review Panels/Boards, Peer Reviews

H. Technical Training or Consultation Provided

I. Academic Service

Academic appointments

Seminars

Courses taught

Students advised

J. Outreach and Social Media 


\title{
Appendix 5B. Findings Template for Use After Review of a Research Scientist Record (RSR)
}

\author{
U.S. GEOLOGICAL SURVEY \\ Research Scientist Record-Findings
}

Scientist:

Current Position, Series, and Grade:

Peer Group:

Panel Date:

\begin{tabular}{|c|c|c|c|}
\hline Panel consensus scores & Factor score range & Point values & Grade \\
\hline Factor 1 & $2-10$ & $8-14$ & GS-11 \\
\hline Factor 2 & $2-10$ & $16-24$ & GS-12 \\
\hline Factor 4 & $4-20$ & $36-44$ & GS-14 \\
\hline Total score & & $46-54$ & GS-15 \\
\hline
\end{tabular}

The panel's total consensus score of is equivalent to grade

Instructions: In evaluating a Research Scientist Record, the peer review panel members assign points for Factors 1-4 as described in the Research Grade Evaluation Guide (OPM, 2006).

\section{Factor 1. Research Assignment}

Insert finding here, with specific language: Findings must provide the reasons, with specific examples, on why the panel reached a specific factor level based on the RSR, and why the next higher factor score was not reached.

\section{Factor 2. Supervisory Controls}

Insert finding here, with specific language: Findings must provide the reasons, with specific examples, on why the panel reached a specific factor level based on the RSR, and why the next higher factor score was not reached.

\section{Factor 3. Guidelines and Originality}

Insert finding here, with specific language: Findings must provide the reasons, with specific examples, on why the panel reached a specific factor level based on the RSR, and why the next higher factor score was not reached.

\section{Factor 4. Contributions, Impact, and Stature}

Insert finding here, with specific language: Findings must provide the reasons, with specific examples, on why the panel reached a specific factor level based on the RSR, and why the next higher factor score was not reached. 


\section{Appendix 5C. Development Scientist Record Template \\ U.S. GEOLOGICAL SURVEY \\ Development Scientist Record}

This template is used by U.S. Geological Survey (USGS) scientists whose positions are classified on the basis of a work assignment that is more than 25 percent directed to development. These positions are subject to the Equipment Development Grade Evaluation (EDGE) process to determine the appropriate position classification level as the scientist moves from entry level to full performance level (GS-15; that is, grade 15 of the General Schedule described by the Classification Act of 1949 for Federal civilian employees). The EDGE process is defined in the U.S. Office of Personnel Management's (OPM's) "Equipment Development Grade Evaluation Guide” of 1968 (EDGE Guide). Instructional information in blue should be removed in final document.

\section{PART I. BACKGROUND INFORMATION}

Name:

Date Prepared:

Cost Center:

Region or Mission Area:

Classification Title, Series, and Grade:

Date of Entrance to Federal Service:

Date of Last Promotion:

Date of Last Equipment Development Grade Evaluation by a Peer Review Panel:

Supervisor:

Provide up to five keywords that characterize your development assignment: 


\section{WORK ENVIRONMENT}

(Limit 1 page) The first sentence in this paragraph should explain where the position is located organizationally and include the duty station, if different from the location of the organization. Example: The position is located in the Hydrological Services Division of the Regional Office. The incumbent serves as primary investigator or project chief for complex, multiyear hydrologic studies.

In addition, provide a concise description of the purpose of the position, and your work environment. Include collaboration and major sources of funding, if relevant. It is also appropriate in this section to talk about structural factors in your center that impact your development role. For example: how a person interacts with supervisor, how a center assigns projects and project leads, and similar things may inform the panel about your development role.

If applicable, document other major (nondevelopment) responsibilities or assignments and include the percentage of time spent on such duties. Such duties may include the following:

- Technical assistance related to the assignment; committee assignments; technology transfer; consultations

- Facility or laboratory management (including compliance with the U.S. Geological Survey Quality Management System (QMS)

- Special assignments (for example, safety officer responsibilities)

- Substantive supervisory duties (for example,. supervising staff in an organizational unit)

\section{TOP THREE CONTRIBUTIONS}

(Limit 1 page) Briefly describe what you consider to be your top three contributions. Tie each to the relevant factor or factors (see below for factor descriptions). Note: there will be space in the factor narratives to elaborate on these contributions. Listing them upfront is intended to set the stage for reviewing the factor narratives. 


\section{PART II. FACTOR NARRATIVE STATEMENTS}

Each of these four narratives addresses one of the four factors that are scored in this process. Development scientists are strongly urged to read the OPM EDGE Guide, with the understanding, of course, that the guidelines from 1968 are wildly out of date.

\section{Factor I. Nature of the Assignment}

(Limit 2 pages) The narrative for Factor I deals with the nature, scope and characteristics of current work being undertaken by the incumbent. In the case of a team leader, a level should be credited which reflects the scope and character of projects being conducted by the leader's team. In the case of a team member, the level should be based not on the total projects carried by the team, but upon the specific projects, or portion of the team, carried by the incumbent.

Describe your development assignment and define the primary areas(s) of work, with attention to the following:

- The variety and intensity of knowledge required to achieve solutions with reference to the depth of investigation required and the difficulty involved in overcoming obstacles

- The degree to which the problem has been isolated and defined

- The number and nature of variables or elements involved (for example, unknowns, critical obstacles, difficulty)

- The extent to which objectives can be defined

- Approach(es) taken to solve scientific or engineering problems

- The variety and depth of knowledge and expertise required to solve problems

- The intrinsic difficulty of techniques employed or necessity to develop or modify techniques

- The necessity to translate abstract concepts into easily understood statements of theory or models

- The importance of and utility of end products in solving problems and being useful for managers, decision makers, and policymakers

- The importance of work in opening new areas of research or development

In considering the expected end product of the development effort, the impact of the results on scientific theory and engineering practice may be of significance. Also important are these considerations:

- The extent and complexity of the required validation processes

- The necessity for converting abstract concepts into hardware or into easily understood statements of theory

- The effectiveness of the product in solving other problems and in opening new areas of investigation

Do not describe each individual study or project but rather focus on the major themes of your development program. Individual titles and funding sources can be listed in appendix A of this Development Scientist Record and can be referenced in the narrative. 


\section{Factor II. Supervision Received}

(Limit 1 page) The narrative for Factor II deals with the supervisory guidance and control exercised over the position. Much care is required to evaluate this factor. In experimental development, a considerable amount of effective supervision may exist with only a minimum of formal supervisory contact. On the other hand, consultation with colleagues is essential to maximum effectiveness of employees at all levels and should be distinguished from supervision.

Describe your relationship with your supervisor and your current level of independent performance. Specify the following:

- Your supervisor's role (for example, science center director, supervisory scientist)

- How work is assigned (for example, consider the nature of guidance provided, employee's freedom in choosing a course of action)

- How independently work is performed

- Technical and administrative guidance and control exercised by supervisor

- Degree to which you are able to bring resources (money, personnel) to projects

- How work is reviewed and the acceptance of your results and final products

- Freedom to represent your results and products to other organizations and agencies, policymakers, and the public

Use caution in distinguishing between consultation and supervisory control and guidance.

\section{Factor III. Guidelines and Originality}

(Limit 2 pages) The narrative for Factor III reflects the degree to which (1) guidelines are available and useful and (2) innovations in concepts, methods, and interpretations are involved in the assignment.

Describe the creative thinking, analysis, synthesis, evaluation, judgment, resourcefulness, and insight needed to perform your work. Identify guidance and indicate the degree of applicability (for example., how available or useful are technical handbooks, reports, patent disclosures, guidance from technical specialists?). Also describe the intrinsic difficulty in applying available guides to your current assignment.

Address the following topics:

- The degree of technical judgment, intuition, and insight required to fill in, adapt. or extend theories, methods, and techniques

- The level of experience required to adapt a new technique or use a new theory when the application and results are similar to existing ones

- The level of judgment required to apply existing techniques or theories when their use is risky and the results are inconclusive

Describe originality (for example, technical judgment, creativity, resourcefulness) needed to fill in, adapt, or extend theories, methods, and techniques.

If you use established techniques for your field, describe how you are applying those techniques to complex and original questions or problems.

Reference information contained in appendixes as appropriate. 


\section{Factor IV. Qualifications and Contributions}

(Limit 6-8 pages) The narrative for Factor IV is the largest piece to the evaluation, and it addresses your contributions and the impacts of your development projects and products.

When describing your contributions, do not simply state you have produced $x$ number of scientific papers and do not list every single paper here (use appendixes B and C of this Development Scientist Record for these lists). Instead, describe how your work has contributed to your scientific field and society. Use examples from the products listed in the appendixes to support your description.

The degrees of Factor IV are expressed in part in terms of contributions and recognition in a specialized field. In some situations, security regulations or other circumstances prevent publication of development results. Thus, it may be impossible to evaluate the work on the basis of its impact on the larger engineering and scientific community. In such cases, the work must be evaluated by means of the best possible judgment of its importance and the impact it has as a technological or development accomplishment for a specific project or program. In some cases, there may be impact on the agency's overall development program or mission.

When describing the impact of your work, include how your work has had an impact on scientific and (or) societal issues; if your work has set new research directions for yourself or others; if you have developed new methods, techniques, or tools to be used by others; and how your work has driven management or policy outcomes. You may reference papers or presentations and other supporting materials included in the appendixes. Note that appendixes D-G of this Development Scientist Record offers a place to put a wide variety of materials that may speak to your impact and stature.

When describing your stature, provide evidence of stature such as requests for expert advice or consultation by other professionals or managers; requests to exercise leadership on development teams or projects; invitations to serve on advisory boards or to lead committees, workshops, and symposia; invitations to present your work or address scientific or professional organizations; recognition by other professionals or groups; and honors or awards. Reference information contained in appendixes as appropriate.

\section{PART III. REFERENCES}

List name and contact information for your supervisor and center director and other references (five or more are recommended) for use by the primary reviewer. Select peers, cooperators, and end users who can support your leadership, impact, and stature as described in the above narratives. 


\section{PART IV. APPENDIXES}

You are encouraged to number the items listed in the appendixes so that you can easily refer to them in the text; for example, A1, A2, B1, B2, and so on. Only include appendixes relevant to you, but do not change the letter please.

A. List of Active or Recently Completed (Since Last Review) Projects; include title, funding source, amount, and dates

B. Bibliography

Published reports

Papers approved for publication; they must have approval by the Bureau approving official (BAO)

Unpublished technical reports

C. Presentations

Invited presentations

Contributed presentations since last promotion

D. Code and Data Products

E. Inventions and Patents

F. Letters of Support; limit of five

G. Exhibits (such as testimonials, recognitions, media coverage)

H. Awards (include descriptions 1-2 sentences long)

I. Editorships, Review Panels/Boards, Peer Reviews

J. Technical Training or Consultation Provided

K. Academic Service

Academic appointments

Seminars

Courses taught

Students advised

L. Outreach and Social Media 


\title{
Appendix 5D. Findings Template for Use After Review of a Development Scientist Record (DSR)
}

\author{
U.S. GEOLOGICAL SURVEY \\ Development Scientist Record-Findings
}

Scientist:

Current Position, Series, and Grade:

Peer Group:

Panel Date:

\begin{tabular}{lccc}
\hline Panel consensus scores & Factor score range & Total point values & Grade \\
\hline Factor I & $1-5$ & $4-6$ & GS-9 \\
Factor II & $1-5$ & $8-11$ & GS-11 \\
Factor III & $1-5$ & $13-16$ & GS-12 \\
Factor IV & $2-10$ & $18-21$ & GS-13 \\
$\quad$ Total score & & $23-26$ & GS-14 \\
& & 28 and above & GS-15 \\
\hline
\end{tabular}

The panel's total consensus score of is equivalent to grade

Instructions: In evaluating a Development Scientist Record, the peer review panel members assign points for Factors I-IV as described in the Equipment Development Grade Evaluation Guide (OPM, 1968).

\section{Factor I. Nature of the Assignment}

Insert finding here, with specific language: Findings must provide the reasons, with specific examples, on why the panel reached a specific factor level based on the DSR, and why the next higher factor score was not reached.

\section{Factor II. Supervison Received}

Insert finding here, with specific language: Findings must provide the reasons, with specific examples, on why the panel reached a specific factor level based on the DSR, and why the next higher factor score was not reached.

\section{Factor III. Guidelines and Originality}

Insert finding here, with specific language: Findings must provide the reasons, with specific examples, on why the panel reached a specific factor level based on the DSR, and why the next higher factor score was not reached.

\section{Factor IV. Qualifications and Contributions}

Insert finding here, with specific language: Findings must provide the reasons, with specific examples, on why the panel reached a specific factor level based on the DSR, and why the next higher factor score was not reached. 


\section{Appendix 5E. Cover Sheet for Research Scientist Record (RSR) or Development Scientist Record (DSR)}

\section{U.S. GEOLOGICAL SURVEY \\ Cover Sheet for a \\ Research Scientist Record (RSR) or Development Scientist Record (DSR)}

I certify that my RSR or DSR was prepared in accordance with U.S. Geological Survey (USGS) guidelines and is a complete and accurate representation of my research or development work and that I adhere to the Bureau's ethics and scientific integrity guidelines.

I understand that if the RSR or DSR does not conform to USGS guidelines, the RSR or DSR will be set aside and will not be reviewed until the information is provided. This issue will delay review.

Name:

Signature:

Date:

I have reviewed the RSR or DSR.

Supervisor

Name:

Email:

Phone:

Signature:

Date:

\section{Center Director}

Name:

Email:

Phone:

Signature:

Date: 


\section{Appendix 5F. Guidelines for Scoring in Excess of Level E Scoring in Excess of Level $\mathrm{E}$}

The U.S. Office of Personnel Management's (OPM's) Research Grade Evaluation Guide of 2006 (RGE Guide) provides scoring guidance up to the GS-15 level. However, scores above level E are required for a scientist to be eligible for a senior scientist (ST) position. By law, agencies must properly classify ST positions, and agency heads are responsible for establishing qualification standards for senior-level positions. The U.S. Geological Survey (USGS) has developed standards for scoring above level E. The below standards for each factor describe a level of $\mathrm{G}$ which is the highest score level available in the USGS. No criteria are provided for a level F. As with the lower scoring levels as described in the RGE Guide, a panel should assign level F when work falls between levels $E$ and G. For example, if the peer review panel's assessment is that work exceeds level $E$ criteria but does not fully satisfy level $\mathrm{G}$ criteria, then the work is awarded level $\mathrm{F}$ and 12 points for Factors 1-3 or 24 points for Factor 4.

\section{Factor 1. Research Assignment—Level G (14 Points)}

Research assignments at level $\mathrm{G}$ have the following characteristics:

- The researcher is responsible as a team leader for formulating and tackling broad-scale critical problems of national or international scope and importance

- The researcher is responsible for addressing basic research problems of such fundamental interest and extraordinary difficulty that projects influence planned activities of numerous scientists in government, academic institutions, and private industry

- Projects are pushing frontiers in several areas of science that are above level $\mathrm{E}$

- New hypotheses, concepts, and techniques must be developed for approach and interpretation, frequently challenging existing theory with irrefutable insights on processes or phenomena studied

- The assignment and leadership exercised influence the shaping of agency program goals, advancement of programs, and understanding of the total field

- Results should be a series of contributions to the field that clearly demonstrate over a substantial period that effectiveness of the research is recognized to lead in defining the area under study or the field of science as a whole

\section{Factor 2. Supervisory Controls-Level G (14 Points)}

The supervisory relationship for scientists at level $\mathrm{G}$ has the following characteristics:

- The supervisory relationship fully reflects recognition of the researcher as a top authority in the field internationally and as a distinguished and extraordinary scientist

- Technical supervision is nonexistent and administrative oversight is cursory

- There are few if any bounds on the development of the research, and the research influences the direction of the organization's overall technical program

- There is a degree of confidence in and reliance on the researcher's productivity, competence. and judgement, such that there is an unusual level of support for recommendations, as well as for most novel and as-of-yet unproven investigations

- Interpretations, recommendations, and conclusions having major impacts on matters of great urgency and significance are furnished to other agencies and the professional community 


\section{Factor 3. Guidelines and Originality—Level G (14 Points)}

At level G, guidelines, pertinent literature, and methodology descriptions do not exist for the researcher's pioneering projects.

Originality is demonstrated by the following conditions:

- Work by the researcher is characterized by the application of such unusual productivity, creativity, and depth of insight into the fundamental nature of phenomena and their relationships as to produce a substantial variety of new methods and techniques, new approaches to formerly intractable problems, identification of new problems to be attacked, and important new concepts and discoveries

- New areas are opened up for exploration; the findings may have applicability to other fields of science and technology; and there is likely to be a major stimulus to scientific and technological effort and achievement in the researcher's field of endeavor

\section{Factor 4. Contributions, Impact, and Stature-Level G (28 Points)}

At level G, contributions and impacts are demonstrated by the following accomplishments:

- The researcher has demonstrated outstanding leadership in a broad field of research that has influenced significantly the advancement of agency programs and the planned activities of numerous scientists in other agencies, academic institutions, and private industry

- Contributions by the researcher are of such importance and magnitude that they help to shape agency program goals and serve to move the art forward to the extent that they have widespread applicability to other fields of science and technology

- The researcher has made at least one of the following contributions:

- Authored a number of seminal publications that have had a major impact on advancing the field and that are accepted as definitive of important areas of it

- Made major discoveries that have solved problems of great importance to the international scientific community, the agency, or the public. Scientific contributions have had a widespread application to other fields

Stature is demonstrated by the following accomplishments:

- The researcher is an internationally recognized authority and leader in an area of broad scientific interest and investigations; typically has received honors from major organizations for accomplishments; and is sought as an advisor and consultant on scientific and technological programs that extend well beyond the researcher's own field

- The researcher has acted as a nexus for those seeking to expand their knowledge of the field, learn critical thinking skills and research techniques, and apply scientific knowledge to management, policy, and strategic investment

- The researcher's personal competence is likely to be a major consideration in agency sponsorship of programs in the researcher's field

- The researcher has demonstrated professional courtesy, equity, integrity, honesty, objectivity, and fairness in all activities and has shown unselfish cooperation in advancing agency goals 


\title{
Appendix 5G. Findings Form for Scientist Considered for Promotion to Senior Scientist (ST)
}

\author{
U.S. GEOLOGICAL SURVEY \\ Findings Form for Scientist Considered for \\ Promotion to Senior Scientist (ST)
}

The text below demonstrates how strengths and weaknesses could be described for an applicant being considered for promotion to a senior scientist (ST) position. The information could be written by the ST Evaluation Committee for the U.S. Geological Survey Director. It could also be provided as feedback to the applicant. The ST Evaluation Committee is being proposed for the updated evaluation process in the USGS.

\section{Scientific Leadership}

Strength: XX's productivity and impact were very impressive until 2015, and it is clear that the scientist's work has substantially impacted wildlife ecology. During his or her career, XX defined and influenced the direction of wildlife ecology nationally and internationally by writing seminal papers that are widely cited and used by land managers. XX is still consistently invited to give departmental and international seminars, which indicates the stature of XX in the field of wildlife ecology.

Weakness: Since 2015, there has been little scientific productivity, including service on committees and review panels, and thus XX has had limited impact.

\section{Mentoring}

Strength: $\mathrm{XX}$ is an excellent mentor of scientists in developing countries when conducting research and writing papers with them.

Weakness: XX has advised only two early-career scientists for a short time and has not advised any students during his or her 30-year career. XX has also not written reference letters or honor nominations and has not appeared to use his or her network to facilitate career development. Overall, his or her contribution to mentoring has been very limited.

\section{Scientific Society Membership}

Strength: $\mathrm{XX}$ is a member of several scientific societies relevant to his or her career. XX has substantially contributed to the direction of these by being on their governing boards, serving as president of the xxx society, and participating on various committees throughout his or her career.

Weakness: None.

\section{U.S. Geological Survey (USGS), U.S. Department of the Interior (DOI), and U.S. Government Service}

Strength: XX has participated in writing two strategic plans for his or her science center.

Weakness: XX has not contributed substantially to any USGS, DOI, or U.S. Government service at the regional or national level. 


\title{
National-Level External Panels or Advisory Committees
}

\author{
Strength: None.
}

Weakness: XX has never served on any national-level external panels or scientific advisory committees.

\section{Influencer}

Strength: In the past, XX has clearly been an influencer in the field of wildlife ecology. He or she has had many collaborators, citations, and invitations to speak at meetings and at a variety of institutions nationally and internationally; these experiences are evidence that other scientists have sought his or her expertise.

Weakness: XX has had very few collaborators in the past 4 years. Few people seem to now be seeking his or her expertise. XX has not applied his or her knowledge of wildlife ecology to management, policy, or strategic investment and has not helped to set strategic directions in wildlife ecology within and outside the USGS.

\section{Science Communication}

Strength: XX is an excellent speaker and communicates science well to other scientists.

Weakness: XX shows little evidence of communicating his science to other audiences outside academia, such as land managers and the lay public, despite his or her research field being of high interest and relevance to both. XX has not represented USGS science to outside groups including national media interviews.

\section{Ethics}

Strength: XX has never been found in violation of USGS ethics or scientific integrity policies. XX is a generous coauthor, ensuring appropriate credit to collaborators.

Weakness: None.

\section{Summary}

XX's past scientific record has been one of high productivity, and XX has clearly been a major influencer in his or her field; however, there has been little activity in this regard in the past 4 years, and this change is a concern. Similarly, while XX's work has been highly relevant to his or her subfield of wildlife ecology, he or she has shown few direct contributions to research, policy, and management beyond this field and it is suggested XX reach beyond the boundaries of his or her subfield. XX's mentoring has been limited to his or her own research projects when overseas, and he or she is encouraged to start working with younger scientists. XX's substantial contribution to science through participation in scientific societies is to be commended and it is suggested he or she contribute in a similar fashion to USGS and DOI activities at the regional and national levels. XX has demonstrated high ethical standards throughout his or her career. XX is also encouraged to use his or her excellent reputation in the wildlife ecology world to inspire and educate scientists, managers, and policymakers worldwide on global, broad scientific issues through various media outlets. 


\section{Appendix 5H. Standard Reviewer Questions for References U.S. GEOLOGICAL SURVEY
Standard Reviewer Questions for References}

The primary and secondary reviewers should use these questions to ensure that the Research Grade Evaluation (RGE) system is consistent across disciplines and panels in the U.S. Geological Survey. Additional and followup questions are acceptable. The reviewers shall contact the scientist's supervisor, center director, and at least two other references. In addition, the reviewers should take written notes on the reference's responses.

1. How long have you known the scientist?

2. In what capacity do you know the scientist?

3. Can you briefly describe the scope and breadth of the scientist's work? (Factor 1)

4. Does the scientist typically work as an individual principal investigator (PI), a member of a research team, or a team leader? How effective is the scientist in these roles? (Factors 1 and 2)

5. For supervisor or center director: To what degree does the scientist have the ability to define and execute his or her research agenda? (Factor 2)

6. How would you characterize the complexity, difficulty, and challenges of the work of the scientist? (Factor 3)

7. How does the scientist show originality in his or her work? To what extent does the scientist's work require the development of new approaches, techniques, and methods? Can you provide examples? (Factor 3)

8. Please describe the overall impact of the work of the scientist to the following parties (Factor 4):
a. Scientific community
b. Resource managers
c. Industry
d. Policymakers
e. Society

9. Please describe how the scientist demonstrates leadership in the following circumstances (Factor 4):
a. When working on research projects
b. When working as a member of research teams
c. When working with information users (such as resource managers, policymakers, industry)
d. When working with students, junior scientists, peers, and leadership
e. When interacting with the scientific community

10. Can you share any perspectives on how the scientist mentors and trains students and early career scientists? (Factor 4)

11. Can you provide any information about the scientist's service to the scientific community, the USGS, and others? (Factor 4)

12. How would you describe the scientist's standing and reputation in your field and your organization and at national and international levels? Please provide specific examples. (Factor 4)

13. Can you provide any examples of how the scientist's work or leadership has been applied in policy or management contexts? (Factor 4)

14. How have you used the work of the scientist? (Factor 4)

15. In what ways has the scientist's work helped to advance his or her field? Have you seen other scientists building on the work of the scientist? (Factor 4)

16. In what area(s) does the scientist have opportunities for growth and development? (all Factors 1-4)

17. Does the scientist make nonscientific contributions to the field, to the science center, and to the USGS? (Factor 4)

18. Have you observed the scientist demonstrating moral and ethical leadership when working with junior staff and scientists, peers, agency leadership, or stakeholders? (general)

19. Do you have anything else you'd like the peer review panel to know when reviewing the scientist? (all

Factors 1-4) 


\section{Appendix 6. Report on Beta Test of the Recommended New Formats for the Research Scientist Record and Findings Templates and Processes Used by Peer Review Panels}

\section{Introduction}

In the fall of 2018, the Research Grade Evaluation Review Team (RGE Review Team) of the U.S. Geological Survey (USGS) conducted a beta test of the recommended new formats for the Research Scientist Record (RSR) and findings templates and the processes used by peer review panels. We invited scientists subject to RGE processes to volunteer either to create an RSR in the proposed new format or to serve on a beta test panel. Sixteen scientists submitted beta RSRs, and all of these were submitted to RGE peer review panels for evaluation. An additional five scientists formed a beta test panel to evaluate the RSRs with all the new processes, and 5 of the 16 beta RSRs were evaluated by this panel. All of the volunteers understood that this was a mock process and results were not official. The remaining beta RSRs were evaluated in regular peer review panels.

Two surveys were conducted to collect reactions to the test RSR and findings templates: one to the authors of the test RSR packets and one to panel members who reviewed the test packets and provided responses in the test findings template, both in the mock panel and in the regular panels that evaluated the beta RSRs. The RGE coordinators from the USGS Office of Scientific Quality and Integrity (OSQI) also collected verbal assessments during panel review of the test packets.

\section{Beta RSR Results}

Overall, the responses received from the scientists submitting the RSRs in the beta format and the panel members reviewing the beta packets were mostly positive. Relative to the current format for RDSRs (Research and Development Scientist Records), all test RSR respondents rated the test format either about the same or much better.

To determine reactions to the RGE process, respondents were asked to quantify their experience submitting an RSR for evaluation and their experience serving on an RGE review panel. All respondents who submitted a beta RSR had completed at least one RDSR in the past and were therefore familiar with the old format. Fifty percent of respondents had served on at least one panel in the past, whereas 50 percent had never served on a panel. Of the panel members who submitted responses about reviewing the test RSRs, 58 percent had served on at least one panel, and 83 percent had experience writing and submitting an RDSR for review.

\section{Factor Narratives}

Because the most significant change to the RSR format required the research scientist to address each factor in a narrative format, both groups surveyed - scientists who submitted test RSR packets and test packet reviewers - were asked to comment on that change. Several of the test RSR authors expressed concerns with this new approach, but the majority were in favor of this change. Similarly, the majority of the test packet reviewers found the new format to be an improvement over the old format, but a few respondents had concerns. Below are the most common advantages and disadvantages of the four-factor narrative approach as reported by the respondents:

Pros:

- Gives the research scientists a chance to show how they see their work fitting into the four factors

- Allows research scientists to address the definitions of each factor and cite relevant examples

- Straightforward and intuitive

- Less redundant

- Page limits

- Easier to score

Cons:

- Large amount of overlap between sections (factors)

- Difficult to write outside of the structure of going project by project

- Less substance showing the accomplishments of the scientists. More opinion and less science objectives and accomplishments

- A lot of information appeared to be missing (compared to the previous format) and the reviewer had to conduct more research to fill in the blanks

- Difficult to understand supervisory control and independence (factor 2) 
- Easier for research scientists to inflate their accomplishments. Reviewers spent more time verifying the narrative content

\section{Recommendations:}

- Provide training and exemplar RSRs to help scientists successfully convert to the narrative format

- Have two reviewers (primary and secondary) conduct the interviews with the references. Contact more references. Include guidelines in the scientist training on whom to select as a reference. Include guidelines in panel training on best ways to interview references

- Enforce limits on the number of pages that can be written for each factor

- Add requirement for research scientist to include citations from appendixes for each statement in the narrative in order to help with cross-referencing

- For factor 2, clarify via training and RSR instructions that this factor does not include the scientist's history of supervising others

\section{Supporting Materials}

Both surveys included a question regarding supporting materials (appendixes) and whether they adequately reflect the writer's impact, stature, and contributions. Although the majority of both groups surveyed felt the content of the appendixes was adequate, there were several suggestions for improvement:

\section{Recommendations:}

- Include the previous requirement to include top three publications, products, or contributions

- Retain the requirement to include the amount contributed to the paper. Consider moving away from percentages and implementing ranges or categories to get away from the precision of providing a percentage

- Include a category in the appendixes that focuses on social media achievements

- Include a category in the appendixes that focuses on software and data products

- Include a category on outreach

\section{Guidance and Training}

The research scientists submitting the test RSR were given little guidance on completing the RSR in the test format. When surveyed, they were asked what additional guidance and training were needed, if any. Below are the recommendations received:

\section{Recommendations:}

- Provide an example RSR

- Provide more guidance on the format and structure of factors 3 and 4

- Alert research scientists well ahead of time of the requirement to list their funding sources so they can begin tracking them

- Include timeframe to consider, for example, entire career, USGS time, time since last promotion, for each section

\section{Overall Format and Other Recommendations}

Respondents for both surveys were asked to provide thoughts on other improvements to the test RSR format outside the topics mentioned above. Below are recommendations regarding overall RSR formatting and other topics:

\section{Recommendations:}

- Include a section for education, similar to that included in the old RDSR format

- Include a section for the scientist to include professional and work experience, similar to what was included in the old RDSR format

- Add page numbers to template

- Insert breaks between sections

- Enforce page limits

- Add "Seeking conversion to RGE/EDGE" near the beginning of the template under "PART I: BACKGROUND INFORMATION"

- Label the parts alphabetically instead of numerically (that is, change "PART I" to "PART A") to eliminate the confusion between the parts and the factors 


\section{Test Findings Template}

All panel members who reviewed an RSR in the new format were asked to use the new test findings template for their evaluation. They were then asked what they thought of the new findings template. Thirteen panel members responded to the survey. Of the 13 responses, 11 were from respondents who had previously submitted an RDSR for evaluation and 8 were from respondents who had previously served on an RGE peer review panel.

Of the panel members who responded to the survey, 61.5 percent were the primary reviewers of a test RSR packet and provided panel results using the test findings template. The remaining respondents did not write the comments in the findings template but participated in panel discussions and scoring of the test RSR, and approved of the information entered in the findings template.

Panel members were asked to rate the current and the test findings formats on a scale of 1 (poor) to 5 (excellent). For the current format, 38.8 percent of respondents gave ratings in the 4-5 range, whereas, for the test findings template, 61.5 percent gave ratings in that range. Just over half of the respondents (53.8 percent) found the test findings template easier to use than the current format, whereas 30.8 percent thought it was about the same.

Some of the comments about the test findings template that were collected by OSQI staff and from the survey are below:

\section{Verbal comments received by OSQI staff:}

- Feedback written in the test format is negative

- Feedback still does not provide scientists with what they need to do to get to the next level

- Better examples are needed

- Takes longer to write

- No gender-neutral language: the "individual" instead of "they"

\section{Comments from the written survey:}

- Test findings required more thought and required examples to defend score, which is a good thing but took more time

- Need more and better examples

- When justifying a score, require that two or more examples or pieces of evidence are used for each factor. Standardize so reviewers know what they need to provide to justify scores

- Encourages the panelists to provide more specific detail about how each part of the packet addresses the factors for RGE

- New format is more honest and focuses on why the score was received

- The example findings document was helpful

- A four-word teaching philosophy should be used when providing feedback: coach, correct, encourage, praise

- Clearly state to the scientist why he or she is receiving the score

- The test format was much colder and cookie cutter 



\section{Appendix 7. Explanations of Terms Used in This Report}

The table below defines acronyms and short terms used in this report. In addition, it explains the relevance of the terms to the U.S. Geological Survey (USGS) processes for evaluating research, development, and senior scientists. Existing terms and proposed new terms are included.

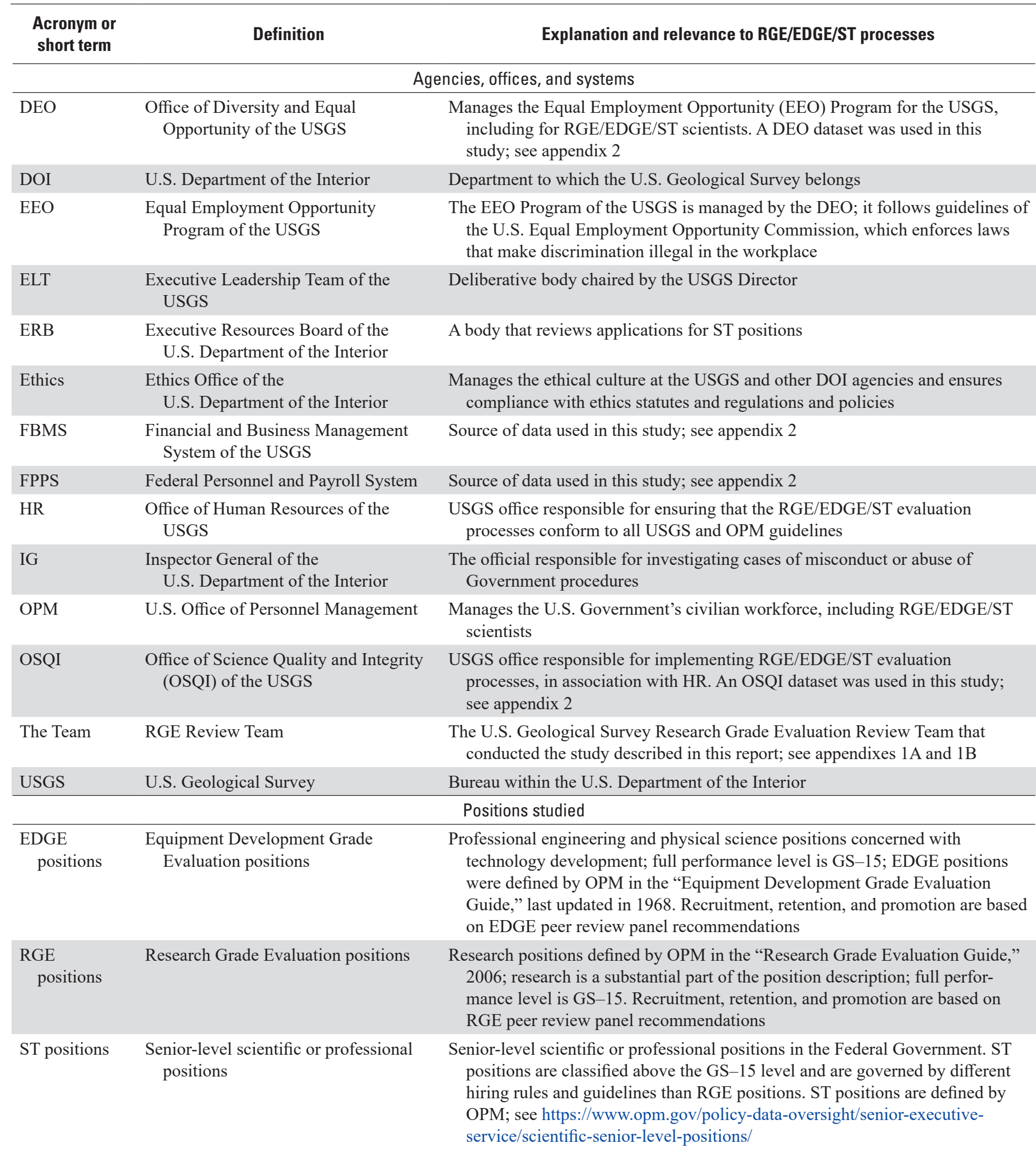




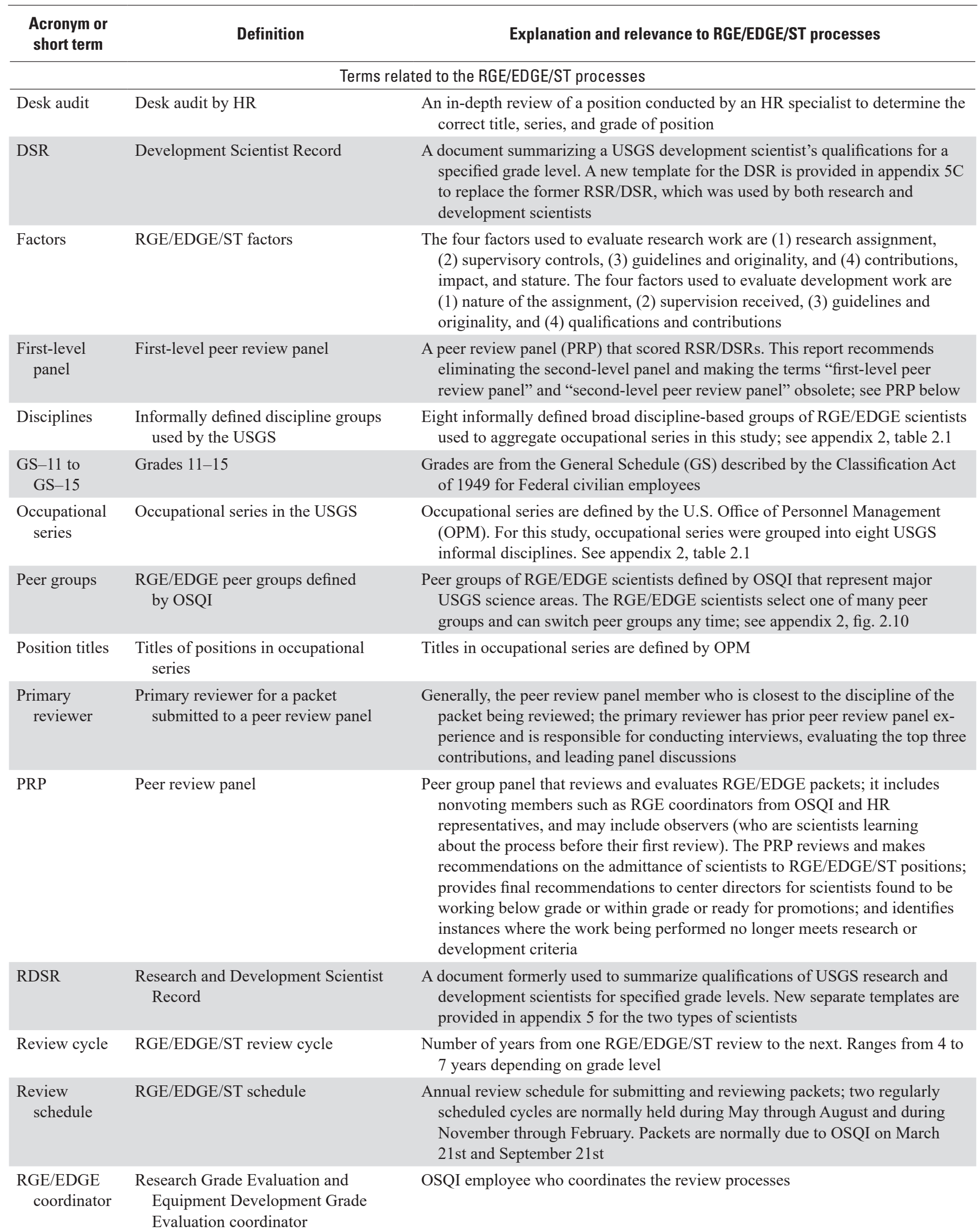




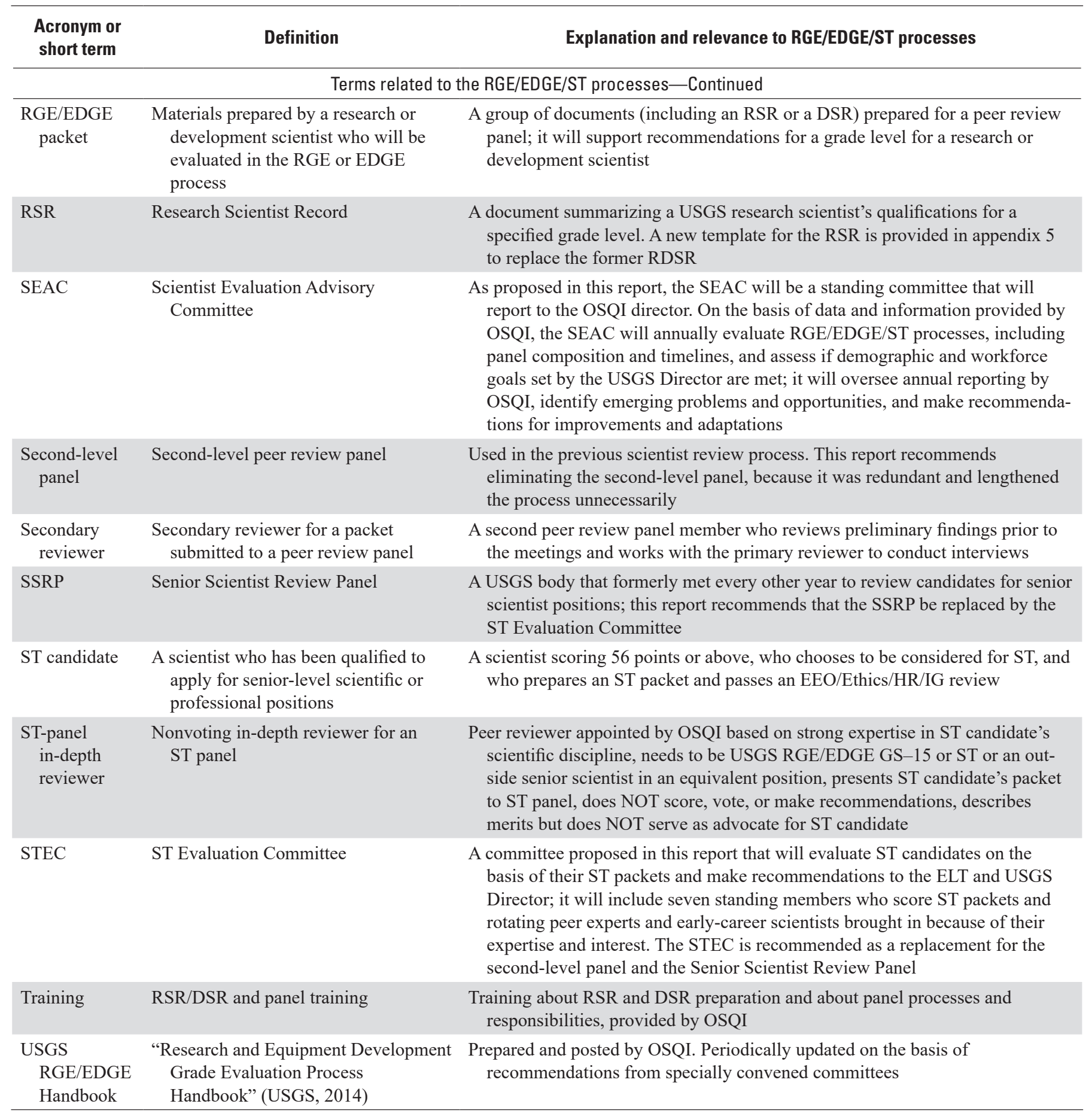




\section{Appendix 8. Additional Criteria for Senior Scientist (ST) Positions}

An ST position is a senior-level scientific or professional position in the U.S. Federal Government. The U.S. Office of Personnel Management's website defines ST positions: “This unique category of Federal jobs covers non-executive positions classified above the GS-15 level, and involves performance of high-level research and development in the physical, biological, medical, or engineering sciences, or a closely-related field" (https://www.opm.gov/policy-data-oversight/ senior-executive-service/scientific-senior-level-positions/).

An ST scientist is a senior employee in a scientific or technical field who has an exemplary scientific record of high productivity and who provides direction and positive contributions to his or her field. In addition, a scientist who has reached the ST level demonstrates personal leadership in areas that go beyond his or her direct contributions to research. An ST scientist is a positive role model, using his or her position, reputation, and stature to advance the careers and facilitate the contributions of others both within and outside of the U.S. Geological Survey (USGS) and to improve the organizations with which they interact. ST scientists model the highest ethical standards and through their example and engagement encourage others to do the same. They serve as formal and informal mentors, allowing others to achieve their full potential.

Importantly, these mentorship roles extend beyond the cadre of USGS scientists and include individuals who may most benefit from association with a scientist of great stature and repute. These individuals may be early in their scientific careers, come from groups underrepresented in science, or serve under-resourced organizations, communities, and countries. The ST scientist has earned a reputation that inspires and educates scientists, managers, and policymakers worldwide. He or she acts as a nexus for those seeking to expand their knowledge of the field, learn critical thinking skills and research techniques, and apply scientific knowledge to management, policy, and strategic investment and planning.

The ST scientist encourages the creation and use of sound, defensible science, protects and advances scientific integrity, and supports the Federal science enterprise. Furthermore, the ST scientist represents the USGS as a member or leader of national and international working groups, committees, and external science advisory teams, and serves as a public face of the USGS to Congress, the administration, stakeholders, and the media (table 8.1). 
Table 8.1. Examples of roles and responsibilities that characterize a successful ST scientist.

[DOI, U.S. Department of the Interior; ST scientist, senior-level employee in scientific or technical fields; USGS, U.S. Geological Survey]

\begin{tabular}{|c|c|}
\hline Role & Responsibility \\
\hline $\begin{array}{l}\text { Scientific } \\
\text { leadership }\end{array}$ & $\begin{array}{l}\text { - Sustain scientific productivity with high societal impact as recognized by the scientific community } \\
\text { within and outside the USGS } \\
\text { - Define and influence the direction of a scientific field } \\
\text { - Provide international leadership in a broad scientific discipline such as ecology, geology, or hydrology }\end{array}$ \\
\hline $\begin{array}{l}\text { Mentor and role } \\
\text { model }\end{array}$ & $\begin{array}{l}\text { - Support career advancement of mentees within and outside the USGS (for example, by writing } \\
\text { reference letters and honor nominations, serving on graduate committees, using one's network to } \\
\text { facilitate career development) } \\
\text { - Share authorship of reports with junior scientists and scientists in developing countries }\end{array}$ \\
\hline $\begin{array}{l}\text { Scientific society } \\
\text { leadership }\end{array}$ & $\begin{array}{l}\text { - Serve in high-level leadership positions that influence the direction of a scientific organization (for } \\
\text { example, become an officer, member of a governing board, leader of disciplinary group, or committee } \\
\text { chair) } \\
\text { - Serve as journal editor-in-chief or other senior editor position }\end{array}$ \\
\hline $\begin{array}{l}\text { USGS, DOI, and } \\
\text { U.S. Government } \\
\text { service }\end{array}$ & $\begin{array}{l}\text { - Provide leadership in drafting, advancing, and communicating white papers, strategic plans, and other } \\
\text { high-level documents } \\
\text { - Lead USGS national committees } \\
\text { - Review national-level USGS program proposals } \\
\text { - Serve in important internal roles as requested by the Executive Leadership Team (for example, accept } \\
\text { acting positions and ad hoc leadership positions) }\end{array}$ \\
\hline $\begin{array}{c}\text { External panels } \\
\text { and advisory } \\
\text { committees }\end{array}$ & $\begin{array}{l}\text { - Serve on national and international external panels (for example, work with agencies such as } \\
\text { the National Science Foundation; National Academies of Science, Engineering, and Health; and } \\
\text { Intergovernmental Panel on Climate Change) } \\
\text { - Serve on important State- and regional-level panels such as a Governor's advisory committee }\end{array}$ \\
\hline Influencer & $\begin{array}{l}\text { - Act as a nexus for those seeking to expand their knowledge of the field, learn critical thinking } \\
\text { skills and research techniques, and apply scientific knowledge to management, policy, and strategic } \\
\text { investment } \\
\text { - Work with government agencies, science organizations, and public-sector entities to set strategic } \\
\text { directions through formal and informal engagement } \\
\text { - Influence research, policy, and management directions within and outside the USGS }\end{array}$ \\
\hline $\begin{array}{l}\text { Science } \\
\quad \text { communication }\end{array}$ & $\begin{array}{l}\text { - Communicate and translate complex scientific concepts and discoveries into words and pictures that } \\
\text { capture the interest and imagination of various nonscientists, including managers, policymakers, and } \\
\text { the general public } \\
\text { - Represent the USGS and our objective science to outside groups, including the national media, and } \\
\text { avoid advocacy } \\
\text { - Encourage the creation and use of sound, defensible science, protect and advance scientific integrity, } \\
\text { and support the Federal science enterprise }\end{array}$ \\
\hline Ethical behavior & $\begin{array}{l}\text { - Demonstrate professional courtesy, equity, integrity, honesty, objectivity, and fairness in all activities } \\
\text { - Cooperate unselfishly in advancing agency goals } \\
\text { - Comply with laws and ethical standards in research and personal conduct } \\
\text { - Assume personal accountability for actions }\end{array}$ \\
\hline
\end{tabular}




\section{Appendix 9. Key Recommendations for Updating the Research Grade Evaluation Process for the U.S. Geological Survey}

The key recommendations listed in table 9.1 are copied from the text and compiled here for ease of reference. They are listed in the same order here and in the text. They reflect the conclusions of the Research Grade Evaluation (RGE) Review Team of the U.S. Geological Survey after it conducted a detailed study.

Table 9.1. Summary of key recommendations discussed in the text for updating the Research Grade Evaluation (RGE) process for the U.S. Geological Survey (USGS).

[Terms used in the middle column: Data analysis, a detailed analysis of workforce data (app. 2); Survey, data from surveys of stakeholders (app. 3); Benchmarking, a comparison of methods to evaluate research scientists (app. 4); Best practices, commonly accepted practices of known efficacy. Other terms: DEO, Office of Diversity and Equal Opportunity of the USGS; FPPS, Federal Personnel and Payroll System; OPM, U.S. Office of Personnel Management; OSQI, Office of Science Quality and Integrity of the USGS; SEAC, Scientist Evaluation Advisory Committee (proposed in this report); STEC, ST Evaluation Committee (proposed in this report); ST, senior scientist]

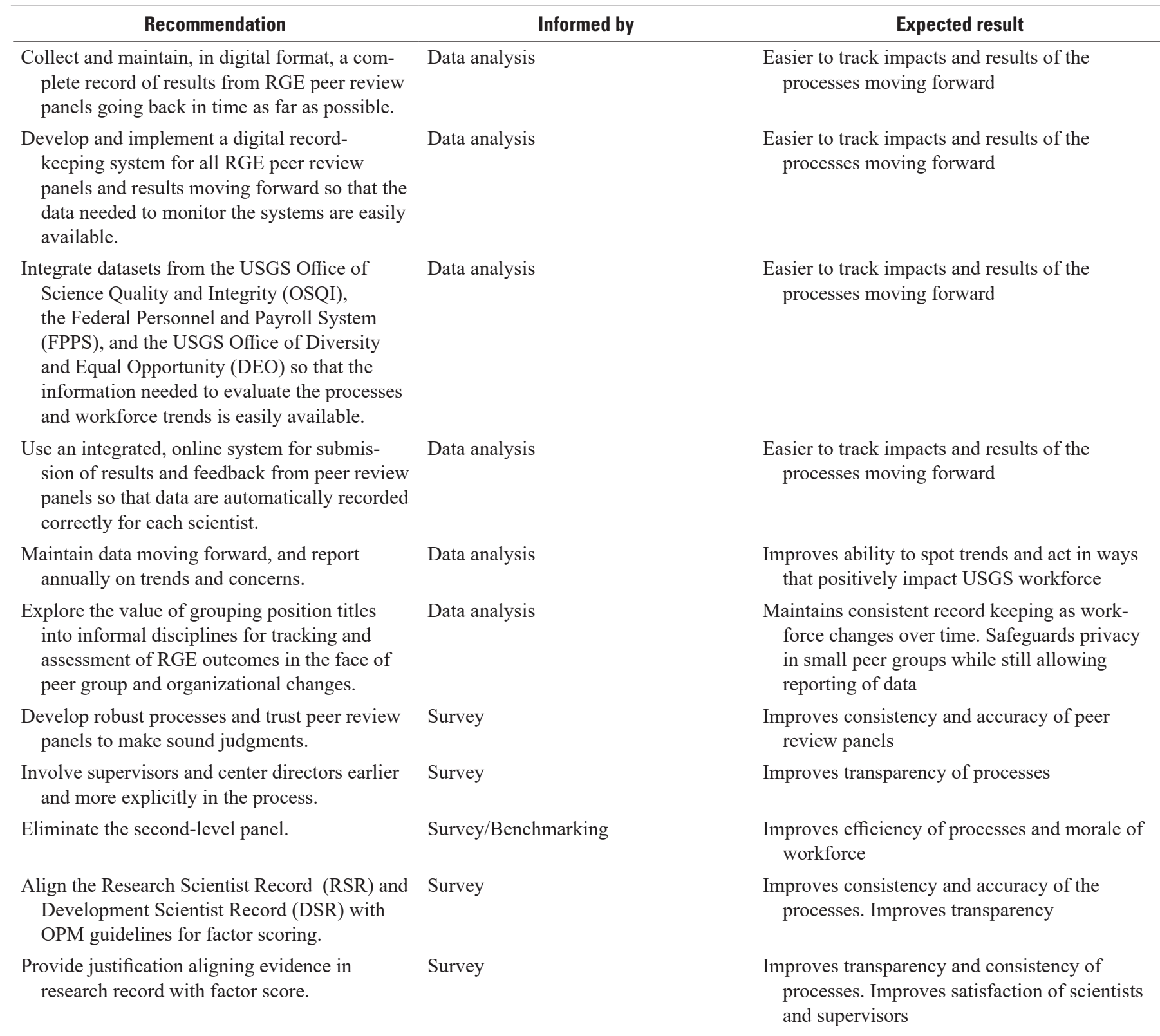


Table 9.1. Summary of key recommendations discussed in the text for updating the Research Grade Evaluation (RGE) process for the U.S. Geological Survey (USGS).-Continued

\begin{tabular}{|c|c|c|}
\hline Recommendation & Informed by & Expected result \\
\hline $\begin{array}{l}\text { Develop and implement new guidelines and } \\
\text { training classes for multiple stakeholders. }\end{array}$ & Best practices & $\begin{array}{l}\text { Improves transparency and will lead to better } \\
\text { prepared scientists, panel members, and } \\
\text { supervisors }\end{array}$ \\
\hline $\begin{array}{l}\text { Extend review cycle for research and } \\
\text { development scientists in GS-14 and GS-15 } \\
\text { positions to } 6 \text { and } 7 \text { years, respectively. }\end{array}$ & Benchmarking & $\begin{array}{l}\text { Matches promotion rates more closely and } \\
\text { reduces work for scientists at the General } \\
\text { Schedule grades of GS-14 and GS-15 }\end{array}$ \\
\hline $\begin{array}{l}\text { Encourage all scientists subject to the Research } \\
\text { Grade Evaluation (RGE) and Equipment } \\
\text { and Development Grade Evaluation (EDGE) } \\
\text { processes to participate in panels. Consider } \\
\text { requiring all such scientists to at least ob- } \\
\text { serve a panel before their first review. }\end{array}$ & Survey & $\begin{array}{l}\text { Improves transparency. Helps scientists better } \\
\text { prepare for their own reviews }\end{array}$ \\
\hline $\begin{array}{l}\text { Finalize findings during the panel meeting and } \\
\text { refrain from changing them after the panel } \\
\text { adjourns. }\end{array}$ & Best practices & $\begin{array}{l}\text { Improves efficiency and reduces potential for } \\
\text { bias }\end{array}$ \\
\hline $\begin{array}{l}\text { Forward data and evaluations from peer review } \\
\text { panels to the Scientist Evaluation Advisory } \\
\text { Committee (SEAC) so that the committee } \\
\text { can conduct its oversight functions. }\end{array}$ & Best practices & $\begin{array}{l}\text { Improves transparency. Provides data to assure } \\
\text { consistency }\end{array}$ \\
\hline $\begin{array}{l}\text { Provide timely feedback. Create clear } \\
\text { guidelines for next steps if the scientist or } \\
\text { supervisor disagrees with panel findings. }\end{array}$ & Survey/Benchmarking & Improves transparency and morale \\
\hline $\begin{array}{l}\text { Clearly articulate the requirements for and role } \\
\text { of ST scientists in the science enterprise, as } \\
\text { both leaders in their fields and ambassadors } \\
\text { for USGS science. }\end{array}$ & Best practices & $\begin{array}{l}\text { Reframes the paradigm of ST rank to its proper } \\
\text { position at USGS }\end{array}$ \\
\hline $\begin{array}{l}\text { Fully inform all scientists who score } 56 \text { or more } \\
\text { points about the process, requirements, and } \\
\text { expectations of ST rank. }\end{array}$ & Best practices & $\begin{array}{l}\text { Allows interested scientists to move forward } \\
\text { with ST application and those not interested } \\
\text { to opt out }\end{array}$ \\
\hline $\begin{array}{l}\text { Create a standing committee to continue the } \\
\text { work of the RGE Review Team by providing } \\
\text { ongoing evaluation of the processes for } \\
\text { continuous improvement and by maintaining } \\
\text { data on the vitality and diversity of the } \\
\text { scientific workforce. }\end{array}$ & Best practices & $\begin{array}{l}\text { Allows for continual adjustment to the processes } \\
\text { as needed. Informs leadership on workforce } \\
\text { trends }\end{array}$ \\
\hline
\end{tabular}


Table 9.1. Summary of key recommendations discussed in the text for updating the Research Grade Evaluation (RGE) process for the U.S. Geological Survey (USGS).-Continued

\begin{tabular}{|c|c|c|}
\hline Recommendation & Informed by & Expected result \\
\hline $\begin{array}{l}\text { Charter a committee to investigate the } \\
\text { possibility of implementing a peer review } \\
\text { process for operational scientist (nine- } \\
\text { factor) positions. }\end{array}$ & Survey/Best practices & $\begin{array}{l}\text { Improves understanding of USGS science work- } \\
\text { force and morale among scientists }\end{array}$ \\
\hline $\begin{array}{l}\text { Formalize a recurring Federal Science Bench- } \\
\text { marking meeting and collaboratively develop } \\
\text { new guidelines for evaluating development } \\
\text { scientists that DOI could submit to OPM. }\end{array}$ & Best practices & $\begin{array}{l}\text { Allows for ongoing conversation among Federal } \\
\text { agencies. Results in updated guidelines for } \\
\text { scientists working in technical fields }\end{array}$ \\
\hline $\begin{array}{l}\text { Publish the RGE Review Team's final report in } \\
\text { its entirety as a USGS report. }\end{array}$ & Best practices & Improves transparency \\
\hline
\end{tabular}





\section{$\frac{\mathbb{2}}{3}$}

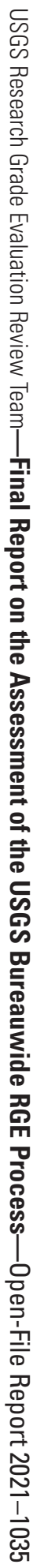

